\title{
Eigentum - Paradigma für ein dem Gemeinwohl verpflichtetes Rechtsinstitut
}

\section{A. Einleitung}

Trotz aller Unsicherheiten und Veränderungen, die sich aus der fortschreitenden Globalisierung und Ausdifferenzierung unserer Gesellschaft ergeben und die durch die stets knappen Kassen der öffentlichen Hand noch zusätzlichen Auftrieb erhalten, besteht nach wie vor ein breiter gesellschaftlicher Konsens über die Gemeinwohlbindung des Eigentums. Dieser Konsens zeigt sich vor allem im unangefochtenen Fortbestand des wirtschaftspolitischen Leitprinzips der sozialen Marktwirtschaft. ${ }^{1}$ Selbst die ,Ökonomisierung ${ }^{6}$ unserer Lebenswelt mit ihrem Glauben an marktförmige Lösungen und ihrer Maxime der Nutzenmehrung und Kostenminderung scheinen die Gemeinwohlbindung des Eigentums nicht ernsthaft in Frage stellen zu können. Doch vielleicht täuschen auch nur Unbestimmtheit und Offenheit des Gemeinwohlbegriffs Beständigkeit und Kontinuität des Gemeinwohlgedankens vor. Ändern sich, wie bei uns geschehen, die Grundüberzeugungen darüber, wie und welche Aufgaben der Staat wahrnehmen soll, ${ }^{2}$ wird statt auf staatliche Eigenregie und Intervention nunmehr auf die Selbstregulierungskräfte der privaten Akteure gesetzt, so kann dies nicht ohne Auswirkungen auf die Vorstellungen und Formen der Gemeinwohlbindung des Eigentums bleiben. Offenbar ist mit dem Akzeptieren einer Gemeinwohlbindung erst wenig entschieden: Selbst der Anhänger einer strikt liberalistisch-marktwirtschaftlichen Wirtschafts- und Eigentumsordnung kann sich für eine solche Bindung aussprechen. Der Streit zwischen diesem und dem Vertreter des wohlfahrtsmaximierenden Staates setzt erst bei der konkreten Ausformung der Eigentumsordnung ein.

Im Unterschied zu den europäischen Nachbarländern werden in Deutschland die Auseinandersetzungen um das Gemeinwohl in besonderer Weise durch das Verfas-

I In diesem Sinne statt vieler Kaufmann 1997, S. 155 ff. Anderer Auffassung offenbar Isensee 1996, S. 9 f. Nach dem Zusammenbruch der sozialistischen Diktaturen Osteuropas und der dortigen Transformation in marktwirtschaftliche Ordnungen sowie der fortschreitenden Privatisierung ist nicht mehr klar, in welchen Kampfarenen Isensee das Privateigentum zu verteidigen sucht.

2 Repräsentativ dargestellt von Naschold/Bogumil 1998, S. 37 ff.; Schuppert 2000, S. 901 ff. 
sungsrecht bestimmt. Während sich die verfassungsrechtlichen Bindungen in den anderen Ländern im wesentlichen in der Sicherung eines Mindestmaßes an Rationalität staatlicher Regelungen erschöpfen, ${ }^{3}$ gehen die vom Bundesverfassungsgericht entwikkelten Anforderungen weit über dieses Mindestmaß hinaus. Infolgedessen scheint die Frage, wer das Gemeinwohl definiert, bereits beantwortet zu sein: Es ist die Verfassung und ihr bundesverfassungsgerichtlicher Mund. Dies wiederum suggeriert eine Stabilität und Unveränderbarkeit, wie sie dem Verfassungsrecht eigen zu sein scheint. ${ }^{4}$ Bedenkt man jedoch, daß sich die Eigentumsordnung - jedenfalls auf längere Sicht betrachtet ständig verändert, so drängt sich der Gedanke auf, daß sich die Vorgaben der Verfassung in symbolisch-rhetorischen Bindungen ${ }^{5}$ erschöpfen. Doch lassen sich gerade in neuerer Zeit auch gegenläufige Bestrebungen beobachten, die darauf abzielen, die marktwirtschaftlichen Grundzüge der heutigen Wirtschaftsordnung als durch die Eigentumsgarantie verbürgt anzusehen. ${ }^{6}$ Zwischen diesen beiden Seiten ist der rechtliche Diskurs um die Gemeinwohlbindung des Eigentums gespannt.

Um in diesem Wirrwarr von Fragen und Gesichtspunkten nicht die Orientierung zu verlieren und $\mathrm{zu}$ einem anschaulichen Bild einer gemeinwohlpflichtigen Institution zu gelangen, soll im ersten Schritt der Wandel des Eigentumsverständnisses am Ende des 19. und zu Beginn des 20. Jahrhunderts in Deutschland betrachtet werden. In dieser Zeit treten erstmals die Gerichte in den bis dahin politisch geführten Auseinandersetzungen um die Definition des Gemeinwohls auf und formen nicht nur die Grundpflicht der Enteignung zu einem Schutzschild der Eigentümer gegenüber dem demokratischen Gesetzgeber, sondern überführen die Auseinandersetzungen in einen auch rechtlichen Diskurs. Es ist dies die Geburtsstunde des verfassungsrechtlichen Diskurses über Eigentum und Gemeinwohl. Auf der Grundlage dieser Betrachtungen soll anschließend geklärt werden, was Eigentum ist: Gibt es ein natürliches Eigentum oder handelt es sich um ein rechtliches Phänomen und welche Eigenheiten besitzt es? Wie steht es mit seinem verfassungsrechtlichen Schutz und wie verhält sich das Eigentum zur Handlungsfreiheit?

\section{B. Wandel des Eigentumsverständnisses}

Im folgenden Abschnitt sollen zunächst einige markante Punkte nachgezeichnet werden, die beim Herausbilden des Eigentumsverständnisses der bürgerlichen Verkehrsgesellschaft bedeutsam gewesen sind. Diese Skizze bildet die Folie, auf der die Veränderungen des verfassungsrechtlichen Eigentumsverständnisses während der Weimarer Zeit eingehender betrachtet werden. Diese Veränderungen sind von großem Interesse, weil dort nicht nur die verfassungsrechtliche Einbindung der Auseinandersetzungen um die Ausgestaltung und Begrenzung des Eigentums und damit jene spezifisch deutsche Eigenheit des Eigentumsdiskurses einsetzte, sondern das Reichsgericht als neuer Akteur

\footnotetext{
Siehe nur die Länderübersichten bei Günter 1998, 2, Kap.

4 Näher dazu Schuppert 1995, S. 32 ff.

5 Näher zum Phänomen der Verfassungsrhetorik Schuppert/Bumke 2000, S. 74 ff.

6 Repräsentativ Depenheuer 1999, Rn. 9 f.
} 
in diesem Diskurs eintrat. Unter anderem Vorzeichen übernahm später das Bundesverfassungsgericht die reichsgerichtliche Position, deren Bedeutung das Gericht aufgrund seiner Kompetenzen stark ausbaute. Doch auch unabhängig davon sind die Wandlungen des Eigentumsverständnisses untersuchungswürdig, weil es gar nicht so viele Beispiele gibt, an denen sich tiefgreifende Veränderungen innerhalb einer Institution beobachten lassen und bei denen so unterschiedliche Erklärungen für den Verständniswandel vorgetragen werden. Eng damit verknüpft ist der eigenartige Umstand, daß die Veränderungen andere Punkte betrafen als die, die von den zeitgenössischen Analytikern und späteren Kommentatoren als entscheidend herausgestellt wurden.

\section{Herausbilden einer bürgerlichen Eigentumsordnung}

\section{Transformation der Eigentumsordnung und das autonome Privatrecht}

Im Laufe des 19. Jahrhunderts vollzog sich die Transformation der feudal-patrimonialen Herrschafts- und Güterordnung in die bürgerliche, auf dem Grundsatz gleicher Rechte beruhende Rechtsordnung. Dieser Prozeß verlief weder geradlinig noch gleich in den verschiedenen Ländern des früheren Deutschen Reiches. Zu einem Ende kam er erst während der Weimarer Zeit (z. B. mit der endgültigen Auflösung der Fideikommisse, Art. 155 Abs. 2 Satz 2 RV 1919). Seine Geschwindigkeit und Intensität hing wie auch die Frage der Entschädigungsbedürftigkeit von der politischen Stärke der adligen Feudal- und Privilegienrechtsinhaber gegenüber dem Landesherrn und dem Bürgertum ab.

Mit Blick auf die Gemeinwohlbindung des Eigentums ist dabei von besonderem Interesse, wie die Herausbildung einer bürgerlichen Eigentumsordnung damit einherging, daß privates und öffentliches Recht als kategorial unterschiedliche Sphären konzipiert wurden. Diese kategorische Unterscheidung diente dazu, jenen Bereich, in dem die Beseitigung von überkommenen Rechtspositionen entschädigungslos hinzunehmen sei, von dem Bereich abzugrenzen, in dem dies nur gegen Zahlung einer angemessenen Entschädigung erfolgen durfte. Die theoretische Grundlage bildete die Lehre vom Schutz wohlerworbener Rechte. Ihr lag die Vorstellung zugrunde, daß der Landesherr einem Untertan zwar seine Privilegien ${ }^{8}$ entziehen darf, er ihn dafür jedoch zu entschädigen hat. ${ }^{9}$

Mit Hilfe der Unterscheidung zwischen öffentlichen und privaten Rechten wurden nun die wohlerworbenen Rechte aufgespalten. Auf der einen Seite standen nunmehr die staatlichen Hoheitsrechte und auf der anderen die privaten Vermögensrechte. Mit Hilfe dieser Unterscheidung wurde es möglich, die wohlerworbenen Rechte oder Privilegien in eine Rechtswelt zu überführen, die auf dem Gedanken bürgerlicher Rechtsgleichheit beruhte und mit der die Einräumung von Privilegien für einzelne private Rechtsträger

7 Einen Überblick über die Entwicklung bietet Siemann 1995, S. $109 \mathrm{ff}$.

8 Die facettenreiche Bedeutung des Begriffs wird kurz nachgezeichnet im Handwörterbuch zur Deutschen Rechtsgeschichte, Sp. $2005 \mathrm{ff}$.

9 Anschaulich beschrieben von Lübbe-Wolff 1986, S. $104 \mathrm{ff}$. 
unvereinbar war. Aus Privilegien wurden entweder objektive Hoheitsrechte oder subjektive Privatrechte. ${ }^{10}$ Feudalrechte, wie beispielsweise die Patrimonialgerichtsbarkeit ${ }^{11}$ oder die Rechte zur Abgabenerhebung, wurden als hoheitliche Befugnisse eingeordnet, die entschädigungslos beseitigt werden konnten. ${ }^{12}$ Demgegenüber wurden Nutzungsrechte an Grund und Boden als Eigentumsrechte angesehen, die man nur gegen Entschädigung hätte entziehen können. Die Lehre vom Schutz wohlerworbener Rechte ging in diesem Prozeß in dem sich parallel dazu herausbildenden Schutz des Privateigentums auf. ${ }^{13}$

Die immer schärfere Zweiteilung von öffentlichem und privatem Recht, ${ }^{14}$ deren gesellschaftstheoretisches Fundament eine entsprechende Trennung zwischen Staat und Gesellschaft ist, führte zur Vorstellung, daß das private und das öffentliche Recht über grundlegend verschiedene Funktionen verfügen: Das Privatrecht bildet die Sphäre, in der die rechtlich gleich und unabhängig gestellten Beteiligten nach eigenen Nutzenentscheidungen in Rechtsbeziehungen zueinander treten und auf dieser Grundlage Güter sei es die eigene Arbeitskraft, ein ideeller Gegenstand, ein Recht, eine bewegliche Sache oder ein Grundstück - tauschen. Das ,unverfälschte " Privatrecht ${ }^{15}$ ähnelt dem idealen Markt, auf dem ohne jede Transaktionskosten und Wissensunterschiede eine Güteraustausch stattfindet und so die optimale, am individuellen Nutzen ausgerichtete Ausnutzung der knappen Güter erreicht wird. Konstitutiv für dieses Privatrecht sind eine umfassende Vertragsfreiheit und das Eigentumsrecht als Gewährleistung umfassender Verfügungs- und Nutzungsmacht. Schranken für die Beteiligten ergeben sich aus dem Grundsatz formal gleicher Rechte, der sich ohne Schwierigkeiten in das Grundkonzept einfügt. ${ }^{16}$ So läßt sich scheinbar problemlos das private Nachbarrecht in die Vorstellung umfassender Verfügungs- und Nutzungsmacht einfügen. Mit dieser Vorstellung eines autonomen, sich selbst organisierenden Privatrechts sind zu Beginn des 19. Jahrhundert die Forderungen nach Gewerbefreiheit, der freien Verfügung und Nutzung des Grundeigentums und allgemeiner gesprochen nach staatlicher Deregulierung durch Transformation der alten Ordnung in eine bürgerliche Rechtsordnung verbunden. ${ }^{17}$ Dahinter stand die Überzeugung, daß diese Gesellschafts- und Wirtschaftsord-

${ }^{10}$ Siehe Lübbe-Wolff 1986, S. $110 \mathrm{ff}$; Mohnhaupt 1995, S. 139 ff.

11 Zu den um ihre Beseitigung geführten Auseinandersetzungen näher Werthmann 1995, S. 65 ff., $159 \mathrm{ff}$.

12 So ordnet Art. 42 Preußische Verfassung 1850 an: „Aufgehoben ohne Entschaedigung sind: I) Die Gerichtsherrlichkeit, die gutherrliche Polizei und obrigkeitsrechtliche Gewalt, sowie die gewissen Grundstuecken zustehenden Hoheitsrechte und Privilegien; 2) die aus diesen Befugnissen, aus der Schutzherrlichkeit, der frueheren Erbuntertaenigkeit, der frueheren Steuer- und Gewerbeverfassung herstammenden Verpflichtungen."

13 So Stödter 1933, S. 93 ff.

14 Zu dieser Entwicklung näher Bullinger 1968.

15 Siehe dazu Nörr 1996a, 224 ff. in Anknüpfung an die Privatrechtsgesellschaftskonzeption von F. Böhm.

16 So begründet Puchta 1881, S. 164 eine Pflicht des Eigentümers, auf andere Eigentümer Rücksicht zu nehmen, um „einen fortwährenden rechtlichen Kriegszustand" zu verhindern.

17 Die Praxis bot ein sehr viel uneinheitlicheres Bild. Anschaulich verfolgen läßt sich dies an den Auseinandersetzungen um die Ansiedlung von erheblich störenden Gewerbebetrieben. Dort kam es 
nung das Gemeinwohl optimal verwirklicht. ${ }^{18}$ Nur als Teil dieser Vorstellungswelt wie auch als eine Form ihrer Verwirklichung läßt sich das bürgerliche Eigentum einschließlich seiner verfassungsrechtlichen Gewährleistung verstehen. Entgegen dem Plädoyer von Carl Schmitt ${ }^{19}$ läßt sich Eigentum nur aus seiner Funktion heraus begreifen. Die Substanz, die Schmitt dem Eigentum zuspricht und deren Verlust er beklagt, ist auch nur Ausdruck einer bestimmten funktionellen Form; eben jener, die ihr aus der Vorstellungswelt eines autonomen Privatrechts erwächst.

Auf der anderen Seite entsteht ein öffentliches Interesse, das im scharfen Gegensatz zum Interesse des Bürgers gedacht wird. Die Bewahrung dieses Interesses obliegt nunmehr allein dem öffentlichen Recht, dessen Aufgabe in der Durchsetzung und Sicherung des autonomen Privatrechts gesehen wird. ${ }^{20}$ Die zunehmende Intervention zum Schutz verschiedener gesellschaftlicher Gruppen wird deshalb als Durchbrechung und Beeinträchtigung des Privatrechts verstanden. Durch die kategorische Gegenüberstellung von privatem und öffentlichem Interesse bleibt der Umstand ausgeblendet, daß das „Durchbrechen“ im Interesse Privater erfolgt und nicht im Namen einer davon irgendwie losgelösten Allgemeinheit. Spätestens nach dem sog. „Gründerkrach“ (1873) und mit der dann einsetzenden und immer stärker werdenden staatlichen Aktivität in Wirtschaft und Wohlfahrt ${ }^{21}$ verliert die Vorstellung eines autonomen Privatrechts ihre gesellschaftliche Leitbildfunktion. ${ }^{22}$ An ihre Stelle tritt die Vorstellung der Wirtschaft als einer kollektiven und gebundenen Ordnung, die durch Unternehmenskooperationen geprägt wird und in der Produktion, Absatz und Preis durch Absprachen festgelegt und der staatlichen Aufsicht unterworfen werden. Nach umfassender Inpflichtnahme der Wirtschaft im Krieg bildet sich am Ende das Modell einer gemeinwirtschaftlichen Ordnung heraus: In ihm blieben die Produktionsmittel in privater Hand. Es wurden jedoch die Preise für die gesellschaftlich wichtigen Güter hoheitlich festgesetzt und die Verteilung bzw. der Verkauf staatlich organisiert. ${ }^{23}$

zu einer weitgehenden Überlagerung des Privatrechts durch das öffentliches Zulassungsrecht. Siehe dazu Brüggemeier 1996 sowie mit zum Teil abweichenden Wertungen Thier 2000.

${ }^{18}$ Anschaulich geschildert von Böhm 1933, S. 326 ff., 350: „[...] dann wird der Kooperationsplan von der verfassungsmäßig zuständigen Herrschaftsinstanz entworfen und beschlossen, dann ist also jedes Individualverhalten gemeinnützig, das im Einklang, und jedes Individualverhalten sozialschädlich, das im Widerspruch mit dem einmal angeordneten Kooperationsplan steht." Siehe ferner den lehrreichen wirtschaftsphilosophischen Abriß bei Ladeur 2000, Teil I.

19 Es ist die zentrale These von Schmitt 1958, S. 118 ff, daß die Ausdehnung des Eigentumsbegriffs zur Auflösung des Eigentumsinstituts und des Instituts der Enteignung führt, da die Institute durch die Ausweitung „,funktionalisiert und entsubstanziiert" werden. In diesem Sinne auch Stödter 1933, S. 149.

${ }^{20}$ In diese Richtung tendierend Puchta 1881, S. 163.

${ }^{21}$ Siehe Stolleis 1989, S. 129 ff.

22 So Nipperdey 1991, S. 336.

23 Auf diesem Modell fußten dann auch die Überführung der Kohle- und Kaliwirtschaft in Zwangssyndikate (RGBl. I, 342 v. 23. März 1919). Durch das Sozialisierungsgesetz vom 23. März 1919 (RGBI. I, 341) wurde die Möglichkeit einer Sozialisierung des Produktiveigentums gegen angemessene Entschädigung eröffnet. Insgesamt wurde durch diese Entscheidung aber zunächst auf die 


\section{Verfassungsrechtlicher Schutz des Eigentums}

Zu Beginn des 19. Jahrhunderts bildete sich das sog. absolute Eigentumsverständnis heraus. Zugleich begann das Zeitalter der Konstitutionalisierung und mit ihm die verfassungsrechtliche Gewährleistung des Eigentumsschutzes. Berücksichtigt man, daß erst in der Verfassung von 1919 die Sozialbindung des Eigentums (Art. 153 Abs. 3 RV 1919) festgeschrieben wird, so liegt die Frage nahe, welches Eigentumsverständnis die früheren Verfassungen prägte. In diesem Zusammenhang hat Jörg-Detlef Kühne die These aufgestellt, daß bereits $\S 164$ Abs. I RV 1848 mit dem absoluten Eigentumsbegriff gebrochen habe. ${ }^{24}$ Seiner Meinung nach zeichnete sich ,bei dem Eigentumsschutz der Paulskirche eine Mittellösung zwischen dem frühliberalen, individualistischen und dem sozialegalitären Verständnis seit 1919 ab". ${ }^{25}$ Umgekehrt wird man daraus schließen dürfen, daß nach Kühnes Auffassung bis dahin ein absolutes Eigentumsverständnis vorgeherrscht hat. Art. 164 Abs. 1 RV 1848 hatte folgenden Wortlaut:

„Das Eigentum ist unverletzlich.

Eine Enteignung kann nur aus Rücksichten des gemeinen Besten, nur auf Grund eines Gesetzes und gegen gerechte Entschädigung vorgenommen werden."

Der erste Satz könnte ein absolutes Verständnis nahe legen. Doch wurde das Wort ,unverletzlich" nicht im Sinne von ,uneinschränkbar" verstanden. Vielmehr sollten dadurch willkürliche, d. h. ungesetzliche Eingriffe der Verwaltung in das Eigentum untersagt werden. $^{26}$ Auch der zweite Satz begründete keinen umfassenden Eigentumsschutz. Nicht in jeder gesetzlichen Bestimmung, durch die die Verfügungs- oder Nutzungsbefugnis des Eigentümers festgelegt und damit im Vergleich zum absoluten Eigentumsrecht beschränkt wurde, sah man eine Enteignung. Um die Mitte des Jahrhunderts hatte der Enteignungsbegriff bereits eine bestimmte Gestalt gewonnen: Bei einer Enteignung erfolgte der konkrete Zugriff auf das Eigentum, um ein bestimmtes öffentliches Unternehmen zu verwirklichen (näher unter 3). Enteignung war die Durchbrechung der bestehenden Eigentumsordnung, nicht deren inhaltlich Änderung. Aus diesem Grund sowie aufgrund der Überlegung, daß mit Art. 164 RV 1848 ein allgemeines Prinzip aufgestellt werden sollte, das der näheren Ausführung durch die Länder bedürfe, verwarf man etwa den Änderungsvorschlag, entschädigungslose Beschränkungen zugunsten von Forsten, Torfstichen und Wiesenbewässerung festzuschreiben. Ferner lehnte man auch eine nähere Bestimmung der gesetzgeberischen Befugnisse im allgemeinen $a b .^{27}$

Beibehaltung und Stabilisierung der überkommenen Wirtschaftsordnung gesetzt. Siehe Huber 1992, S. 995 ff., 1104 f.; Winkler 1993, S. 84 ff.

${ }^{24} \mathrm{Vgl}$. Kühne 1998, S. 251.

${ }^{25}$ Ebd., S. 250.

${ }^{26}$ Allgemein zur Unverletzlichkeitsformel Kühne 1998, S. 339 ff., speziell zur Eigentumsgarantie kann zudem auf die Entstehungsgeschichte des im Wortlaut gleichen Art. 9 der Preußischen Verfassung von 1850 verwiesen werden, wo an der Formulierung festgehalten wurde, da „er eben willkürlichen Enteignungen durch die Regierungsgewalt entgegentrete“ (zitiert nach v. Rönne 1882, S. 99 Anm. 4a). Siehe dazu auch Anschütz 1897, S. 28 ff., Huber 1988, S. I 10.

27 Siehe dazu die Schilderung bei Floßmann 1976, S. 88 ff. 
Doch auch bei den früheren Länderverfassungen sucht man vergebens nach der Anerkennung eines absoluten Eigentumsverständnisses. Den konstitutionellen Monarchien war eine solche außerhalb des staatlichen Zugriffs stehende Rechtsmacht völlig fremd. Stets wurde das Recht zur Enteignung anerkannt. Neu gegenüber dem absolutistischen Zeitalter war allein die Forderung, daß vor der Enteignung die Entschädigung zu leisten sei, $^{28}$ mit der man dem Mißstand nicht geleisteter Entschädigungen begegnen wollte.

Mit anderen Worten: Die bei der Verfassungsgebung 1919 aufgenommene Sozialbindung des Eigentums ist genau so wenig wie Art. 164 RV 1848 ein Bruch mit dem absoluten Eigentum, wenn man darunter das Recht des Gesetzgebers versteht, die Eigentumsordnung auszugestalten und ausnahmsweise Eigentum zu enteignen. ${ }^{29}$ Auch ging es nicht darum, neue Zugriffsmöglichkeiten zu schaffen. Bereits im Kaiserreich beginnt die Zeit massiver staatlicher Intervention. Die Kriegswirtschaft bildet dabei nur den Höhepunkt, bei der unter weitgehender Wahrung der Interessen der Großindustrie eine staatlich regulierte Wirtschaftsordnung entsteht. ${ }^{30}$

Was aber 1848 noch besteht und am Ende des 19. Jahrhunderts verloren geht, ist die Zuversicht in die Selbstregulierungskräfte der auf dem Privateigentum gründenden Wirtschaftsordnung. Das Gemeinwohl hatte sich nicht als das mittelbare Resultat aus den freien Verfügungsentscheidungen der Eigentümer eingestellt. Durch das Auferlegen der Grundpflicht „Eigentum verpflichtet“ (Art. 153 Abs. 3 Satz 1 RV 1919), wird das Eigentumsverständnis der bürgerlichen Verkehrsgesellschaft zwar nicht vollständig in Frage gestellt, doch erheblich verändert: Das legitimatorische Fundament, das in der Vorstellung vom Eigentum als natürlichen Herrschaftsrechten über Boden und beweglichen Sachen ruhte, bricht zusammen. Das Versagen privaten Eigentums zur Gewährleistung des gesellschaftlichen Wohlstands führt dazu, daß die Eigentumsrechte zur Disposition des Staates gestellt werden. Deutlich wird dies vor allem an der Möglichkeit entschädigungsloser Enteignungen durch das Reich nach Art. 153 Abs. 2 Satz 2 RV 1919 und aus der Formulierung des Art. 153 Abs. 1 Satz 2 RV 1919, wonach sich der Inhalt und die Schranken des Eigentums aus den Gesetzen ergeben.

\section{Das Rechtsinstitut der Enteignung}

Während des 19. Jahrhunderts bildete sich das Institut der Enteignung als ein relativ klar umgrenzter Regelungskomplex heraus. Die Enteignungsgesetze in den deutschen Ländern bezogen sich nur auf Grundstücke. Der Grund dafür war, daß mit der einsetzenden Industrialisierung in einem bis dahin unbekannten Ausmaß Grundstücke zum Aufbau einer Infrastruktur (Straßen, Eisenbahn, Schiffahrtswege, Telegraphen) erforderlich wurden. Erlaubt war die Enteignung entweder entsprechend einem gesetzlich umschriebenen Katalog von Unternehmen, wie zum Beispiel Festungen, Kirchen, Straßen, Häfen, Ei-

28 Z. B. §30 Satz I Verf. Königreich Württemberg 1819; §35 Satz 2 GG Königreich Hannover 1833.

29 Von der sog. Legaltheorie wurde das Eigentum stets als eine Einrichtung verstanden, die der gesetzlichen Ausformung bedurfte. Siehe Stier-Somlo 1911, S. 4 ff.

${ }^{30}$ Siehe nur die Darstellung von Nussbaum 1922. Speziell zum Eigentumsrecht Goldschmidt 1920, S. 58 ff.; Stödter 1933, S. 112 ff. Zu der sich daraus entwickelnden Disziplin des Wirtschaftsrechts als einer Gemengelage zwischen öffentlichem und privatem Recht Stolleis 1999, S. 226 ff. 
senbahnen u. a. m. oder wenn ein öffentliches Interesse an der Verwirklichung eines Unternehmens bestand, das auch durch private Hand erfolgen konnte. ${ }^{31}$ Über die Notwendigkeit einer Enteignung entschied in den meisten Ländern die höchste Verwaltungsbehörde, deren Entscheidung abgesehen von Bayern, Hessen-Darmstadt und Württemberg keiner gerichtlichen Kontrolle unterlag. ${ }^{32}$ Aus dem Erfordernis der Notwendigkeit schloß man darauf, daß die Enteignung nicht weiter gehen durfte als zur Verwirklichung des Unternehmens erforderlich sei. Darüber hinaus war ,diese Notwendigkeit $[\ldots]$ aber nicht als eine absolute und unbedingte $\mathrm{zu}$ verstehen, dergestalt, daß ohne die Enteignung bestimmter Rechte das Unternehmen überhaupt nicht ausgeführt werden könnte“. ${ }^{33}$ Allein im Streit über die Höhe der Entschädigung konnten die Zivilgerichte angerufen werden. $^{34}$

Ob Enteignung stets den Entzug eines Eigentumsrechts im Sinne einer Übertragung desselben auf einen anderen voraussetzte oder auch bloße Beschränkungen, wie zum Beispiel ein Bauverbot, um die Sicherheit einer Festungsanlage zu gewährleisten oder den Gefahren durch Funkenflug vorzubeugen, den Tatbestand einer Enteignung erfüllten, war umstritten. Wichtig im vorliegenden Zusammenhang ist nur, daß Beschränkungen zulässig waren und allenthalben vorkamen. ${ }^{35}$

Einen zentralen Begriff des Enteignungsrechts bildete das öffentliche Interesse, das mit Hilfe der Enteignung realisiert werden sollte. Einig war man sich dabei, daß rein fiskalische Interessen des Staates nicht ausreichen sollten, um eine Enteignung zu rechtfertigen. ${ }^{36}$ Eine positive Umschreibung zu geben, fiel schwer. ${ }^{37}$ Dies verwundert nicht,

${ }^{31}$ Die Vorstellung, daß auch zugunsten eines von privater Seite durchgeführten Unternehmens Enteignungen erfolgen können, wurde im Zuge der Durchsetzung des staatsrechtlichen Positivismus auf die Vorstellung eingeengt, es müsse sich stets um ein öffentliches Unternehmen handeln (so Mayer 1924, S. 9, 11 f., unter Verweis auf das erforderliche öffentliche Interesse). Klar die frühere Position darstellend v. Rönne 1882, S. 107, sowie ausführlich zu der Diskussion Layer 1902, S. 228 ff., aus heutiger Sicht Grimm 1979, S.132, 135 f.

32 Siehe dazu Fleiner 1908, S. 1 ff; Grimm 1979, S. 130 f; Malmedier 1999, S. 132 f., sowie die Skizze zum verwaltungsgerichtlichen Rechtsschutz von Ogorek 1988.

33 Layer 1902, S. 357.

34 Die Beschränkung der gerichtlichen Kontrolle auf die Frage, ob und in welcher Höhe ein Ersatzanspruch bestand, galt auch noch während der Weimarer Republik, siehe Wolff 1929, S. 192.

35 Während der Entzug von Eigentumsrechten stets mit einer Übertragung dieser Rechte auf das zu verwirklichende Unternehmen einhergingen, waren Beschränkungen nicht notwendig mit einer Rechtsübertragung verbunden. Teilweise wurde die Übertragung als notwendiges Merkmal einer Enteignung angesehen, so Anschütz 1897, S. 34, und später Wolff 1929, S. 191. Genauer ist demgegenüber die Forderung von Mayer 1924, S. 21, der verlangt, daß ,es sich um einen Eingriff in das Grundeigentum handeln [muß], der sich ausdrücken läßt als ein Recht des Unternehmers an dem betroffenen Grundstück", wobei aber nur Rechte in Betracht kommen, die nach dem bürgerlichen Recht möglich sind. Andere Beschränkungen fallen unter die Kategorie der „öffentlichrechtlichen Eigentumsbeschränkung". Das RG hatte sich in RGZ 41, 142 für eine analoge Anwendung des Enteignungsentschädigungsanspruch ausgesprochen, wenn eine Beeinträchtigung oder Entziehung ohne Übertragung auf den Staat erfolge. Die Entscheidung stützt freilich zugleich die Ansicht, daß die Enteignung durch das Moment der Übertragung gekennzeichnet wird.

${ }^{36} \mathrm{Vgl}$. Layer 1902, S. $185 \mathrm{f}$.

${ }^{37}$ Eine ausführliche Übersicht bei Layer 1902, S. $181 \mathrm{ff}$. 
ist es doch bis heute nicht gelungen, das öffentliche Interesse zu definieren. ${ }^{38}$ Verwiesen wurde auf die Aufgaben oder Zwecke des Staates. Freilich führte dies zu Schwierigkeiten, eine Enteignung zugunsten privater Unternehmungen zu rechtfertigen, da dies dem Staat nur mittelbar dienen konnte. Auch durch die Gegenüberstellung von Gemeinund Sonderinteresse anstelle des sich unter Umständen mit dem Gemeininteresse dekkenden Individualinteresses versuchte man das öffentliche Interesse genauer zu fassen. $^{39}$

Doch selbst innerhalb dieses Regelungskomplexes wurde die erstrebte und verfassungsrechtlich anerkannte Verbindung von Enteignung und Entschädigung nicht ausnahmslos gewahrt. So sah beispielsweise das preußische Recht entschädigungslos hinzunehmende Nutzungsbeschränkungen von Grundstücken in der Umgebung von Festungsanlagen vor. ${ }^{40}$

Neben diesem engeren, auf Grundstücke bezogenen und meist durch Rechtsübertragungen gekennzeichneten Enteignungsverständnis wurde im 19. Jahrhundert der Enteignungsbegriff auch in einem weiteren Sinne verwandt. Enteignung war danach jeder entschädigungspflichtige Eingriff in ein Eigentumsrecht. ${ }^{41}$ Als Teil des gemeinen Rechts wurde ein Entschädigungsanspruch für den Fall anerkannt, daß der Staat ein wohlerworbenes Recht im öffentlichen Interesse beseitigt oder beeinträchtigt. Als Gegenstände dieses Entschädigungsanspruchs kamen neben beweglichen Sachen ${ }^{42}$ das Patentrecht, Fischerei- und Jagdrecht oder das Bergwerksrecht in Betracht. ${ }^{43}$ Vereinzelt wurden auch Forderungen als mögliche Gegenstände benannt, doch fehlte es an praktischen Beispielen. ${ }^{44}$ Der verfassungsrechtlich bzw. einfachrechtlich anerkannte Schutz des Eigentums reichte also über das grundstücksbezogene Institut der Enteignung hinaus. Durch einen Entschädigungsanspruch wurden so gut wie alle vermögenswerten privaten Rechte geschützt.

In allen Ländern kam es zu Enteignungen im weiteren Sinne unmittelbar durch Gesetz. Daß der Gesetzgeber dabei eine Entschädigungsleistung versagen konnte, war allgemein anerkannt. Umstritten war die Rechtslage nur, falls der Gesetzgeber keine ausdrückliche Regelung getroffen hatte. Außerhalb Preußens sprach man sich überwiegend für das Bestehen eines Entschädigungsanspruchs aus. Auch das Reichsgericht entschied in diesem Sinne und erkannte an, daß, ,im Falle der Aufhebung eines wohlerworbenen Rechtes durch die Gesetzgebung ohne weiteres ein privatrechtlicher Anspruch gegen den Staat auf volle Entschädigung stattfindet, soweit nicht dieser Anspruch durch die Gesetzgebung besonders ausgeschlossen worden ist" ". ${ }^{45}$ Innerhalb des

38 Siehe dazu statt vieler Häberle 1970, S. 719 ff.; Uerpmann 1999, S. 316 ff.

39 So Layer 1902, S. $216 \mathrm{ff}$.

40 Näher v. Rönne 1882, S. 117 f. mit Anm. 3. Erst durch Reichsgesetz v. 31. Dezember 1871, RGBI. 1871, S. 459 ff. wurde ein Entschädigungsanspruch anerkannt.

${ }^{41}$ Siehe dazu die ausführliche Darstellung bei Layer 1902, S. 67 ff., 563 ff.

${ }^{42}$ So v. Rönne 1882, S. $103 \mathrm{f}$.

43 Vgl. Layer 1902, S. $565 \mathrm{ff}$.

${ }^{44}$ In RGZ 41, 191 wird ein Entschädigungsanspruch bei Beeinträchtigung eines vertraglich begründeten vermögenswerten Rechtes anerkannt.

45 RGZ 12, 1, 3. In diesem Sinne auch RGZ 41, 191, 193. 
preußischen Königreiches setzte sich im Anschluß an die königliche Order vom 4. Dezember 1831 die Ansicht durch, daß weder durch die Art. 74 f. Einl. ALR noch durch Art. 9 Verf. 1850 im Fall einer Enteignung ein Anspruch auf Entschädigung gegenüber dem König und damit auch gegenüber dem Gesetzgeber gewährleistet ist. ${ }^{46}$

Nicht alle nachteiligen eigentumsgestaltenden Rechtsakte wurden jedoch als Enteignung oder Eingriff in ein wohlerworbenes Recht angesehen. Enteignung war die Beeinträchtigung oder das Durchbrechen der bestehenden Eigentumsordnung. Durch „Eigentumsbeschränkungen “" ${ }^{47}$ wurde hingegen die Eigentumsordnung insgesamt verändert. Letzteres war - so die ganz herrschende Ansicht - entschädigungslos hinzunehmen. ${ }^{48}$ So wurde z. B. das private Nachbarrecht, wie etwa die Hinnahme von Immissionen, als Eigentumsbeschränkung verstanden.

\section{Die Mär von der klassischen Enteignung}

Erst zu Beginn des 20. Jahrhunderts erfolgt die Einengung des Enteignungsbegriffs und ihre gleichzeitige Auszeichnung als „klassisch" ${ }^{49}$ Infolge seiner scharfen Konturierung vor allem durch Otto Mayer ${ }^{50}$ faßte Walter Jellinek den Enteignungsbegriff folgendermaßen zusammen:

Enteignung ist „die Entziehung oder Belastung von Grundstücken oder dinglichen Rechten an ihnen, soweit die Maßnahme für ein bestimmtes öffentliches Unternehmen nötig ist, durch Verwaltungsakt gegen Entschädigung". 51

Die Gründe für diese begriffliche Engführung sind nicht leicht auszumachen. Ein gewichtiges Motiv wird man in dem Ziel von Otto Mayer sehen können, das Verwaltungsrecht aus einer überschaubaren Zahl möglichst klar strukturierter und scharf umrissener Rechtsinstitute aufzubauen, um es als ein dem Zivilrecht ebenbürtiges Rechtsgebiet auszuweisen. Später diente der Rückgriff auf das Institut der Enteignung auch dazu, die Veränderungen während der Weimarer Zeit aufzuzeigen. ${ }^{52}$ Doch stellten sich die Veränderungen vor dem Hintergrund eines vermeintlich klassischen Enteignungsinstituts anders dar als vor dem eines unbefangenen Rückblicks auf die vielfältige und disparate

${ }^{46}$ Ausführlich zu der königlichen Order und der Rechtslage in Preußen Anschütz 1897, S. 71 ff.

47 Diesen Begriff wählte Layer 1902, S. 41.

${ }^{48}$ Vgl. ebd., S. 61 f. m. w. N.

49 Diese Aussage wurde und wird vielfach bestritten. Die Konzeption eines engen Enteignungsbegriffs für das 18. und 19. Jahrhundert zeichnet Kutscher 1937, S. 28 ff., 39 ff. nach. Ähnlich wie hier Stödter 1933, S. 89 ff., wobei dieser auf die uneinheitliche Rspr. des RG aufmerksam macht. Übersehen wird die Weite des Enteignungsbegriffs während des 19. Jahrhunderts von Glos 1998, S. 39 ff., der deshalb mit seiner - bereits von Stödter 1933, S. 93 ff., geteilten - These, daß nicht der Eigentums-, sondern nur der Enteignungsbegriff erweitert wurde (ebd., S. 69 ff., 83 f.), nur die halbe Wahrheit trifft.

50 Vgl. Mayer 1924, § 33. Zu weiteren Vertretern dieser Ansicht Layer 1902, S. 565 Anm. I.

51 Jellinek 1931, S. $402 \mathrm{ff}$

52 Vgl. Anschütz, 1933, S. 707 f. 
tatsächliche Enteignungspraxis während des 19. Jahrhunderts, so daß die Frage nach den Gründen nur um so dringlicher hervortritt.

\section{Die Entwicklung des Eigentumsverständnisses während der Weimarer Republik}

\section{Die verfassungsrechtliche und -politische Ausgangslage}

\section{a) Die Wirtschaftsverfassung der Reichsverfassung}

„Als die Verfassungsgebende Deutsche Nationalversammlung Ende Februar 1919 ihre Hauptaufgabe, die Ausarbeitung einer neuen Reichsverfassung, in Angriff nahm [...] stand fest, daß die Verfassung keine sozialistische, sondern eher eine liberale Handschrift tragen würde. ${ }^{\text {"53 }}$ Diese Einschätzung gilt auch für den fünften, das Wirtschaftsleben regelnden Abschnitt der Reichsverfassung, sofern man unter dem Wort sozialistisch eine auf Gemeineigentum gründende Planwirtschaft versteht. Bei der Ausgestaltung dieses Abschnitts trafen drei Grundtendenzen aufeinander:

\footnotetext{
„Das allgemeine, wenig konkrete Ziel einer gerechteren, sozialeren Wirtschaftsordnung; die Einsicht, jenes Ziel nicht schon in der Verfassung selbst verwirklichen zu können, sondern dem Gesetzgeber offen halten, aber auch überantworten zu müssen; schließlich das Streben nach Garantie tradierter Rechte auch gegenüber möglicher späterer Umgestaltung. “54
}

Erstmals in der deutschen Verfassungsgeschichte wurde im Abschnitt „Wirtschaftsleben“ der Versuch unternommen, die Grundbeziehungen zwischen Staats- und Wirtschaftsleben zu regeln. Das Leitprinzip wurde in Art. 151 Abs. 1 niedergelegt, danach sollte „die Ordnung des Wirtschaftslebens [...] den Grundsätzen der Gerechtigkeit mit dem Ziele der Gewährleistung eines menschlichen Daseins für alle entsprechen“. Der Berichterstatter des Verfassungsausschusses Hugo Sinzheimer führte in den Beratungen der Nationalversammlung dazu aus:

„Dieser Gedanke besagt, daß die wirtschaftliche Freiheit des einzelnen nicht Selbstzweck, kein selbständiges Gut für sich ist, sondern, daß die wirtschaftliche Freiheit des einzelnen nur insoweit im Wirtschaftsleben gelten soll, als diese Freiheit eine soziale Funktion erfüllt. Von diesem Grundgedanken aus ist der gesamte Rechtsstoff [ ...] behandelt. ${ }^{55}$

Diese soziale Funktion zeigte sich zum einen in der Aufstellung von Grundpflichten des Eigentümers (Art. 153 Abs. 3 RV), insbesondere bei der Bodenbearbeitung (Art. 155 Abs. 3 Satz 1 RV), und einer sittlichen Arbeitspflicht zum Wohl der Gemeinschaft (Art. 163 Abs. 1 RV). Zum anderen fand sie ihren Ausdruck in der durch Art. 156 Abs. 1 RV eröffneten Möglichkeit einer Überführung von privaten Unternehmen in Gemeineigentum, der Enteignung von Grundbesitz zur Gewährleistung einer den Bedürfnissen ge-

\footnotetext{
53 Winkler 1993, S. 99

${ }^{54}$ Gusy 1997, S. 342.

55 Sinzheimer, in: Deutsche Nationalversammlung 1919, S. 4258.
} 
recht werdenden „Wohn- und Wirtschaftsheimstätte“ (Art. 155 Abs. 2 RV) sowie der Errichtung von Zwangskartellen (Gemeinwirtschaft) nach Art. 156 Abs. 2 RV. Schließlich kam sie darin zum Tragen, daß nicht nur die Grundzüge der privaten Eigentumsordnung (Art. $152 \mathrm{ff}$. RV), sondern auch die einer künftigen Arbeitsordnung entworfen wurden. Sie beruhte auf der Anerkennung der Arbeitskraft als eigenständigem Rechtsgut $^{56}$ und der endgültigen Verabschiedung des Gedankens eines patriarchalischen Arbeitsverhältnisses. ${ }^{57}$ Es wurde eine staatliche Pflicht zum Schutz der Arbeitskraft (einschließlich der geistigen Arbeit) statuiert (Art. 157 Abs. 1, 158 Abs. 1 RV), ein Anspruch auf Arbeitslosenunterstützung anerkannt, der seine Wurzel im Recht auf Arbeit und nicht länger im Gedanken staatlicher Armenfürsorge fand. Das Recht auf betriebliche und überbetriebliche Mitbestimmung wurde ebenso wie das Recht, Koalitionen zu bilden (Gewerkschaften, Arbeitgeberverband) anerkannt (Art. 165 RV). Auf diese Weise versuchte man den schroffen Gegensatz von Kapital (Eigentum) und Arbeit einzuhegen und menschenwürdige Arbeitsbedingungen zu schaffen. Dazu gehörte auch der Staatsauftrag eines angemessenen Versicherungsschutzes bei Mutterschaft, Krankheit, Unfall und Alter (Art. 161 RV). Auch wenn mit der Eigentums- und der Vertragsfreiheit (Art. $152 \mathrm{f}$. RV) der Grundmodus einer marktwirtschaftlich funktionierenden Wirtschaftsordnung anerkannt wurde, so standen diese Garantien doch wie auch die Gewerbefreiheit in Art. 151 Abs. 3 RV unter dem Vorbehalt gesetzlicher Regelung. „Daraus ergibt sich“ - nach Ansicht Hugo Sinzheimers -, „daß nicht etwa ein verfassungsmäßiger Schutz diese[r] individuellen Rechtsbeziehungen gewährleistet ist, sondern daß über ihren Schutz die gewöhnliche Gesetzgebung verfügen soll. “58 ${ }^{58}$ Trotzdem wurde damit im Grundsatz ein privatwirtschaftliches Ordnungsmodell anerkannt. Nur schloß dies staatliche Intervention nicht aus. Zumal dies in einer Zeit staatlicher Zwangs- und Planwirtschaft auch mehr als seltsam erschienen wäre. Die Wirtschaft sollte nicht dem Prinzip der Selbstorganisation (Marktprinzip) überlassen bleiben. Der gesellschaftliche Zusammenhalt ließ sich in der Massendemokratie nur herstellen, wenn der Staat das neue Leitbild einer menschenwürdigen Arbeits- und Lebenssituation zu verwirklichen suchte und deshalb auch zur gesellschaftlichen Umverteilung bereit war. ${ }^{59}$

Die Wirtschaftsordnung, wie sie von der Verfassung in groben Umrissen gezeichnet und mit Hilfe einiger Grundprinzipien ausgestaltet wurde, entsprach nur teilweise der wirtschaftlichen Realität. Die neue Ordnung war ein verfassungsrechtliches Programm, das der Umsetzung durch Staat und Gesellschaft bedurfte. Letztlich wurde es nur in kleinen Teilen, wie etwa dem Siedlungsrecht, der Betriebsmitbestimmung und der Arbeitslosenunterstützung und auch nur in den ersten Jahren der Republik verwirklicht. Die sozialen, wirtschaftlichen und politischen Auseinandersetzungen standen einer weitergehenden Realisierung von Anfang an entgegen. Später scheiterte die weitere Realisierung an den politischen Machtverhältnissen.

\footnotetext{
56 Vgl. Radbruch 1930, S. 349; Sinzheimer in: Deutsche Nationalversammlung 1919, S. 4260.

57 Siehe Reichold 1995, S. 24 ff.

${ }_{58}$ Sinzheimer in: Deutsche Nationalversammlung 1919, S. 4258.

$59 \mathrm{Vgl}$. Böhm 1933, S. 340 ff.
} 
b) Verfassungsbindung des Gesetzgebers

Die Weimarer Republik brachte Deutschland die erste Massendemokratie. Mit dem gesellschaftlichen Modell des 19. Jahrhunderts, das zwischen Staat und Gesellschaft schied und dem Staat die Aufgabe zuwies, über der durch Interessengegensätze und Egoismen zerrissenen Gesellschaft das Gemeinwohl zu verwahren und zu verwirklichen, konnten die staatlichen Institutionen nicht mehr angemessen erfaßt werden. Obwohl nunmehr erstmals ein politisches System auf dem Gedanken beruhte, daß die staatliche Gewalt den Bürgern gegenüber verantwortlich war, konnte das Schreckgespenst des Parlamentsabsolutismus übergroß und wirkungsmächtig aufgemalt werden. ${ }^{60}$ Um den Gefahren durch vermeintlich radikale Mehrheiten zu begegnen, besann man sich in der Staatsrechtswissenschaft auf die Verfassung als Grenze staatlichen Handeln.

Dabei war der Gedanke der Verfassungsbindung als solcher nicht neu. ${ }^{61}$ Selbst durch die oktroyierten Verfassungen des 19. Jahrhunderts band sich der König selbst und unterwarf sich den institutionellen Bindungen. Auf diesen institutionellen Bindungen, wie dem Erfordernis parlamentarischer Mitwirkung bei Eingriffen in die Freiheit des Bürgers, fußte zu einem großen Teil der Schutz des Bürgers vor dem Staat. Mit diesem Konzept war dem Parlamentsabsolutismus aber nicht beizukommen, weil sich daraus allein prozedurale Anforderungen herleiten ließen.

Das Neue der während der Weimarer Zeit einsetzenden Bemühungen gegenüber der überkommenen Verfassungsbindung bestand darin, daß man der Verfassung inhaltliche Bindungen auch gegenüber dem Gesetzgeber zu entnehmen begann und sich nicht länger mit der Beachtung kompetenzieller Befugnisse (z. B. in Form von Mitwirkungsrechten) begnügte. ${ }^{62}$ Ergänzt und zur vollen Wirksamkeit entfaltet wurde diese Konzeption, indem man versuchte, die Frage, ob der Gesetzgeber die Vorgaben auch beachtet habe, den Gerichten zu überantworten. ${ }^{63}$ Dies war trotz aller Diskussion um ein richterliches Prüfungsrecht im 19. Jahrhundert noch undenkbar gewesen, ${ }^{64}$ da sich dieses Recht, wie die Verfassungsbindung überhaupt, nur auf die kompetenziellen Befugnisse der verschiedenen Staatsorgane zueinander beziehen konnte.

Der Verfassung solche inhaltlichen Vorgaben zu entnehmen, war jedoch alles andere als leicht. Denn der Grundrechtsteil bestand aus Programmsätzen, die Leitlinien für eine künftige Gesetzgebung darstellten, oder aus kurzen Gewährleistungen, wie beispielsweise dem Recht zur freien Wohnungswahl (Art. 111 Satz 1 RV), der Bewegungsfreiheit (Art. 114 Satz 1 RV) oder der Eigentumsgarantie (Art. 153 Abs. 1 Satz 1 RV), die über den thematischen Bezugspunkt hinaus keinerlei Anknüpfungspunkte für eine inhaltliche Konkretisierung boten. Außerdem waren diesen Garantien Gesetzesvorbehalte beigefügt, die es entweder nur dem Reichs- oder auch dem Landesgesetzgeber erlaub-

${ }^{60}$ Zur Parlamentarismuskritik während des Kaiserreichs siehe Schönberger 1997, S. 176 ff., 284 ff.

${ }^{61}$ Eine Übersicht bietet Wahl 1981, S. 485 ff.

${ }^{62}$ Zu letzterem sehr klar G. Jellinek 1919, S. 395.

${ }^{63} \mathrm{Zu}$ dieser Diskussion während der Weimarer Zeit zusammenfassend Hippel 1932, S. 546 ff., aus heutiger Zeit zeichnen Wendenburg 1984 und Gusy 1997, S. 216 ff., die Auseinandersetzungen nach.

${ }^{64}$ Aus der damaligen Diskussion Laband 1911, S. 44 ff.; Jellinek 1919, S. 396 ff.; aus heutiger Sicht Ogorek 1986. 
ten, die Freiheiten zu beschränken. Soweit solche Gewährleistungen durch Landesgesetz einschränkbar waren, wurden sie oft als ,leerlaufend“ bezeichnet, ${ }^{65}$ weil man sich nicht vorstellen konnte, wie der Gesetzgeber an eine Freiheit gebunden sein soll, die er einschränken darf. Es bedurfte deshalb erheblicher interpretatorischer Phantasie, um zu inhaltlichen Vorgaben zu gelangen.

Von den verschiedenen Ansätzen erwies sich nur ein einziger als tragfähig, nämlich der Gedanke der Einrichtungsgarantie, ${ }^{66}$ der von der bundesrepublikanischen Grundrechtsdogmatik übernommen wurde. ${ }^{67}$ Durch eine Einrichtungsgarantie sollte „ein Minimum dessen“, was das „Wesen“ des Rechtsinstitutes ,ausmacht“, vor dem gesetzgeberischen Zugriff geschützt werden. ${ }^{68}$ Daneben bot sich der in Art. 109 RV niedergelegte Gleichheitsgrundsatz an, um den Gestaltungsspielraum des Gesetzgebers zu begrenzen. ${ }^{69}$ Zwar sollte ein Verstoß nur vorliegen, wenn eine Ungleichbehandlung „willkürlich“" erfolgt, „d. h. auf dem Mangel einer ernsthaften Erwägung beruhen würde“" ${ }^{40}$ doch beinhaltete diese Umschreibung einen beträchtlichen Auslegungs- und Anschauungsspielraum, der sich leicht zu Lasten des Gesetzgebers nutzen ließ.

\section{c) Die Emanzipation der Gerichte vom Gesetzgeber}

Unabhängig von diesen Bestrebungen in der staatsrechtlichen Literatur begann das Reichsgericht während der Kriegs- und der ersten Kriegsfolgejahre immer stärker gestalterisch das positive Gesetzesrecht fortzubilden, um angemessene Regeln zur Bewältigung des wirtschaftlichen Zusammenbruchs zu entwickeln. Anschaulich heißt es dazu in einem Beschluß des Reichsgerichts:

„Es gibt drei Quellen, aus denen das subjektive Recht geschaffen wird, einmal das Partei[en]recht, [...] dann der Weg der Gesetzgebung und drittens das richterliche Recht. [...] Wenn das Gesetz versagt, tritt der Richter an die Stelle des Gesetzgebers für den einzelnen Fall. Hier ist häufig von einer Lücke der Gesetzgebung die Rede, aber das ist nicht zutreffend. [...] Alle Gesetzgebung, auch das Bürgerliche Gesetzbuch ist in Wirklichkeit nur Stückwerk. "“71

Für das Verhältnis zwischen Richter und Gesetzgeber war die Frage entscheidend, wie weit das richterliche Prüfungsrecht bei Gesetzen reicht. Für das Landesrecht traf Art. 13 RV eine positive, ein solches Prüfungsrecht anerkennende Regelung. Dieses Prüfungsrecht nahm das Reichsgericht auch von Anfang an in Anspruch. ${ }^{72}$

65 Thoma 1930, S. 21.

66 Zu weiteren Ansätzen siehe Bumke 1998, S. 111 ff.

${ }^{67}$ Dazu statt aller Stern 1988, S. $763 \mathrm{ff}$.

68 Thoma 1930, S. 33; Schmitt 1928, S. 171 ff. Siehe zur damaligen Diskussion auch Gusy 1993, S. $165 \mathrm{ff} ., 177 \mathrm{ff}$.

${ }^{69}$ Diese Funktion hebt Triepel 1924, S. 26 ff., deutlich hervor. Sich ihm anschließend etwa Leibholz 1959, S. 30 ff. Eine ausführliche Kritik dieser Position findet sich bei Mainzer 1929.

70 Triepel 1924, S. 30.

71 RG, Juristische Wochenschrift 1922, S. 910, zitiert bei Nörr 1996b, S. 13 f.

72 So z. B. RGZ 103, 200, 201 vom 18. November 1921: „Der Prozeßrichter hat das einschlägige geltende Gesetz anzuwenden. Findet er, daß landesrechtliche Vorschriften $[\ldots]$ mit reichsrechtlichen Vorschriften in Widerspruch stehen, so hat er gemäß Art. 13 Abs. 1 und Art. 102 RVerf. das 
Sehr viel unsicherer und in der Wissenschaft umstrittener war die Frage, ob ein Gericht Reichsrecht auf seine Vereinbarkeit mit der Verfassung überprüfen durfte. ${ }^{73}$ In der Literatur bejahten jene, die eine inhaltliche Bindung des Gesetzgebers an die Verfassung durchzusetzen versuchten, ein solches Prüfungsrecht, da ohne gerichtliche Kontrolle die Verfassungsbindung nicht wirksam durchsetzbar war. Uneinheitlich war die Haltung des Reichsgerichts. Obwohl dieses schon in einer frühen Entscheidung ein solches Prüfungsrecht annahm, ${ }^{74}$ sah der dritte Senat den Richter in einer späteren Entscheidung nicht als befugt an, ein Reichsgesetz nicht anzuwenden, das aufgrund seines Inhalts womöglich der Verfassung widersprach. ${ }^{75}$ Demgegenüber hielt der fünfte Senat an der richterlichen Prüfungskompetenz fest. ${ }^{76}$ Doch muß dabei beachtet werden, daß Gegenstand der Prüfung nicht Parlamentsgesetze, sondern stets gesetzesvertretende Rechtsverordnungen gewesen sind. Erst im Aufwertungsurteil vom 4. November 1925 fiel die Entscheidung zugunsten einer Prüfungs- und Verwerfungsbefugnis auch gegenüber Parlamentsgesetzen des Reichstages. ${ }^{77}$ Unter Bestätigung seiner früheren Entscheidung ${ }^{78}$ verwarf es die vielfach erhobenen verfassungsrechtlichen Bedenken gegen das Aufwertungsgesetz ${ }^{79}$ Das Gericht nutzt mit dieser Entscheidung die Gelegenheit, die Gerichte als neue Gemeinwohlakteure zu etablieren, die sich nicht länger nur an den Vorgaben des Gesetzgebers orientieren, sondern eine eigenständige Definitionsmacht in Anspruch nehmen. Dies gelingt dem Reichsgericht, indem es das parlamentarische Handeln stützt und ihm die Weihe der Verfassungsmäßigkeit erteilt. Die befriedende und legitimierende Wirkung der Entscheidung machte es dabei Parlament und Regierung praktisch unmöglich, sich dem kontrollierenden Zugriff des Reichsgerichts zu entziehen. ${ }^{80}$

Deutlich wird hierbei zweierlei: Auf der einen Seite taucht im Prozeß der Gemeinwohldefinition und -verwirklichung mit der Gerichtsbarkeit ein neuer Gemeinwohlakteur auf, der sich nicht länger bloß an den Vorgaben des Gesetzgebers orientiert, sondern eine eigene Definitionsmacht entfaltet. Auf der anderen Seite hält sich das Reichsge-

Recht und auch die Pflicht, das betreffende Landesgesetz für nicht geltend zu erklären und außer Anwendung zu lassen."

${ }^{73}$ Siehe dazu Gusy 1997, S. 216 ff.; Friedrich 1997, S. 380 ff.

${ }_{74} \mathrm{Vgl}$. RGZ 102, 161, 164.

75 RGZ 107, 315, 317. Mit dieser Entscheidung sprach sich der Senat indirekt gegen die vom Richterverein des Reichsgerichts in seiner Erklärung vom 8. Januar 1924 (JW 1924, S. 90) der politischen Führung angedrohte Möglichkeit aus, einem gesetzlich angeordneten Aufwertungsverbot die rechtliche Gefolgschaft zu versagen. Dazu näher Nörr 1996b, S. 18 f.; Berkemann 1986, S. 84 ff.; Klemmer 1996, S. $235 \mathrm{ff}$.

${ }^{76}$ Nicht ausdrücklich, aber in der Sache RGZ 107, 370, 375 ff.; ausdrücklich RGZ 107, 377, 379.

77 Vgl. RGZ 111, 320, 322 f. Zur früheren Rspr. des RG Klemmer 1996, S. 250 Anm. 747.

${ }^{78} \mathrm{RGZ} 107,370 \mathrm{ff}$.

79 Die Entscheidung bildet den Abschluß des sog. Aufwertungsstreits zwischen Reichsgericht und politischer Führung. Zu diesem näher Rüthers 1988, S. 64 ff;; Berkemann 1986; Gusy 1997, S. 217 f. m. w. N.; Nörr 1996b, S. 18 ff. Eine ausführliche und genaue Rechtsprechungsanalyse findet sich bei Klemmer 1996, S. $169 \mathrm{ff}$.

${ }^{80}$ Siehe dazu Berkemann 1986, S. 89 f., erheblich zurückhaltender fällt die Einschätzung der Bedeutung dieser Entscheidung bei Klemmer 1996, S. 252 ff., aus. 
richt bei der Konkretisierung der verfassungsrechtlichen Maßstäbe zurück. Auf das Angebot, auf den Generalmaßstab des Gleichheitsgrundsatzes zurückzugreifen, verzichtet das Gericht wohlweislich, um sich nicht zum Spielball in der politischen Auseinandersetzung zu machen.

Allgemeiner gesehen bildet die hier angesprochene Emanzipation der Gerichte einen Teil der sich in der zweiten Hälfte des 20. Jahrhunderts nochmals erheblich verstärkenden Tendenz einer Verselbständigung des Rechtssystems gegenüber dem politischen System. Je stärker rechtsspezifische Institutionen, wie Gerichte, die Ausgestaltung der Rechtsordnung übernehmen und je mehr Bereiche vom Recht erfaßt und durchdrungen werden, desto autonomer wird das Recht gegenüber dem politischen System. Den Schlußstein, durch den sich das Rechtssystem gegenüber seiner Umwelt abzuschließen vermag, bildet dabei die Verfassung, ${ }^{81}$ sobald deren inhaltlicher Vorrang von den Gerichten auch gegenüber dem Gesetzgeber durchgesetzt wird.

\section{Die Eigentumsgarantie in der Rechtsprechung des Reichsgerichts}

Wie nun schlugen sich die beschriebenen Veränderungen - das neue Selbst- und Gestaltungsverständnis der Gerichte, die Bemühungen um eine Verfassungsbindung des Gesetzgebers und der Bedeutungswandel der Grundrechte - konkret im Bereich der Eigentumsgarantie nieder? Daß die Tätigkeit des Reichsgerichts gerade in diesem Bereich von erheblicher praktischer Bedeutung war, kann man der rückblickenden Einschätzung Willibalt Apelts entnehmen. In seiner Geschichte der Weimarer Verfassung führt er aus:

\footnotetext{
„Die Auffassung wurde sofort vom Reichsgericht aufgegriffen und in einer Reihe von Entscheidungen weiterentwickelt, bis es [...] zu der Folgerung gelangte: wenn das Wort Eigentum in Art. 153 Abs. 1 im weitesten Sinne auszulegen sei, also Rechte aller Art darunter fallen, dann müsse auch Abs. 2 so ausgelegt werden, daß jeder Eingriff der Staatsgewalt in ein durch Abs. 1 geschütztes Recht als Enteignung zu bewerten sei. Mit dieser Auffassung, der sich anzuschließen andere hohe Gerichtshöfe nicht zögerten, hatte sich das Reichsgericht einen Hammer geschmiedet, mit dem es nicht nur das in langer Verwaltungserfahrung erprobte Rechtsinstitut der Enteignung, sondern noch sehr viel weiteres, nämlich einen beträchtlichen Teil des gesamten aus der Zeit des konstitutionellen Staatsrechts überkommenen, von sozialem Geiste erfüllten Verwaltungsrechts zerschlug. [...]

Das Fazit dieser Entwicklung in Theorie und Praxis ist für die deutsche Demokratie [...] so schmerzlich wie bedenklich gewesen. In zahlreichen Schriften hat der Rechtsradikalismus der Weimarer Republik vorgeworfen, sie habe als einen charakteristischen Ausdruck liberalistischen Staatsdenkens den einzelnen von allen Bindungen an die Gesamtheit losgelöst [...]. [...] Ein solcher Vorwurf ist unberechtigt gegenüber dem ursprünglichen Sinn, den die Freiheitsrechte $[\ldots]$ gehabt haben $[\ldots]$. Er ist nicht völljg gegenstandslos gegenüber einer Entwicklung, wie sie die Praxis des Reichsgerichts [...] durch die überraschende Auslegung des Art. 153 heraufgeführt hat. ${ }^{82}$
}

\footnotetext{
81 In diesem Sinne Luhmann 1993, S. 476 ff

82 Apelt 1946, S. 341, 344.
} 
Daneben wird man auch die Frage im Auge behalten müssen, in welchem Umfang tatsächlich mit dem überkommenen Eigentumsschutz gebrochen wurde. Oft wird nämlich behauptet, das Reichsgericht habe den Schutzbereich der Eigentumsgarantie ausgedehnt und sei vom überkommenen klassischen Enteignungsverständnis abgewichen. ${ }^{83}$

\section{Der Schutzbereich der Eigentumsgarantie}

Den Eigentumsschutz beschränkte das Reichsgericht nicht auf das Eigentum im Sinne des Bürgerlichen Rechts ( $\$ 903$ BGB). Es ging davon aus, daß auch aus der Feudalordnung überkommene Positionen geschützt sind, wenn sie nur privatrechtlicher Natur sind, ${ }^{84}$ oder es sich um alte wohlerworbene Rechte handelt. ${ }^{85}$ Das Gericht bejahte einen weiten, auch Forderungsrechte umfassenden Eigentumsbegriff. ${ }^{86}$ Geschützt wurden danach ,alle subjektiven Privatrechte“, die über einen Vermögenswert verfügten. ${ }^{87}$

\section{Der Kreis der enteignungsfähigen Gegenstände}

Da die Eigentumsgarantie in Art. 153 Abs. 1 RV keinen eigenständigen Schutz vor Eingriffen bot, sondern allein die Möglichkeit bestand, eine Entschädigung zu verlangen, falls es sich bei dem Eingriff um eine Enteignung gehandelt hatte, bestimmte das Reichsgericht den Schutzbereich der Eigentumsgarantie über den Kreis enteignungsfähiger Gegenstände. Einen dementsprechend weiten Kreis begründet das Gericht mit folgender Überlegung:

„Es ist kein innerer Grund erkennbar, daß die Gesetzgebung der Gegenwart verfassungsmäßigen Schutz gegen den Eingriff in die subjektiven Rechte nur in jenem beschränkten [auf das Eigentum i. S. d. § 903 BGB] Umfange sollte gewähren wollen, nicht aber auch gegen Eingrif-

83 So aus der damaligen Zeit begrenzt auf die Enteignung die Veränderungen aufgreifend Anschütz 1933, S. 708 ff.; Schelcher 1930, S. 201 ff.; ablehnend Schmitt 1958, S. 110 ff. Aus heutiger Sicht Gusy 1997, S. 346 f.; Rittstieg 1975, S. 254 f., 271 .; v. Brünneck 1984, S. 29 ff.

${ }^{84}$ So ausdrücklich RGZ 111, 123, $130 \mathrm{ff}$. und die bestätigende Anmerkung von Mende 1926, S. 253 ff. Implizit vorausgesetzt bereits in RGZ 103, 200. Da das Reichsgericht dabei von der gefestigten Rechtsüberzeugung ausgehen konnte, daß feudale Rechtspositionen, die privatrechtlichen Charakter besaßen und einen Vermögenswert hatten (letzteres sah etwa Stein 1962, S. 75 f., als entscheidend an) grundsätzlich nur gegen eine Entschädigung entzogen werden konnten, überzeugt die von Rittstieg 1975, S. 257 geäußerte Kritik m. E. nicht. Denn der Reichsverfassung von 1919 läßt sich kein Hinweis entnehmen, daß der „vorrepublikanischen Status quo" nicht verfassungsrechtlich geschützt werden sollte.

85 Gegenstand der Entscheidung RGZ 136, 113 war ein Steuerbefreiungsprivileg. Die Aufhebung dieses wohlerworbenen Rechts wird vom Gericht als Enteignung qualifiziert. Auch hier stellt das Gericht auf die privatrechtliche Eigenschaft des Rechts ab (S. 124).

86 Vgl. RGZ 111, 320, 328 .

87 RGZ 109, 317, 319 umschreibt dabei den Kreis enteignungsfähiger Gegenstände. Dies setzt einen entsprechenden verfassungsrechtlichen Schutz voraus. 
fe in sonstige Rechte, die nach ihrem wirtschaftlichen Werte wie nach der Art des Eingriffs eben so sehr des Schutzes bedürftig sein können. “ 88

Vergleicht man dies mit dem früheren Rechtszustand, führte die Ansicht des Reichsgerichts zu keinen grundlegenden Veränderungen. Neu war allein, daß nunmehr auch Forderungen enteignet werden konnten. Entgegen anderslautender Behauptungen in der damaligen Literatur ${ }^{89}$ war der Eigentums- bzw. Entschädigungsschutz vor der Weimarer Zeit nicht auf Grundstücke beschränkt. Sicherlich gab es ein enges, auf Grundstücke bezogenes Verständnis, das auf den Enteignungsgesetzen der Länder gründete. Doch kam es auch anderweitig zum Entzug oder zur Beschränkung vermögenswerter privater Rechte gegen Leistung einer Entschädigung. ${ }^{90}$ Auch bei diesen Eingriffen wurde die Entschädigung nicht als bloße Frage der Billigkeit verstanden. Im Erhalt des Vermögenswertes wurde bereits im 19. Jahrhundert ein Rechtsgebot gesehen.

\section{Die Merkmale eines enteignenden Eingriffs}

Enteignungen konnten nicht nur durch Verwaltungsakt, sondern auch unmittelbar durch ein Gesetz erfolgen. ${ }^{91}$ Beide Formen kannte man bereits im 19. Jahrhundert. Eine Enteignung ging meist mit einer Rechtsübertragung einher und diente in aller Regel dem Ziel, ein bestimmtes im öffentlichen Interesse bestehendes Unternehmen zu verwirklichen. Als zwingende Merkmale des Enteignungsbegriffs sah das Reichsgericht die beiden Gesichtspunkte allerdings nicht an. ${ }^{92}$ Beispielsweise ordnete es den Entzug von Ansprüchen $^{93}$ oder die durch zwangsweise Wohnungseinweisung ${ }^{94}$ bzw. Eintragung als Baudenkmal ${ }^{95}$ bewirkten Nutzungsbeschränkungen als Enteignungen ein. ${ }^{96}$ „Eine Enteignung“ - so formulierte es das Gericht schließlich - ,ist schon dann anzuerkennen,

${ }^{88}$ RGZ 109, 317, 319.

${ }^{89}$ Siehe die Nachw. in Anm. 49 f. sowie Richter 1931, Sp. 658 ff. Bezeichnend sind ferner die Ausführungen von Schelcher 1930, S. 204 f., wo immer wieder vom Eigentum im ,eigentlichen “ oder „engeren" Sinne gesprochen wird, aber die Grenze letztlich gegenüber Forderungen gezogen wird und der Schutz weit über Grundstücke hinausreicht.

90 Dies gesteht ein Gegner des weiten Enteignungsbegriffs wie Schelcher 1930, S: 201, zu.

${ }^{91}$ Siehe RGZ 109, 317 f.; 111, 320, 326.

92 In eine andere Richtung weist nur RGZ 107, 261, 263 f., wo es heißt: „Es ist nicht anzunehmen, $\mathrm{da} \beta$ die Reichsverfassung unter dem Begriff der Enteignung etwas anderes verstanden hätte, als das in dem größeren Teile von Deutschland geltende preußische Enteignungsgesetz." Das Gericht fährt dann allerdings folgendermaßen fort: „Danach ist freilich eine Enteignung auch im Sinne der Reichsverfassung nicht bloß dann für gegeben zu erachten, wenn das Eigentum zwangsweise auf einen anderen übertragen wird, sondern auch schon im Falle einer zwangsweisen Einschränkung des Eigentums zugunsten eines Dritten. “

93 Vgl. RGZ 136, 113, 123.

94 Vgl. RGZ 105, 253; 111, 224, 226.

95 Vgl. RGZ 116, 268, 272.

96 Vgl. RGZ 128, 18, 33. Bereits in einer früheren Entscheidung hatte das Reichsgericht in der Nutzungsbeschränkung durch Bauverbot aufgrund einer Fluchtlinie „im Wesen nichts anderes als eine ,Teilenteignung“" gesehen (RGZ 63, 298, 300). 
wenn das Recht des Eigentümers, mit seiner Sache [...] nach Belieben zu verfahren, zugunsten eines Dritten beeinträchtigt wird."97

Konnte demnach jede Beeinträchtigung eines bestehenden Eigentumsrechts eine Enteignung sein, stellte sich die praktisch äußerst wichtige Frage, wie sich die Enteignung von bloßen Eigentumsbegrenzungen unterscheiden ließ. Eigentumsbeschränkungen durfte der Gesetzgeber nach Art. 153 Abs. 1 Satz 2 RV erlassen, ohne dadurch zu Entschädigungsleistungen verpflichtet $\mathrm{zu}$ werden. Als entscheidend sah das Gericht schließlich an, daß es sich um einen „Einzeleingriff“" handeln muß,

\begin{abstract}
„der nicht alle im Geltungsbereich eines Gesetzes befindlichen Grundstücke oder Rechte gleichmäßig, sondern nur einzelne von ihnen oder einen engen Kreis von einzelnen Grundstücken oder Rechten trifft, ihnen ein besonderes Opfer zugunsten der Allgemeinheit auferlegt [...]. Den Inhalt und die Schranken des Eigentums allgemein zu regeln, die zulässigen Rechte an Grundstücken und die Voraussetzungen ihrer Entstehung allgemein zu bestimmen, muß dem Gesetzgeber vorbehalten bleiben, ohne daß er dabei durch eine Pflicht zur Entschädigung gehindert werden kann". 98
\end{abstract}

Dies hatte zur Konsequenz, daß „eine Enteignung dann nicht in Betracht [kommt], wenn ein Gesetz ganz allgemein den Inhalt und die Schranken von Rechten und Befugnissen bestimmt und damit zwar auch in bestehende Berechtigungen eingreift, aber zugleich das betreffende Rechtsgebiet als Ganzes für die Zukunft regelt und Schranken für neu zu erwerbende Rechte aufstellt" ${ }^{* 99}$ Bei der Abgrenzung zwischen entschädigungspflichtiger Enteignung und entschädigungslos hinzunehmender Eigentumsbegrenzung griff das Gericht demnach auf ein formales Kriterium zurück. Nicht die Intensität oder Schwere des Eingriffs, sondern die Größe des Adressatenkreises war entscheidend (sog. Einzelakttheorie). ${ }^{1}$

Verfassungsbindung, die weite Enteignungskonzeption und ihre konsequente Anwendung machten die Abgrenzung zwischen entschädigungsloser Eigentumsbegrenzung und entschädigungspflichtiger Enteignung zur alles entscheidenden Frage der Eigentumsdogmatik. Entgegen der Behauptung von Otto Kirchheimer handelte es sich dabei jedoch nicht um ein Problem, welches erst durch das Eigentums- bzw. Enteignungsverständnis des Reichsgerichts heraufbeschworen worden war. ${ }^{101}$ Das Problem stellte sich bereits im 19. Jahrhundert, nur hatte es damals mangels verfassungskräftigem Entschädigungsanspruch keine praktische Relevanz erlangt. ${ }^{102}$ Die Abgrenzung

${ }^{97}$ RGZ 116, 269, 272

${ }^{98}$ StGH, RGZ 124, Anhang S. 19, 33.

${ }^{99}$ RGZ 129, 146, 149. So auch im wichtigen sog. Gefrierfleisch-Fall (RGZ 139, 177, 183 ff.).

${ }^{100}$ Sehr klar tritt dies in der Entscheidung RGZ 139, 177 ff. hervor, wo Schäden in Höhe von 53 Millionen Reichmark geltend gemacht wurden.

${ }^{101} \mathrm{Vgl}$. Kirchheimer 1972, S. 223, 268.

${ }^{102}$ Für den engeren Enteignungsbegriff - Übertragung eines Rechts auf einen Dritten zur Realisierung eines bestimmten Unternehmens - war dies nicht schwer, man konnte dabei sogar auf die ältere und zwischenzeitlich überholte Vorstellung von der Enteignung als einem privatrechtlich zu beurteilenden ,Zwangskauf" zurückgreifen. Denn es scheint ein Gebot der Gerechtigkeit zu sein, daß zumindest der Wertverlust ersetzt wird, wenn man gezwungen wird, einem anderen seinen Eigentumsgegenstand zu übergeben. So auch Kirchheimer 1972, S. 246. 
zwischen Enteignung und Eigentumsbegrenzung führte anfänglich zu erheblichen Unsicherheiten in Literatur und Praxis. ${ }^{103}$ Die Frage, ob es deshalb einer reichsgesetzlichen Regelung bedürfe, wurde sogar zum Thema des 36 . Deutschen Juristentages gemacht. Doch zeigte sich im Referat von Walter Jellinek, daß mit dem Herausbilden der sog. Einzelakttheorie die rechtliche Orientierung in hinlänglichem Umfang wiederhergestellt worden war. Ihre Ergebnisse waren in aller Regel vorhersehbar, so daß Jellinek, auch wenn er eine andere Theorie befürwortete, eine reichsrechtliche Regelung nicht länger für erforderlich hielt. ${ }^{104}$ Die Abgrenzungsfrage blieb freilich im Mittelpunkt der eigentumsrechtlichen Diskussion. Ausgehend von der Einzelakttheorie lag es dabei nahe, das maßgebliche inhaltliche Kriterium im Gedanken der Lastengleichheit und damit im allgemeinen Gleichheitsgrundsatz zu erblicken. ${ }^{105}$

\section{Veränderungen des Eigentumsverständnisses}

Welche Veränderungen mit dieser Rechtsprechung einher gingen, ist nicht leicht auszumachen: Gesetzliche Nutzungsbeschränkungen, die, wenn schon nicht als Enteignungen, so doch wenigstens als entschädigungspflichtige Eingriffe bewertet wurden, kannte man auch im 19. Jahrhundert; zum Beispiel in der Umgebung von Festungsanlagen. So gesehen bedeutete auch die Galgenberg-Entscheidung des Reichsgerichts, in der die aus dem Denkmalsrecht resultierenden Nutzungsbeschränkungen als Enteignung angesehen wurden, keinen Bruch mit den überkommenen Anschauungen. Gleiches gilt für das bekannte Fluchtlinien-Urteil, das sich in die bisherige Rechtsprechungslinie einfügte. ${ }^{106}$ Das Entscheidende dürfte deshalb weniger in neuen inhaltlichen Akzentuierungen ${ }^{107}$ als vielmehr darin zu finden sein, daß man die wenigen früheren Beispiele für ein weites Enteignungsverständnis verallgemeinerte und zur Grundregel erhob. Erst auf diese Weise konnte die Enteignung mit jedem beliebigen rechtmäßigen Eingriff in ein Eigentumsrecht gleichgesetzt werden, sofern von dem Eingriff nur ein kleiner Personenkreis betroffen wurde. Es war letztlich die Konsequenz, die früher gefehlt hatte und mit der nun das weite Begriffsverständnis verfolgt wurde, die zu den Wandlungen der Eigentumsverfassung führte.

Doch wäre dies ohne größere Bedeutung geblieben, wenn sich nicht noch als weitere Veränderung das Kompetenzgefüge verschoben hätte. Diese Verschiebung ergab sich aus der Bindung des Gesetzgebers an Art. 153 Abs. 2 RV. Trotz des Umstandes, daß

${ }^{103}$ Siehe etwa die Bemerkungen von Richter 1931, Sp. 649 f.

${ }^{104} \mathrm{Vgl}$. Jellinek 1930, S. 301 ff., 316. Jellinek selbst befürwortete eine stärker materielle Theorie, die die Abgrenzung nach dem Aspekt der Schutzwürdigkeit von Eigentumspositionen vorzunehmen suchte (ebd., S. 304 ff.).

${ }^{105}$ Scharf herausgearbeitet von Stödter 1933, S. 106 ff., 191 ff. Der Gedanke der Lastengleichheit bildete auch in der französischen Literatur das Fundament für den Entschädigungsanspruch; siehe Sass 1992, S. $152 \mathrm{ff}$.

${ }^{106}$ Siehe Breuer 1976, S. $115 \mathrm{ff}$.

${ }^{107}$ Anderer Ansicht die in Anm. 89 nachgewiesen Stimmen sowie Kirchheimer 1972, S. 278; Wittmayer 1926, S. 740, wo dieser von "Zersetzung“ des Instituts der Enteignung spricht (ebenda S. 757). 
man mit einer inhaltlichen Bindung des Gesetzgebers noch wenig vertraut war, fiel es bei dieser Bestimmung nicht schwer, eine Bindungswirkung zu bewerkstelligen. Zwar gab die Bestimmung dem Gesetzgeber ein starkes Eingriffsrecht in die Hand, doch stellte sie daneben qualifizierende Merkmale auf. Ein solcher Eingriff durfte nur ,zum Wohle der Allgemeinheit" erfolgen. Außerdem ließ sich der Bestimmung ein verfassungsunmittelbarer Entschädigungsanspruch entnehmen, der nur durch ein Reichsgesetz ausgeschlossen werden konnte. Erst durch diesen verfassungsunmittelbaren Entschädigungsanspruch entwickelte sich das Enteignungsrecht zu einem der umstrittensten verfassungsrechtlichen Gebiete. Zusammen mit dem weiten Enteignungsverständnis bestand stets die Gefahr, daß landesrechtliche Regelungen zu umfangreichen Entschädigungspflichten führten, die die öffentliche Hand angesichts leerer Kassen nur schwer erfüllten konnte.

Diese Rechtsprechung bescherte den Eigentümern, allen voran denen, die Eigentum an einem Grundstück besaßen, plötzlich Entschädigungsansprüche gegenüber Beeinträchtigungen, die sie früher entschädigungslos hinnehmen mußten. Grundsätzlich stand die Rechtsprechung aber Veränderungen der Eigentumsordnung nicht entgegen. Die Konzeption des Reichsgerichts war strikt formal und richtete sich auch nicht von vornherein gegen den Gesetzgeber. Dies zeigt sich in dem Umstand, daß Eingriffe, die mit der Neugestaltung von Eigentumsrechten einher gingen, als entschädigungslos angesehen wurden, obwohl der gegenteilige Standpunkt relativ problemlos mit Hilfe der Einzelakttheorie und in Anlehnung an die Rechtsprechung zum Denkmalschutz zu begründen gewesen wäre. Das Korsett, das die Rechtsprechung dem Gesetzgeber zog, war nicht sonderlich eng. Doch führten die wirtschaftlichen Verhältnisse dazu, daß die Stellung der Eigentümer erheblich gegenüber gegenläufigen öffentlichen Interessen gestärkt wurde. $^{108}$ Reformen oder gesellschaftliche Umgestaltungen scheiterten nicht an der Rechtsprechung, sondern an den politischen Machtverhältnissen.

Aus heutiger Sicht ist die formale Vorgehensweise des Gerichts ungewohnt. Die Folgen seiner Rechtsprechung dürften dem Gericht seit seiner Galgenberg-Entscheidung bekannt gewesen sein. ${ }^{109}$ Trotzdem hat es, ohne sich mit diesen Konsequenzen ausdrücklich auseinander zu setzen, an seiner Konzeption festgehalten. Das FluchtlinienUrteil, dessen Begründung in der Sache durchaus überzeugen konnte, hatte derartig dramatische finanzielle Auswirkungen, daß durch die Notverordnung vom 5. Juni $1931^{110}$ der alte Rechtszustand reichsrechtlich zum Teil wiederhergestellt wurde. Von einer Selbstbeschränkung des Gerichts kann in diesem Zusammenhang nicht gesprochen werden. ${ }^{111}$ Es entfaltete die Enteignungsbestimmung als umfassende Schutzvor-

\footnotetext{
${ }^{108}$ Trotz anderer Akzentuierung im Ergebnis übereinstimmend Gusy 1997, S. 348.

${ }^{109}$ Schon früh hatte Wolff 1923, S. 24 darauf hingewiesen.

${ }^{110}$ RGBI. I, 279, 309 f., wobei aber der vom RG entwickelte weite und über $\S 13$ Preuß. Fluchtliniengesetz hinausgehende Entschädigungsanspruch nur mit erheblichen Einschränkungen anerkannt wurde (ebd., §3) und mit der Maßgabe, daß die Fälligkeit des Anspruchs auf fünf Jahre hinausgezögert wurde. Im übrigen wurde durch $\S 2$ der alte Rechtszustand wiedereingeführt. Näher dazu Breuer 1976, S. $119 \mathrm{ff}$.

111 Dies ist die These von Nörr 1996a, S. 29 ff. mit Blick auf die Haltung des Reichsgerichts, den Gesetzgeber nicht Maßstäben wie Billigkeit, Treu und Glauben oder Sittlichkeit zu unterwerfen, sondern sich mit der Verfassungsbindung zu begnügen („Der Gesetzgeber ist selbstherrlich und an
} 
schrift des Eigentümers vor staatlichen Zugriffen im Einzelfall, wobei nicht alle diese Beeinträchtigungen Durchbrechungen der Eigentumsordnung darstellten. Um es an einem Beispiel zu verdeutlichen: Mochten die Nutzungsbeschränkungen im Denkmalsrecht auch auf einer Entscheidung im Einzelfall fußen, so hätte man den gleichen Erfolg durch eine gesetzliche Regelung herbeiführen können, die für alle Grundstückseigentümer in gleicher Weise gegolten hätte.

Das Reichsgericht beteiligte sich durch seine Enteignungsrechtsprechung auf wirkungsmächtige Weise an der Konkretisierung des Gemeinwohls. Direkte Aussagen dazu machte es aber selten. Negativ stellte es heraus, daß rein fiskalische Interessen nicht ausreichten, um eine Enteignung zu rechtfertigen. Es müsse ein weitergehendes Interesse mit dem Eingriff verfolgt werden. ${ }^{1 / 2}$ Darüber hinaus stellte es keine einschränkenden Anforderungen an das öffentliche Interesse auf. Sein Betrag kam vermittelter, durch die Entscheidung über die Enteignungsqualität zum Tragen. Das Gericht nahm dabei die ausschließliche Entscheidungskompetenz über die Frage, ob es sich bei einer staatlichen Maßnahme um eine entschädigungspflichtige Enteignung oder um eine entschädigungslos hinzunehmende Eigentumsbeschränkung handelt, für sich in Anspruch. Die mit einer Enteignung verbundenen Kosten mußten dann von der öffentlichen Hand bei der Verfolgung des Gemeinwohls in Rechnung gestellt werden und konnten dazu führen, daß man von der Realisierung Abstand nahm.

Auf der anderen Seite erkannte das Reichsgericht den Vorrang des Reichsgesetzgebers hinsichtlich der Entschädigungsbedürftigkeit eines Eingriffs strikt an. Schloß dieser eine Entschädigung aus, so versuchte das Gericht diese Entscheidung nicht etwa mit Hilfe des Gedankens willkürlicher Ungleichbehandlung zu unterlaufen.

\section{Die Erklärungen des Verständniswandels}

Was waren nun die Gründe für die veränderte Haltung des Reichsgerichts? Trieb die Richter der Wunsch, die bürgerliche Gesellschaft vor ihren nicht mehr so bürgerlichen Parlamenten auf Landes- und Reichsebene zu schützen ${ }^{113}$ oder handelte es sich letztlich mehr um einen Zufall, der sich aus einem Gemisch überkommener Eigentums- und Enteignungsanschauungen und der Konstitutionalisierung der Rechtsordnung ergab? Auf jeden Fall wurden die Veränderungen im Bereich der Eigentumsgarantie als bedeutsam und tiefgreifend wahrgenommen. Dies zeigt sich an den Bemühungen, nicht nur - wie für Staatsrechtswissenschaft typisch - die Veränderungen kritisch-konstruktiv zu begleiten, sondern darüber hinaus nach Erklärungen für sie zu suchen. Läßt man

keine anderen Schranken gebunden als diejenigen, die er sich selbst in der Verfassung oder in anderen Gesetzen gezogen hat." - RGZ 118, 325, 327).

${ }^{112}$ Siehe RGZ 103, 200, 202.

${ }^{113}$ So beispielsweise Triepel 1924, S. 23: „In der Tat ist die Enteignung nicht dazu da, um wirkliche oder vermeintliche,Gefühle der Allgemeinheit, etwa einen in größeren Volkskreisen gehegten Wunsch nach Beseitigung bedeutender Vermögen, zu erfüllen.“ Wolff 1923, S. 21: „die Reichsverfassung [will] auch gegen den konfiskationslüsternen Landesgesetzgeber schützen“". Schmitt 1926, S. 17, 23, wo insbesondere die Bindung an Art. $109 \mathrm{RV}$ mit diesem Ziel gerechtfertigt wird. In diesem Sinne argumentiert auch Stödter 1933, S. 251 f. 
einige repräsentative Kommentatoren aus der Weimarer Zeit zu Wort kommen, ergibt sich ein disparates Bild:

Bei Gerhard Anschütz stößt man auf folgende Überlegungen: ${ }^{114}$

„Es läßt sich nicht leugnen, daß das Privateigentum der Staatsgewalt heute tatsächlich in weit höherem Grade ausgeliefert, also schutzbedürftiger ist als in den Zeiten vor der Staatsumwälzung und dem Weltkriege. Der Krieg hatte eine bis dahin niemals dagewesene Unterwerfung aller privaten Vermögensinteressen unter die Gebote des Staateswohles herbeigeführt, und dieser Kriegs- und Nachkriegssozialismus dauerte noch lange - er dauert, kann man sagen, auch heute noch - in anderen und wechselnden Formen, aber in wenig verminderter Stärke fort. Der deutsche Staat der Gegenwart sieht sich unter dem Drucke politischer, wirtschaftlicher, finanzieller Nöte einerseits gezwungen, viel rücksichtsloser in das Privateigentum einzugreifen [Aufwertungsgesetzgebung, Wohnungszwangswirtschaft], als es der alte Staat jemals wagte und brauchte. ${ }^{115}$ Andererseits fordert die allgemeine Verarmung, daß auf die Vermögensverhältnisse des einzelnen in höherem Maße Rücksicht genommen wird, als dies in früheren Zeiten notwendig war. Das alles bedeutet, im Vergleich mit der Vorkriegszeit, eine völlig geänderte Lage des Verhältnisses der Staatsgewalt zum Einzelrecht - eine Änderung, die es rechtfertigt, ja fordert, die dem Schutz und der Garantie der Einzelrechte, vorab des Privateigentums dienenden Normen der RVerf nicht eng, sondern weit, nicht im kollektivistischen, sondern im individualistischen Sinne, mithin - was Art. 153 Abs. 2 anlangt - so auszulegen, daß der hier gewährleistete Anspruch auf angemessene Entschädigung bei Enteignungen weitgehend und kräftig zur Auswirkung kommt. “"116

Noch stärker auf die konkreten gesellschaftlichen und politischen Schwierigkeiten in der Anfangsphase der Republik begründet sah Albert Hensel - wenn auch nicht speziell mit Blick auf die Eigentumsgarantie - die Rechtsprechung des Reichsgerichts und den Rückgriff auf die Verfassung an. So schreibt er:

„In der großen Krise des Rechtsstaates, die weniger durch die Revolution als durch die Inflation und ihre Folgeerscheinungen hervorgerufen wurde, war es Aufgabe der Rechtsprechung, an Rechtsbewußtsein zu retten, was zu retten war. [...] In den Krisenjahren konnten die Grundrechte in ihrem älteren, einfacheren und festeren Gefüge mehr als je zuvor Rettung bringen. So ist es kein Zufall, daß gerade in den Jahren 1922-1925 die Masse der Grundrechtsjudikatur anschwillt. ${ }^{\text {"117 }}$

${ }^{114}$ Anschütz folgend aus heutiger Sicht v. Brünneck 1984, S. 45.

${ }^{115}$ In diesem Sinne äußert sich auch Krückmann 1925, S. 35 ff.; ders. 1930, S. 5: „Man unterstellte also eine Enteignung unmittelbar durch Gesetz etwa im Jahre 1920. Es würde schwerlich bezweifelt worden sein, daß Derartiges zulässig sei. Damals waren freilich ganz andere Sicherheiten gegen Übergriffe von irgendwelchen Parlamentsmehrheiten gegeben, es funktionierten vor allem auch die Impondarabilien als Aufsicht und notfalls als Korrektur des Rechtslebens in ganz anderer Weise als heute."

${ }^{116}$ Anschütz 1933, S. 710 f. In diesem Sinne auch Wittmayer 1926, S. 756: „Der Anreiz dazu liegt darin, daß einerseits die außergewöhnlichen Verhältnisse der Kriegs- und Nachkriegszeit einen großen Bedarf an nur z. T. enteignungsähnlichen Eingriffen in das private Recht ergeben haben und andererseits die neue Reichsverfassung (Art. 156) einen ungemein weiten Rahmen für gemeinwirtschaftliche Bestrebungen geschaffen hat."

${ }^{117}$ Hensel 1929, S. 1, 2. 
Eine deutlich anders akzentuierte Antwort als die bisher angeführten gab Otto Kirchheimer. Aus seiner Sicht hatte sich eine

,rückläufige Tendenz entwickelt, die aus der Weimarer Verfassung ein Bollwerk des alten bürgerlichen Rechtsstaates machen will. Mittelpunkt dieser neuen rückläufigen Tendenzen sind die Art. 109 und 153 der Reichsverfassung geworden, deren Verletzung von jeder in ihrem Status quo bedrohten Interessengruppe meist gemeinsam vorgeschützt wird“. ${ }^{118}$

Das Enteignungsverständnis des Reichsgerichts und der herrschenden Meinung in der Literatur ist seiner Meinung nach

„Ausdruck der veränderten parlamentarischen Machtverhältnisse in der Nachkriegszeit. Da das Bürgertum fürchten muß, daß im Parlament heute eine seinen Privatinteressen feindliche Eigentumsgesetzgebung zustande kommt, wird die diesbezügliche Gesetzgebung einer neuen Instanz unterworfen, die dem Bürgertum günstiger schien." "1 T9

Im Hintergrund stand dabei die Überzeugung Kirchheimers, daß die Enteignung nach der Konzeption des Art. 153 RV 1919 und dem Willen des Verfassungsgebers ${ }^{120}$ keinerlei Schutz gegenüber dem Gesetzgeber bot. ${ }^{121} \mathrm{Da}$ dies jedoch keinesfalls so zwingend war, wie Kirchheimer glaubte, dürfte deutlich geworden sein. ${ }^{122}$

Gegen die von Kirchheimer ${ }^{123}$ vorgebrachte Erklärung ist eingewandt worden, daß die Entscheidungstätigkeit des Reichsgerichts nicht gegen den neuen demokratischen Gesetzgeber gerichtet gewesen sei. Das Gericht habe vielmehr in den entscheidenden Situationen - Wohnungsbeschlagnahme, Aufwertungsstreit, Gefrierfleischfall - den Reichsgesetzgeber gestützt. ${ }^{124}$ Andererseits ist in der Rechtsprechung aber auch wenig davon zu spüren, daß dort die Folgen des Interventionsstaates bedacht und verarbeitet wurden.

Diese Erklärungsansätze bedenkend und die zuvor gemachten Überlegungen einstellend wird man folgendes sagen können: Zunächst läßt sich festhalten, daß jede inhaltliche Bindung des Gesetzgebers zu einer Bewahrung des bestehenden beziehungsweise

${ }^{118}$ Kirchheimer 1972, S. 256, in diesem Sinne auch S. 258, 269, 276 (seine Einschätzung teilen Wieacker/Weber 1935, S. 46 f.).

${ }^{119}$ Kirchheimer 1972, S. 268 f.

${ }^{120} \mathrm{Zu}$ Recht kann sich Kirchheimer auf Sinzheimer berufen, der einen Eigentumsschutz nur im Rahmen der einfachen Rechtsordnung anerkennen wollte (Deutsche Nationalversammlung 1919, S. 4285). Einschränkend muß aber hinzugefügt werden, daß Sinzheimer mit keinem Wort auf die Enteignungsbestimmung einging. Die anschließenden Ausführungen der Abgeordneten zur Enteignung führen in der hier interessierenden Frage einer Bindung des Gesetzgebers nicht weiter. Doch wird zumindest erkennbar, daß hier deutlich unterschiedliche Vorstellungen bestanden (ebd., S. 4278 ff,). Eine abweichende Einschätzung der Entstehungsgesichte findet sich bei Eschenbach 1996 , S. $55 \mathrm{ff}$.

${ }^{121}$ Kirchheimer 1972, S. 265 f., 268.

${ }^{122}$ Das Institut besaß nie die scharfe Umgrenzung, wie dies im nachhinein behauptet wurde. Es würde außerdem sehr schwer fallen, den Sinn des Entschädigungsausschlusses zu erklären, wenn mit der Enteignung nur das enge Institut gemeint gewesen wäre. Denn in diesen Fällen war es doch, wie Kirchheimer selbst sagte, ein Gebot der Gerechtigkeit, zu entschädigen.

${ }^{123}$ Sie wird geteilt von Rittstieg 1975, S. 271; Apelt 1946, S. 341 ff.

124 So v. Brünneck 1984, S. 40 f., der aber durchaus die sichernde Wirkung der Rspr. sieht (ebd., S. 42). 
überkommenen Rechtszustandes führt, da jede Veränderung verfassungsrechtlich gerechtfertigt werden muß. Auch eine Verfassung, die klare Entscheidungen für eine Reform getroffen hat, ist darauf angewiesen, daß sich entsprechende Mehrheiten finden. Lassen sie sich nicht mobilisieren, so gewinnt das Beharrungsvermögen des Status quo an Bedeutung. Bei der Sicherung der bestehenden Eigentumsordnung war das Reichsgericht gegenüber dem Reichsgesetzgeber stets deutlich zurückhaltend. Ein Grund dafür ergab sich zwar auch aus der noch fehlenden Praxis, der Verfassung inhaltliche Maßstäbe zu entnehmen. Doch wird man hinter der oft an formalen Kriterien anknüpfenden Rechtsprechung letztlich inhaltliche Überzeugungen vermuten dürfen: Das Gericht wollte den Freiraum, den die Verfassung bei der Neu- und Umgestaltung der Eigentumsordnung erkennbar bot, nicht in Frage stellen. Andererseits wollte sich das Gericht auch nicht länger mit einer ,vollziehenden“ Rolle begnügen. Die äußeren Wirren der Nachkriegszeit ließen einen solchen Schritt zu, ohne daß man daraus einen allzu deutlichen antidemokratischen, gegen den Parlamentsabsolutismus gerichteten Effekt herauslesen mußte. Doch - und darin gründet die Ambivalenz der Rechtsprechung - gesellte sich dazu eine gegenläufige, das überkommene gesellschaftspolitische System konservierende Wirkung - gleichgültig, ob bewußt vom Gericht erstrebt oder nicht. Letztlich waren es wohl die politischen Verhältnisse einer labilen und innerlich zerstrittenen Massendemokratie und nicht die interventionistischen Aktivitäten des Staates, die das Reichsgericht zu dem beschrittenen Weg veranlaßten.

\section{Was ist Eigentum?}

Charakteristisch für ein Eigentumsrecht ist, daß dem Rechtsinhaber ein Gegenstand als ihm gehörend zugewiesen wird und er deshalb diesen Gegenstand nutzen (z. B. verfügen, benutzen, verbrauchen) und andere von seiner Benutzung ausschließen kann. Bei dem Gegenstand kann es sich um eine reale Sache (z. B. eine bewegliche Sache, ein Tier), ein ideelles Werk (z. B. ein Patent) oder ein Recht (z. B. ein Pfandrecht) handeln. Durch ein Eigentumsrecht werden nicht nur die Befugnisse des Einzelnen hinsichtlich eines Gegenstandes, sondern und in erster Linie die Rechte und Pflichten zwischen dem Eigentümer des Gegenstandes und allen übrigen Personen, gleichgültig ob es sich um einen Privaten oder einen staatlichen Akteur handelt, festgelegt. Beim Eigentum handelt es sich demnach nicht um eine faktische Beziehung zwischen Eigentümer und einem Gegenstand. Eigentum ist vielmehr ein Kürzel für einen komplexen wie komplizierten und überdies dynamischen, d. h. von Seiten der Nichteigentümer wie von Seiten des Eigentümers veränderbaren Rechtszustand.

\section{Totalität und Abstraktheit des Eigentums}

Hinter der gewählten Charakterisierung des Eigentumsrechts steht die Vorstellung von der Totalität und der Abstraktheit des Eigentums, die sich im Verlauf des 19. Jahrhunderts in der deutschsprachigen Zivilistik herausgebildet hat. Sie bestimmte nicht nur den 
Eigentumsbegriff des Bürgerlichen Gesetzbuches (BGB), sondern ist bis zum heutigen Tag einflußreich geblieben. Ein genauerer Blick auf diese Vorstellungen ist deshalb geboten:

Es bietet sich an, mit zwei gleichermaßen prägnanten wie paradigmatischen Beschreibungen des Eigentumsbegriffs aus dem letzten Drittel des 19. Jahrhunderts zu beginnen: Die erste stammt von Georg Friedrich Puchta und findet sich seinem „Cursus der Institutionen" "125. Dort wird der Eigentumsbegriff wie folgt umschrieben:

„Das Eigenthum ist die totale rechtliche Unterwerfung einer Sache. Es ist das vollkommenste Recht, teils durch seinen Gegenstand, welcher der einzige dem menschlichen Willen völlig hingegebene ist, theils durch seinen inneren Umfang, weil es diesen Gegenstand nach allen Seiten, von denen er im Recht zur Sprache kommt, unterwirft. [...] (Es) ist eine totale Herrschaft über die Sache. Alle Befugnisse, die sich in Beziehung auf eine Sache denken lassen, sind an sich im Eigentum und zwar ausschließlich enthalten. Durch diese Totalität wird es unnütz, die Befugnisse aufzuzählen. “126

Ähnlich beschrieb auch Bernhard Windscheid in seinem „Lehrbuch des Pandekten-

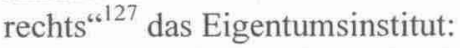

„Daß aber Jemandem eine Sache nach dem Rechte eigen ist, will sagen, daß nach dem Rechte sein Wille für sie entscheidend ist in der Gesamtheit ihrer Beziehungen. Dies zeigt sich nach einer doppelten Richtung: 1) der Eigenthümer darf über die Sache verfügen, wie er will; 2) ein Anderer darf ohne seinen Willen über die Sache nicht verfügen. [...] Das Eigentum ist die Fülle des Rechts an einer Sache [...]. (Es) ist als solches schrankenlos; aber es verträgt Beschränkungen. Aus der Gesamtheit der Beziehungen, in welchen kraft des Eigentums die Sache dem Willen des Berechtigten unterworfen ist, kann durch eine besondere That des Rechts eine oder die andere Beziehung herausgenommen und dem Willen des Eigenthümers entzogen werden." ${ }^{128}$

Bei einer solchen Bestimmung des Eigentums handelt es sich um einen äußerst bemerkenswerten Vorgang: Gelingt es doch auf diese Weise, den Inhalt des Eigentumsrechts einzufangen und auf den Begriff zu bringen, obwohl es sich beim Eigentumsrecht um ein durch eine sehr erhebliche Anzahl rechtlicher Regelungen bestimmtes Recht handelt. $\mathrm{Da}$ es sich dabei nicht um eine Selbstverständlichkeit handelt, zeigt die anglo-amerikanische Diskussion, die überwiegend auf der Vorstellung aufbaut, daß es sich beim Eigentum um ein Rechtsbündel (,,bundel of rights“) handelt. ${ }^{129}$ Lawrence C. Becker, der an eine aus elf Eigentumsbestandteilen zusammengesetzte Eigentumskonzeption von Tony Honore anknüpft, ${ }^{130}$ führt u. a. als mögliche Merkmale des Eigentumsbegriffs an ${ }^{131}$ : Das Recht zum Besitz, Gebrauch und Verbrauch, zur Veränderung, Verfügung, Vererbung, Einkommensnutzung und Veräußerung sowie das Recht auf Schutz vor Beeinträchtigun-

\footnotetext{
${ }^{125}$ Puchta 1881.

${ }^{126}$ Ebd., S. 162 f.

${ }^{127}$ Windscheid 1891.

${ }^{128}$ Ebd., S. 491 f.

${ }^{129}$ Ein kurze Übersicht zur heutigen Diskussionslage gibt Merrill 1998, S. 740 ff.

${ }^{130}$ Honore 1961, S. $107 \mathrm{ff}$.

${ }^{131}$ Vgl. Becker 1977, S. 18 ff. Eine erhellende Analyse über Stärken und Schwächen eines solchen Ansatzes findet sich bei Munzer 1990, Kap. 2.
} 
gen von Seiten der Nichteigentümer. Vergleicht man die beiden Eigentumskonzeptionen, so zeigt sich, daß man die verschiedenen Merkmale auf die abstrakte Umschreibung zurückführen kann. Sie alle bezeichnen entweder spezielle Momente einer umfassend gedachten Sachherrschaft bzw. Sachnutzung oder der Ausschließungsbefugnis Dritter. Freilich läßt sich weder aus der deutschen noch aus der anglo-amerikanischen Kennzeichnung auf den konkreten Inhalt oder die möglichen Gegenstände eines Eigentumsrechts schließen. ${ }^{132}$

Das Eigentumsrecht wird als ein totales und abstraktes Recht konzipiert. Die Totalität zeigt sich im Bezug auf den jeweils erfaßten und dem Eigentümer zugewiesenen Gegenstand. Das Recht beinhaltet ein umfassendes Herrschaftsrecht über den Gegenstand. ${ }^{133}$ Es wird dabei als ein Verhältnis zwischen Rechtsinhaber und Gegenstand begriffen. Ergänzt wird das Herrschaftsrecht um eine Ausschließungsbefugnis anderer Personen von dem Gegenstand. Dieses Verhältnis kann kein totales sein, weil regelmäßig Dritte auf den Eigentumsgegenstand einwirken dürfen. Diese Möglichkeiten werden jedoch mit Hilfe einer Abstraktion aus dem Eigentumsrecht ausgeblendet, ohne dabei verleugnet zu werden. Dies geschieht, indem von den einzelnen denkbaren Rechtsbeziehungen zwischen Eigentümer und Nichteigentümern abstrahiert wird. Beginnt man damit, die konkreten Rechtsverhältnisse zu untersuchen und für jedes einzelne zu bestimmen, wozu das Eigentumsrecht berechtigt, so kommen zwangsläufig die Grenzen des Eigentumsrechts und die mit ihnen korrespondierenden Rechte anderer zur Sprache. Abstrahiert und generalisiert man nun von den einzelnen Rechtsverhältnissen zu einer einzigen umfassenden Ausschließungsbefugnis, so fallen die Rechte anderer aus dem Eigentumsbegriff heraus, obwohl sich an der konkreten Rechtslage nicht das Geringste geändert hat. Aus diesem Grund müssen beide, Puchta wie Windscheid, ihre Darstellung ergänzen, um die Rechte anderer in ihre Eigentumskonzeption einzubeziehen: Bei Windscheid heißt es dazu:

„Die rücksichtslose Durchführung der Consequenzen des Eigenthumsbegriffs ist ohne erhebliche Übelstände nicht möglich; kein positives Recht wird umhin können, von dieser Consequenz Dieses oder Jenes abzubrechen, so daß der Eigenthümer in dieser oder jener Beziehung über seine Sache nicht verfügen, in dieser oder jener Beziehung die Verfügung eines Anderen nicht verbieten darf." 134

Auf die daraus resultierende Konstruktionsfrage gibt Windscheid folgende Antwort:

„Man muß also in die vollständige Definition des Eigenthums die Kategorie des , an sich` aufnehmen. Das Eigenthum ist dasjenige Recht, welches an sich den Willen des Berechtigten entscheidend für die Sache in der Gesamtheit ihrer Beziehungen macht. An sich; das will eben

${ }^{132}$ Beides - die Rückführbarkeit der Elemente und die Unbestimmbarkeit des konkreten Eigentumsinhalts aufgrund des abstrakten Eigentumsbegriffs - übersieht Brocker 1992, S. 395 ff. bei seiner Kritik an einem abstrakten Eigentumsbegriff. Nur soweit sich seine Kritik gegen die Vorstellung eines natürlichen Eigentumsrechts richtet, trifft sie zu.

${ }^{133}$ Diese Seite des Eigentumsrechts wird in ihrer Entwicklung sorgfältig von Hecker 1990 nachgezeichnet. Er zeigt dabei auf, daß das Eigentumsrecht nicht schon immer als umfassendes Herrschaftsrecht über einen bestimmten Gegenstand verstanden wurde.

${ }^{134}$ Windscheid 1891, S. 495. 
sagen: so lange das Recht den Spruch, den es mit der Verleihung des Eigenthums getan hat, nicht in dieser oder jener einzelnen Beziehung zurückgenommen hat. ${ }^{\text {«135 }}$

Puchta wählt einen anderen Weg. Es sucht die Verbindung bei den Einzelbefugnissen herzustellen. Die Befugnisse „,kommen nur zur Sprache, insofern das Eigenthum [...] Beschränkungen unterliegt, wodurch gewisse Befugnisse, die an sich darin enthalten sind, davon getrennt werden". ${ }^{136} \mathrm{Da}$ diese Lösung nicht so glatt ist, wie sie zu sein scheint, zeigt sich an seiner Bemerkung in einer Fußnote, in der es bezüglich des zentralen Begriffs der Totalität heißt: „Nicht die Totalität, sondern die Proprietät, das suum esse, ist das entscheidende Merkmal. “' ${ }^{\text {“137 }}$ Allein, auf der Proprietät läßt sich die von ihm vorgeschlagene Eigentumskonzeption nicht errichten.

Die Möglichkeit von Eigentumsbeschränkungen im privaten oder öffentlichen Interesse wird also keinesfalls geleugnet. Von daher ist es zumindest mißverständlich, wenn immer wieder behauptet wird, daß man bei dieser Eigentumskonzeption die Bindungen des Eigentümers verleugnet habe. ${ }^{138}$ Nur werden sie als von außen kommende Begrenzungen verstanden, durch die das an sich weiterreichende Recht eingeengt wird. Das Eigentumsrecht selbst wird als „ungebunden“ gedacht. ${ }^{139}$ Dies hat zur Folge, daß der konkrete Inhalt des Eigentumsrecht nur noch als Summe von Beschränkungen beschrieben werden kann.

Diese Konstruktion hat zunächst einmal einen ganz praktischen Vorteil: Auf ihr läßt sich eine Beweislastregel gründen. ${ }^{140}$ Solange Eigentumsbeschränkungen als selbstverständlich akzeptiert werden, ist die Konstruktion im übrigen unschädlich. Geht diese Selbstverständlichkeit verloren, so entfaltet die Konstruktion jedoch eine eigentümliche Mächtigkeit, weil die konkrete Reichweite des Eigentumsrechts nur noch als Eingriff in das Eigentum thematisiert werden kann. ${ }^{141}$ Die dem Eigentümer zugewiesene Rechtsmacht weist eine weit überschießende Tendenz auf: Als konkretes Recht einer Rechtsordnung kann man sich das Eigentumsrecht gar nicht vorstellen, ${ }^{142}$ da ein solches Recht stets und überall in Konflikt mit anderen Rechten geraten würde. Allenfalls als Rechts-

135 Ebd., S. 492 Anm. 5.

${ }^{136}$ Puchta 1881, S. 163.

${ }^{137}$ Ebd., S. 162 Anm. a).

${ }^{138}$ Repräsentativ Hedemann 1930, S. 127. Dieser Umstand wird von Gierke 1905, S. 348 Anm. 2 , $358 \mathrm{ff}$., trotz seiner scharfen wie klarsichtigen konzeptionellen Kritik gesehen.

${ }^{139}$ Wiegand 1976, S. $118,147$.

${ }^{140}$ Dies war ein wichtiger Grund für Aufnahme des abstrakten Eigentumsbegriffs in das BGB, siehe die Bemerkungen in Mugdan 1899, S. 145.

${ }^{141}$ Prägnant zusammengefaßt von Schwab 1975, S. 65, 105 ff.

${ }^{142}$ Scharfe Kritik in diese Richtung an der zivilistischen Begriffsbildung übt Ihering 1884, S. 512 ff., zusammenfassend auf S. 523 heißt es: „Es ist also nicht wahr, daß das Eigentum seiner ,Idee " nach die absolute Verfügungsgewalt in sich schlösse. Ein Eigentum in solcher Gestalt kann die Gesellschaft nicht dulden und hat sie nie geduldet - die ,Idee des Eigentums kann nichts mit sich bringen, was mit der ,Idee der Gesellschaft" in Widerspruch steht." Ihering gehörte früher zu jenen, die die nunmehr verworfene „Idee" des Eigentums erst überhaupt in dieser Schärfe entfaltet hatten (vgl. ders. 1874, S. 133 ff.). Der BGB-Gesetzgeber wollte ein solches ,bindungsloses“ Recht nicht schaffen (siehe. Mugdan 1899, S. 142 ff.). Ihm waren Beschränkungen auch über den im BGB statuierten Kreis hinaus eine Selbstverständlichkeit (siehe Mugdan 1899, S. 143). 
prinzip, das gebietet, „daß etwas in einem relativ auf die rechtlichen und tatsächlichen Möglichkeiten möglichst hohen Maße realisiert wird", ${ }^{143}$ könnte man sich das Eigentumsrecht noch vorstellen. Doch handelt es sich dann nicht mehr um die Festlegung des Eigentumsrechts, sondern um die Benennung eines Maßstabs für die rechtliche Ausgestaltung konkreter Eigentumsrechte. Es ist wohl diese überschießende Tendenz, die immer wieder Anlaß für scharfe Kritik am abstrakten oder ,absoluten“ Eigentumsbegriff war. $^{144}$

Man kann also nicht vom abstrakten Eigentumsbegriff auf den Inhalt konkreter Eigentumsrechte schließen. Die Konsequenz dieser Einsicht ist weittragend: Es kann kein natürliches, vor der Rechtsordnung einer konkreten Gesellschaft gedachtes Eigentumsrecht geben. Diese Schlußfolgerung setzt - wie sogleich zu zeigen ist - voraus, daß es unmöglich ist, die Grenzen des Eigentums in gleicher Weise abstrakt zu bestimmen wie den Eigentumsinhalt. Zwei Einwänden sieht sich eine solche Grenzziehung ausgesetzt. Der eine zielt darauf, daß die Anwendungsbedingungen einer abstrakten Eigentumsgrenze stets unsicher bleiben. Nimmt man etwa die Regel, daß keine Handlungen vorgenommen werden dürfen, die zu einer physisch spürbaren Beeinträchtigung des Eigentums führen, ${ }^{145}$ so lassen sich leicht Situationen (z. B. Grenzwertfestsetzungen) ausdenken, in denen das Kriterium zu nicht eindeutigen Entscheidungsregeln führt. Sobald der Bereich des Selbstverständlichen verlassen wird, büßt eben auch der Verweis auf die physische Beeinträchtigung an Evidenz und Direktionskraft ein. Außerdem paßt das Kriterium im Grunde nur bei Grundstücken. Bereits bei der Benutzung einer beweglichen Sache fehlt es am räumlichen Schutzbereich, der beeinträchtigt werden könnte. Es bliebe dann nur der Verweis auf die Gesundheit des Eigentümers und diese führt zu genau den Anwendungsschwierigkeiten, denen man mit dem Ausweichen auf die Gesundheit entgehen wollte. Schließlich kann geistiges Eigentum, wie z. B. Urheber-, Warenzeichen- oder Patentrecht, weder derartige Schädigungen herbeiführen noch kann es so geschädigt werden. Gleiches gilt für die in der heutigen Wirtschaftsordnung sehr wichtige Eigentumsform der Aktie. Die letzten Überlegungen führen zum zweiten Einwand gegen abstrakte Eigentumsgrenzen. Solche Grenzen scheitern bereits an der Vielfalt der Eigentumsgegenstände. Erst recht besitzen sie nicht die erforderliche Komplexität, um der Vielgestaltigkeit der zu regelnden Interessenkollisionen Herr zu werden. Aufgrund ihrer unzureichenden Unterscheidungs- und Direktionskraft läßt sich auf ihnen keine natürliche Eigentumsordnung gründen. Nicht nur sind die Verschonungsund die Nutzungsinteressen der Eigentümer voneinander abzugrenzen, sondern auch die Nutzungsinteressen von Nichteigentümern an Eigentumsgegenständen müssen berücksichtigt werden. Schließlich sind noch die öffentlichen Interessen, wie beispielsweise die Sicherheit und das Vertrauen des Rechtsverkehrs, bei der Ausgestaltung des Eigentums vorzustellen.

${ }^{143}$ So Alexy 1985, S. 75.

${ }^{144}$ Näher zu einer prinzipienorientierten Deutung der Eigentumsgarantie des Grundgesetzes Sieckmann 1998.

${ }^{145}$ Diese Regel wird von Barnett 1998, S. 74 ff. angeführt. Barnett selbst räumt ein, daß sich bei der Anwendung dieser Regel zahlreiche ",hard cases" stellen, die sich nicht allein durch einen Rückgriff auf die Regel selbst lösen lassen. 
Doch vielleicht ließen sich die Schwierigkeiten dadurch lösen, daß man - wie es Peter Behrens vorgeschlagen hat ${ }^{146}$ - die Abgrenzung der Rechtssphären dem Markt überlässt. Indes wäre dieser damit hoffnungslos überfordert. Könnte jeder nach Belieben von seinem Eigentum Gebrauch machen und andere ausschließen, so entstünden gewaltige Transaktionskosten, da für jeden einzelnen Eigentumsgegenstand individuell die Nutzungs- und Ausschließungsbefugnisse festgelegt werden und über diese Festlegungen universelle Verträge geschlossen werden müßten. Über kurz oder lang käme man deshalb dazu, die Aufgabe der Eigentumsausgestaltung Entscheidungsträgern zu überantworten, die verbindlich für jeden in generell-abstrakter Weise die Eigentumsrechte festlegen.

\section{Idee des Eigentums und des Eigentumsrechts}

Totalität und Abstraktheit legen demnach nicht ein Eigentumsrecht fest, sondern umschreiben den Inhalt von Eigentum. Man könnte deshalb auch davon sprechen, daß sich in ihnen die Idee des Eigentums ausdrückt. ${ }^{147}$ Das Eigentumsrecht selbst muß man sich hingegen als ein Recht vorstellen, das einerseits sämtliche bezüglich eines bestimmten Gegenstandes von der Rechtsordnung anerkannten Befugnisse umfaßt (Herrschaftsrecht über die Sache, Verfügungs- und Nutzungsbefugnisse, Ausschließungsbefugnis) und andererseits nicht über das durch die Rechtsordnung bestimmte Maß hinausreicht. Martin Wolff hat diese Bestimmung des Eigentumsrechts in dem in der Weimarer Zeit bedeutendsten Lehrbuch des Sachenrechts vorgeführt. Er schreibt dort:

„Man hat es bisweilen als ein , an sich schrankenloses Recht' bezeichnet (Windscheid), als das Recht, nach freiem Belieben auf die Sache ausschließlich einzuwirken. Allein das geht zu weit: das Einwirkungsbelieben des Eigentümers ist durch die Rechtsordnung stark eingeschränkt, zumal bei Grundstücken, und solche Beschränkungen des freien Beliebens sind nicht Beschränkungen des Eigentums; nicht Lasten, die wie Pfandrechte oder Dienstbarkeiten von außen her das eigentlich weitere Eigentum einengen, sondern sie sind dem Eigentum immanent, sie gehören zur Bestimmung des ,Eigentumsinhalts'. Das Eigentum gewährt nur in gewissen von vornherein durch die Rechtsordnung gegebenen Grenzen ein freies und ausschließliches Einwirkungsrecht." ${ }^{148}$

Reichweite und Inhalt eines bestimmten Eigentumsrechts lassen sich erst aus einer $\mathrm{Zu}$ sammenschau aller Regelungen bestimmen, die Einfluß auf die Eigentümerstellung haben. Dies führt dazu, daß man in einer ganzen Reihe von Fällen gar nicht sicher weiß, wie weit die Nutzungs- und Ausschließungsbefugnisse eines Eigentümers reichen.

\footnotetext{
${ }^{146} \mathrm{Vgl}$. Behrens 1986, S. 123 f., 129 f.

${ }^{147}$ Oft werden inhaltlich gehaltvollere Konzeptionen einer Idee des Eigentums entwickelt (z. B. Munzer 1990, Waldron, 1988, Penner 1997). Solche weitergehenden Annahmen werden meist entwikkelt, um das Institut des Eigentums zu legitimieren. Für die hier im Mittelpunkt der Analyse stehenden Fragen nach den Funktionsweisen des Eigentums ist eine solche „Anreicherung“ aber nicht erforderlich.

${ }^{148}$ Wolff 1929, S. 149.
} 
Mit Blick auf das Thema eines dem Gemeinwohl verpflichteten Eigentums läßt sich aufgrund der bisherigen Überlegungen sagen, daß zwischen Eigentum und Gemeinwohl ein unauflösliches Band besteht. Eigentumsrechte müssen von der einfachen Rechtsordnung ausgestaltet werden. Sie sind Teil des positiven Rechts. Die einfache Rechtsordnung besitzt stets einen Gemeinwohlbezug, der sich u. a. darin zeigt, daß die - normativ betrachtet - wesentlichen Akteure auch in Zeiten der Deregulierung und Privatisierung staatliche Instanzen, allen voran Parlament und Gerichte, sind. Hiervon zu unterscheiden ist die weitere Frage, ob die konkrete Ausformung von Eigentumsrechten dem Gemeinwohl dient. Die Feststellung ist also nicht spektakulär, doch ist damit ein erster fester Pflock geschlagen, von dem ausgehend das Verhältnis zwischen Eigentum und Gemeinwohl genauer vermessen werden kann.

\section{Eigentum und Vertragsfreiheit}

Um zu einer präzisen Vorstellung vom Begriff des Eigentums zu gelangen, muß das Verhältnis zwischen Eigentum und Vertragsfreiheit geklärt werden. Aus gesellschaftlicher Perspektive entspricht dem die Frage nach dem Zusammenhang zwischen Eigentum und bürgerlicher Verkehrsgesellschaft, d. h. einer privat- und marktwirtschaftlichen Wirtschaftsordnung, innerhalb derer einzelne Wirtschaftszweige durchaus vergesellschaftet (vgl. Art. 15 GG) bzw. verstaatlicht sein können. Zur weiteren Aufklärung muß zwischen verpflichtenden und verfügenden Verträgen unterschieden werden. Durch einen verfügenden Vertrag wird das Eigentumsrecht von einem Vertragspartner auf den anderen übertragen. Bei einen verpflichtenden Vertrag verpflichtet sich der eine Vertragspartner dazu, sein Eigentum zu übertragen, und der andere entweder nur dazu, das Eigentum anzunehmen (Schenkung), oder zusätzlich dafür eine Gegenleistung zu erbringen.

Eigentum in dem bisher beschriebenen Sinne wird als umfassendes Herrschaftsrecht über eine Sache gedacht, das es dem Eigentümer erlaubt, den Gegenstand selbst zu nutzen oder ihn anderen zur Nutzung zu überlassen. Eigentum läßt sich demnach nicht ohne die Rechtsmacht, über das Eigentum zu verfügen, vorstellen. Für verpflichtende Verträge könnte sich dies aber anders darstellen. Eine zentrale These, die J. E. Penner in seinem Buch „The idea of property in law" ${ }^{149}$ entfaltet, lautet, daß kein notwendiger Zusammenhang zwischen Eigentum und Verpflichtungsverträgen („Power to Sell“) besteht ${ }^{150}$ und dementsprechend auch das Eigentum nicht unauflöslich in eine marktwirtschaftliche Wirtschaftsordnung eingebunden ist. ${ }^{151}$ An dieser These wäre wenig auszusetzen, wenn Penner - entsprechend seiner Absicht, eine überzeitliche „Idee“ des Eigentums zu entfalten - einen Eigentumsbegriff entwickeln würde, der sich inhaltlich von dem vorliegenden Konzept unterscheidet. Doch auch er geht davon aus, daß das

\footnotetext{
${ }^{149}$ Penner 1997.

${ }^{150}$ Ebd., S. $154 \mathrm{ff}$.

${ }^{151}$ Vgl. ebd., S. 202 ff.
} 
Eigentum dazu berechtigt, es mit anderen zu teilen oder ihnen Nutzungsrechte daran zu übertragen. ${ }^{152}$

Wenn man sich solche Verfügungen ohne verpflichtenden Rechtsgrund vorstellen will, muß man eine Antwort darauf geben können, warum der Eigentümer über sein Eigentum verfügen sollte. Läßt man staatliche Anordnungen als Grund beiseite, weil sie an die Stelle des Eigentümerbeliebens eine Rechtspflicht stellen, so bleibt nur der Gedanke, daß der Eigentümer über sein Eigentum verfügt, um es zu verschenken. Zwei Schwierigkeiten ergeben sich dabei: Die kleinere ergibt sich daraus, daß es sich auch bei der Schenkung um die Form eines Verpflichtungsgeschäfts handelt: Schenker und Beschenkter müssen übereinkommen, daß der Schenker etwa schenken und der Beschenkte es annehmen soll. Auch im Fall der Handschenkung lassen sich - wie besonders klar vor dem Hintergrund der deutschen Rechtsordnung beobachtet werden kann Verfügung und Verpflichtung unterscheiden. ${ }^{153}$ Sehr viel gewichtiger als dieser konstruktive Einwand ist aber, daß das Eigentum so seiner Funktion der Bedürfnisbefriedigung entkleidet wird und gar nicht mehr erklärt werden kann, warum man sich das Eigentum als umfassendes Ausschließungs- und Nutzungsrecht vorstellen sollte. Denn Eigentum wird außerhalb des Bereichs persönlicher Nutzung zu einem selbstlosen Recht: Man kann sein Eigentum nur verschenken oder es selbst nutzen. Dazu paßt der Gedanke einer umfassenden Nutzungs- und Verfügungsbefugnis nicht. $\mathrm{Zu}$ der Idee umfassender Ausschließungs- und Nutzungsbefugnisse gehört die Vorstellung einer entsprechend umfassend gedachten Entscheidungsfreiheit des Eigentümers. Diese Entscheidungsfreiheit läuft leer, sofern man nicht zugleich die Möglichkeit anerkennt, sich für die Verfügung über das Eigentum eine Gegenleistung versprechen zu lassen. Dies zwingt nicht zur Vorstellung eines natürlichen Vertragsrechts, weil es nicht um die konkrete Gestalt der Eigentums- und Vertragsordnung geht, sondern um die Idee des Eigentums, die sowohl der einfachen Rechtsordnung als auch der Verfassungsordnung zugrunde liegt. Wie weit das Eigentümerbelieben tatsächlich reicht, ist damit eben noch nicht entscheiden. Festzuhalten ist jedoch, daß zu der Vorstellung vom Eigentum als dem umfassenden Herrschaftsrecht auch die Freiheit gehört, verpflichtende Verträge zu schließen.

Von hier aus ist es ein kleiner Schritt, die Eigentumsvorstellung als Teil der bürgerlichen Verkehrsgesellschaft auszuweisen: Erforderlich ist nur noch, daß man den Güteraustausch in einer Gesellschaft auf der Eigentums- und Vertragsfreiheit gründen läßt. Je breiterer Raum diesen beiden eingeräumt wird, desto umfassender wird die Gesellschaft marktwirtschaftlich organisiert. Wenn auch die Verbindung zwischen Eigentumsvorstellung und marktwirtschaftlicher Wirtschaftsordnung keine theoretisch-konzeptionell notwendige ist, so ist es doch unwahrscheinlich, daß eine solche Vorstellung sich in einer anderen Wirtschaftsordnung herausbildet. ${ }^{154}$ Man darf deshalb sagen, daß der

\footnotetext{
${ }^{152}$ Siehe ebd., S. 152.

${ }^{153}$ Aufgrund des im deutschen Sachenrecht herrschenden Abstraktionsprinzips (siehe statt aller Wilhelm 1993, Rn. 399 ff.) handelt es sich dort nicht nur um eine analytisch mögliche, sondern um eine von der Rechtsordnung gebotene Unterscheidung.

${ }^{154}$ Dem steht auch nicht entgegen, daß Wiegand 1976, S. $149 \mathrm{ff}$. nur juristisch-dogmatische Gründe auszumachen vermag, die die Autoren im 19. Jahrhundert bewegten, das überkommene Eigen-
} 
Gedanke vom Eigentum als umfassendem Herrschaftsrecht der Vorstellungswelt der bürgerlichen Verkehrsgesellschaft entwächst.

Vor der Verbindung von Eigentum und Marktwirtschaft gewinnt die Gemeinwohlbindung eine neue Perspektive. Offenbar schützt man die Verfügungsfreiheit des Eigentümers und seine Freiheit, zu diesem Zweck verpflichtende Verträge einzugehen, in der Überzeugung, auf diesem Weg das gesellschaftliche Wohl am Besten zu befördern. Die Gesellschaft sieht im Marktprinzip und damit in der Eigentums- und Vertragsfreiheit einen wichtigen Modus gesellschaftlicher Kommunikation. Die liberalistische Theorie benennt auch einen Grund, warum man auf das Eigeninteresse vertrauen sollte: Verfügungs- und Vertragsfreiheit helfen, das zentrale Wissensproblem einer Gesellschaft zu lösen, nämlich die Frage, von wem auf welche Weise die knappen Güter einer Gesellschaft genutzt werden sollen. ${ }^{155}$ Nur - dies wird dann leicht vergessen - setzt die Lösung mittels Marktprinzip die vorherige Ausgestaltung der Eigentumsrechte voraus. ${ }^{156}$ Bei dieser Ausgestaltung müssen grundlegende Konflikte zwischen den Verschonungs- und Nutzungsinteressen der Eigentümer sowie zwischen Eigentümern und Nichteigentümern geregelt werden. Nach dem oben Gesagten ist eine Überantwortung dieses Bereichs an den Markt nicht möglich.

An diesem Punkt findet auch die ,Ökonomisierung ' der Gesellschaft ihr Ende. Die Gefährdungen für das Marktprinzip sind gering. Bindungen und Grenzen der Eigentumsrechte beziehen sich in aller Regel auf das Ausmaß der Nutzungsbefugnisse und die Reichweite der Ausschließungsbefugnisse. Die Übertragung von Gegenständen gleich welcher Art, ob real (Sache, Grundstück), ideell (Kunstwerk, Erfindung) oder rechtlicher Natur (Forderungsrecht) - wird dagegen sehr viel seltener beschränkt.

Auch ohne jeden ordoliberalen Gedanken an die Gewährleistung einer funktionstüchtigen Wettbewerbsordnung als Rahmen- und Sicherungsbedingung der Marktwirtschaft zeigt sich, daß das Marktprinzip selbst auf einem Ineinandergreifen von staatlicher und privater Sphäre beruht. Man kann also das Eigentum als ein klassisches Beispiel für eine Verantwortungsteilung zwischen Staat und Gesellschaft bei der Gemeinwohlverwirklichung betrachten. ${ }^{157}$ Erst auf der Grundlage einer hoheitlich ausgestalteten Eigen-

tumsverständnis zu verwerfen und den abstrakten Eigentumsbegriff anzuerkennen. Dies schließt nämlich nicht aus, daß zu den juristisch-dogmatischen Gründen ein bestimmter rechtlicher und gesellschaftlicher Entwicklungszustand treten mußte, damit diese Gründe für sich genommen so überzeugend wirken konnten. Weitere, sich in die obige Darstellung einfügende Gründe werden von Hecker 1990, S. 212 ff. angeführt.

${ }^{155}$ Grundlegend Hayek 1945, S. 519 ff,; anschaulich dargelegt von Barnett 1998, S. 64 ff. Nach Barnetts Auffassung lassen sich auch eine Reihe von Interessensproblemen mit Hilfe des Marktprinzips lösen (ebd., Part II). Weiterführend dazu Ladeur 2000, S. 1 ff., 56 ff., 81 ff., 204 ff.

${ }^{156}$ Eine klare Darstellung dieses Sachverhalts findet sich bei Brennan/Buchanan 1992, S. 33 f.

${ }^{157}$ Aus der reichen Literatur zum verwaltungswissenschaftlichen Konzept der Verantwortungsteilung mit grundlegenden Beiträgen zur Konzeption Trute 1999 und Voßkuhle 1999. Nach der von Wolfgang Hoffmann-Riem entwickelten Kategorisierung würde es sich aufgrund des Zusammenspiels von rechtlicher (staatlicher) Ausgestaltung und privater Nutzung wohl - entgegen der Ansicht Hoffmann-Riems - um den Fall einer Verantwortungsteilung durch regulierte Selbstregulierung handeln. Näher zu dieser Kategorie die Beiträge in „,Die Verwaltung" 2001. 
tumsordnung kann der Marktmechanismus greifen und jenes „Netzwerk gesellschaftlicher Arbeitsteilung" entstehen, auf dem der gesellschaftliche Wohlstand ruht.

\section{Eigentumsrecht und Eigentumspflichten}

Langsam gewinnen nun auch unsere Überlegungen zu der Frage, was Eigentum ist, die gebotene Komplexität: Eigentum ist ein Recht, dessen genaues Ausmaß erst festgestellt werden kann, nachdem sämtliche Regelungen der Rechtsordnung berücksichtigt wurden, die die Nutzungsbefugnisse an dem Eigentumsgegenstand und die Befugnisse, Einwirkungen von Seiten Dritter zu unterbinden, festlegen. ${ }^{158}$ Die Feststellung wird dadurch erschwert, daß die Reichweite der Nutzungsbefugnisse nicht genau bestimmt ist. Die Grenzziehung muß dann erst von den Gerichten vorgenommen werden. Die Nutzungsbefugnisse berechtigen - regelmäßig - nicht nur zur Eigennutzung, sondern auch zur Fremdnutzung. Insofern umfaßt das Eigentumsrecht auch die Befugnis, verfügende und verpflichtende Verträge über den Eigentumsgegenstand abzuschließen. Schließlich erschöpft sich das Eigentum nicht in der Ausgestaltung eines Rechtsverhältnisses, vieImehr schützt es gerade auch die Entscheidungs-, Gestaltungs- und Handlungsfreiheit des Eigentümers.

Nach der Eigentumsvorstellung der bürgerlichen Verkehrsgesellschaft ist Eigentum kein pflichtgebundenes, treuhänderisches Recht, wie etwa das Recht der Eltern, ihre Kinder zu erziehen. Der Eigentümer wird als im Grundsatz ungebunden gedacht. Gleichwohl kommt das Gemeinwohl dabei nicht zu kurz, da die Möglichkeit von Pflichten anerkannt wird und das konkrete Eigentumsrecht nur nach Maßgabe der einfachen Rechtsordnung existiert. In der einfachen Rechtsordnung können sich eine Viel-

${ }^{158}$ Hösch 2000 hat in seiner Arbeit die Ausschließungsbefugnis als konstitutives Merkmal des verfassungsrechtlichen Eigentumsschutzes herausgestellt und mit der These verbunden, daß Nutzungen des Eigentumsgegenstandes nur dann geschützt seien, wenn sie - wie etwa beim Urheberrecht geschehen - „rechtlich fixiert" sind (S. 138 f., 165 f.), wobei dafür die Umschreibung des Eigentumsinhalts in $\$ 903$ BGB nicht ausreichen soll. Dies führt zu der Konsequenz, daß die Eigennutzung von Grundstücken nur durch Freiheitsrechte geschützt wird. Gegen diese Konstruktion spricht zunächst und entscheidend, daß der Wert eines Eigentumsgegenstandes regelmäßig in erheblichem Umfang von seinen Nutzungsmöglichkeiten bestimmt wird. Wenn der Eigentumsschutz - wie allein schon Art. 14 Abs. 3 GG zeigt - auch dem Wertschutz dienen soll, so ist unklar, warum dann nicht bereits der Bestand der wertbildenden Nutzungsbefugnisse geschützt werden soll. Außerdem nennt Hösch - abgesehen von der fehlenden Bestimmtheit der gewährten Nutzungsbefugnisse keinen Grund, warum beim Grundstückseigentum, entgegen den herkömmlichen zivilrechtlichen Anschauungen, Nutzungen nicht von $\S 903$ BGB geschützt sein sollten. Ein weiterer Einwand ergibt sich aus folgender Überlegung: Wenn der Eigentümer jemandem ein Nießbrauchsrecht einräumt, so handelt es sich bei diesem Recht um ein Nutzungsrecht, so daß an sich das Kriterium der rechtlichen Fixiertheit von Hösch erfüllt sein müßte. Warum aber soll der Nießbraucher in seinem Nutzungsrecht geschützt sein, nicht jedoch der Eigentümer, von dem dieser seinen Nießbrauch herleitet? Bleibt man konsequent, dann lassen sich an beweglichen oder unbeweglichen Sachen gar keine rechtlich fixierten Nutzungsrechte schaffen. Dann stellt sich jedoch die Frage nach dem Rechtsinhalt dieser Rechte. 
zahl von Eigentümerpflichten finden. Trotz des Ausgangspunkts eines ungebundenen Rechts widersprechen sich demnach Eigentumsrecht und Eigentümerpflicht nicht. In Anbetracht der festgestellten Gemeinwohleinbindung war dies freilich auch nicht anders zu erwarten.

\section{Funktionen des Eigentums}

Aus gesellschaftlicher Sicht besteht die zentrale Funktion des Eigentums darin, die Zuordnung und Verteilung gesellschaftlich bedeutsamer Güter zu regeln. Eigentum bildet zum einen den Modus, nach dem diese Güter einzelnen Rechtsträgern, seien es natürliche oder juristische Personen, zugeordnet werden. Zusammen mit der Vertragsfreiheit stellt es zugleich in Form des Marktprinzips den Modus dar, nach dem sich die Verteilung der Güter vollzieht. ${ }^{159}$ Auf diese Weise wird das Wissensproblem der Gesellschaft über die bestmögliche Nutzung seiner Güter - zumindest teilweise - gelöst. Auch darin wird man eine Funktion des Eigentums sehen. ${ }^{160}$

Durch die Zuordnung von Gütern, das heißt durch die Festlegung, in welcher Weise der Eigentümer den Gegenstand nutzen darf und in welchem Umfang er Dritte von Einwirkungen auf den Gegenstand ausschließen kann, werden darüber hinaus soziale Machtpositionen ausgeformt. ${ }^{161}$ Dadurch unterscheidet sich die Eigentumsgarantie von den übrigen Freiheitsrechten und daraus resultiert die Notwendigkeit, Eigentumsrechte durch die einfache Rechtsordnung auszugestalten. Außerdem ist dies der tiefere Grund für das „dialektische Verhältnis", welches nach Auffassung des BVerfG zwischen Privatnützigkeit und Sozialpflichtigkeit des Eigentums besteht. Denn bei der Ausgestaltung der Eigentumsrechte muß nicht nur die freiheitsbegründende Bedeutung, sondern auch die gesellschaftsgestaltende Wirkung des Eigentums berücksichtigt werden.

Aus der Sicht des Einzelnen dient das Eigentum dazu, ihm ,einen Freiraum im vermögensrechtlichen Bereich“ zu gewährleisten. Eigentum schafft u. a. die Voraussetzungen dafür, seinen eigenen Wohlstand zu mehren und sein Leben eigenverantwortlich zu gestalten. Es hat die Funktion eines Freiheitsrechts und schafft zugleich die materielle Basis entsprechender Wahrnehmung der übrigen Freiheitsrechte, um seinen eigenen Wertvorstellungen gemäß leben zu können.

${ }^{159}$ Luhmann 1993, S. 453 ff. sieht in Eigentum und Vertrag die beiden Formen, mit deren Hilfe Wirtschafts- und Rechtssystem strukturell gekoppelt werden.

${ }^{160}$ Ein Versuch, auf der Wissenskategorie aufbauend ein Eigentumsverständnis zu entwickeln, welches vom überkommenen Individualbezug abgelöst ist, findet sich bei Ladeur 2000, S. $204 \mathrm{ff}$.

${ }^{161}$ Diesen Gesichtspunkt betont auch Podlech 1976, S. 42 ff., weitere Überlegungen finden sich dazu bei Stein 1967, S. 64 ff.; Krölls 1994, S. 64 ff. Obwohl der Gesichtspunkt, daß das Eigentumsrecht soziale Macht schafft und figuriert, den markantesten Unterschied zu den übrigen Freiheitsrechten bildet, wird dieser Aspekt regelmäßig übersehen und statt dessen auf die verbindenden Momente zwischen Eigentumsgarantie und den Freiheitsrechten aufmerksam gemacht; paradigmatisch dafür Wendt 1985, S. $80 \mathrm{ff}$. 


\title{
VI. Die Eigentumsgarantie des Grundgesetzes (Art. 14 GG)
}

\section{Der verfassungsrechtliche Eigentumsschutz}

Art. 14 Abs. 1 Satz 1 GG schützt grundsätzlich alle privaten und - unter bestimmten Voraussetzungen $^{162}$ - öffentlichen vermögenswerten Rechte des Einzelnen, „die nach Art eines Ausschließlichkeitsrechts dem Rechtsträger privatnützig zugeordnet sind, auf Eigenleistungen beruhen und als materielle Grundlagen persönlicher Freiheit dienen “. ${ }^{163}$ Stellt sich für das Bundesverfassungsgericht die Frage, ob ein bestimmtes Vermögensrecht durch die Eigentumsgarantie geschützt wird, greift es meist auf den Gesichtspunkt zurück, ob das Recht aufgrund eigener Leistungen geschaffen wurde. Dieses weite Schutzverständnis fügt sich nahtlos in die bisherigen Überlegungen ein. Es paßt gut zu den dargelegten Eigenheiten und Funktionen des Eigentums. Wie nicht mehr anders zu erwarten, reicht auch der verfassungsrechtliche Eigentumsschutz nur soweit, wie dem Eigentümer tatsächlich auch in der einfachen Rechtsordnung Nutzungs- und Ausschließungsbefugnisse an dem Eigentumsgegenstand zugewiesen werden.

Manchmal kann man aber auch bei der Bestimmung des Schutzbereichs der Eigentumsgarantie die eigentümlichen Gemeinwohlverpflichtungen des Eigentums beobachten - so etwa bei den Auseinandersetzungen darüber, ob und unter welchen Bedingungen der Einzelne vor dem Auferlegen öffentlicher Abgaben (z. B. Steuern) durch die Eigentumsgarantie geschützt wird. Schon früh bildete sich in der Rechtsprechung des Bundesverfassungsgerichts die Überzeugung heraus, daß das Vermögen kein Eigentum im Sinne des Art. 14 Abs. 1 GG ist.

\begin{abstract}
„Daraus folgt, daß Art. 14 Abs. 1 GG nicht vor der staatlichen Auferlegung von Geldleistungspflichten schützt. Diese sind nicht mittels eines bestimmten Eigentumsobjekts zu erfüllen, sondern werden aus dem fluktuierenden Vermögen bestritten. Etwas anderes kommt nur dann in Betracht, wenn die Geldleistungspflichten den Betroffenen übermäßig belasten und seiner Vermögensverhältnisse so grundlegend beeinträchtigen, daß sie eine erdrosselnde Wirkung haben."
\end{abstract}

Die Folgen dieser Anschauung sind immens: Der Staat kann allein unter Beachtung des allgemeinen Gleichheitssatzes und der Sicherung des wirtschaftlichen Existenzminimums seiner Bürger auf das Vermögen zugreifen und nicht nur seine Aufgaben finanzieren, sondern auch die Vermögenswerte innerhalb der Gesellschaft umverteilen. Die Bedeutung dieser verfassungsgerichtlichen Grundanschauung tritt besonders klar hervor, wenn man an die Schwierigkeiten denkt, die John Locke damit hatte, die Abgabe-

\footnotetext{
${ }^{162}$ So jedenfalls die h. M.; vgl. BVerfGE 69, 272, 300; anderer Ansicht Depenheuer 1999, Rn. 186 ff. m. w. N.

${ }^{163}$ BverfGE 97, 350, 371 - Währungsunion. Eine grundlegend andere Vorstellung vom Schutzbereich der Eigentumsgarantie entwickelt Lepsius 2002, S. 41 ff. Danach wird die „normgeprägte Sachherrschaft" geschützt. Das zentrale Ziel dieser Revision dürfte sein, einen Maßstab für die Ausgestaltung der konkreten Eigentumsordnung zu entwickeln. Siehe dazu auch Poscher 2001, C.I.3.d.

${ }^{164}$ BVerfGE 78, 232, 243; stRspr.; siehe auch BVerfGE 95, 257, 300 - LPG.
} 
pflicht der Bürger zu legitimieren ${ }^{165}$ und die breite Diskussion, die derzeit in den USA um die Berechtigung staatlicher Steuererhebungen geführt wird.

Diese Rechtsprechung bildet einen wichtigen Baustein des Leitprinzips einer sozialen Marktwirtschaft. Die Gemeinwohlbindung ist hier nicht wie bislang als integrierter Bestandteil des Eigentumsrechts konzipiert, sondern wird indirekt erzeugt, indem das Eigentum nicht vor dem Zugriff des Steuergesetzgebers schützt. Fragen der Umverteilung und der staatlichen Aufgabenwahrnehmung werden so weitgehend aus dem grundrechtlichen Handlungskorsett herausgezogen. Ihre Beantwortung bleibt dem politischen Entscheidungssystem überlassen.

In der sog. Vermögenssteuerentscheidung hat der Zweite Senat des Bundesverfassungsgerichts unter Rückgriff auf die vom Bundesverfassungsrichter Paul Kirchhof entwickelte Konzeption eines Eigentumsschutzes gegenüber dem Steuergesetzgeber ${ }^{166}$ mit dieser Rechtsprechung gebrochen: Zum einen erkennt der Senat einen Substanzschutz für konsolidiertes - bereits versteuertes - Vermögen an, so daß diese Vermögensbestandteile dem Zugriff des Steuergesetzgebers entzogen sind. ${ }^{167}$ Zum anderen leitet er aus Art. 14 Abs. 2 GG einen sog. Halbteilungsgrundsatz ab, demzufolge es nur zu einer hälftigen Teilung zwischen öffentlicher und privater Hand kommen darf. Steuersätze, die deutlich über $50 \%$ liegen, sind danach verfassungswidrig. ${ }^{168}$ In seiner abweichenden Meinung merkt Bundesverfassungsrichter Ernst-Wolfgang Böckenförde kritisch dazu an:

\begin{abstract}
„In einer solchen Vorgabe liegt eine ungerechtfertigte Begrenzung des Gesetzgebers. Sie verkennt, daß die Festsetzung der Steuersätze fundamental von wirtschaftlichen wie politischen Daten abhängt, die unter geschichtlichen Bedingungen stehen und sich ändern können. In Zahlen nachrechenbare Maßgaben, die diesem Rechnung tragen, sind weder möglich noch in der Verfassung enthalten. Die Verfassung überläßt es vielmehr einer politisch verantworteten Steuerpolitik, hier in Reaktion auf die jeweilige Situation und unter Rückgriff auf wirtschaftsund sozialpolitische Überzeugungen das zuträgliche $\mathrm{Maß}$ zu finden. Infolge der Entscheidung des Senats bleibt demgegenüber für eine solche Politik, die den ökonomisch-sozialen Umständen mit verschiedenen Konzepten Rechnung tragen und auch das Maß der staatlicherseits für alle erbrachten, den einzelnen entlastenden Infrastrukturleistungen, wie etwa im Ausbildungsund Hochschulwesen, berücksichtigen können muß, nur noch enger Raum. “169
\end{abstract}

\title{
2. Die gewährleistungsspezifischen Vorgaben der Eigentumsgarantie
}

Durch die besondere Gemeinwohlbindung unterscheidet sich die Eigentumsgarantie von den übrigen im Grundgesetz garantierten Freiheitsrechten. Um dieser Eigenart habhaft $\mathrm{zu}$ werden, braucht man nur die gewährleistungsspezifischen Vorgaben des

\footnotetext{
165 Vgl. Locke 1977, § 140; Brocker 1992, S. 260 ff.

${ }^{166} \mathrm{Vgl}$. Kirchhof 1981, S. $226 \mathrm{ff}$.

${ }^{167}$ Vgl. BVerfGE 93, 121, 136 f. - Vermögenssteuer. Depenheuer 1999, Rn. 207 sieht im sog. Halbteilungsgrundsatz sogar einen allgemein gültigen Maßstab für das Verhältnis zwischen Privatnützigkeit und Sozialpflichtigkeit des Eigentums. Ähnlich Leisner 1989, Rn. 141.

${ }^{168}$ Vgl. BVerfGE 93, 121, 138 - Vermögenssteuer.

${ }^{169}$ BVerfGE 93, 149, 157 - Vermögenssteuer.
} 
Art. 14 GG, also die im jeweiligen Grundrecht begründeten und das Grundrecht charakterisierenden verfassungsrechtlichen Gebote, Leitprinzipien oder Wertungsmaßstäbe, eingehender zu betrachten. ${ }^{170}$ Das Bundesverfassungsgericht umschreibt sie wie folgt:

„Der Gesetzgeber muß bei der Bestimmung von Inhalt und Schranken des Eigentums i. S. v. Art. 14 I 2 GG die schutzwürdigen Interessen des Eigentümers und die Belange des Gemeinwohls in einen gerechten Ausgleich und ein ausgewogenes Verhältnis bringen. Er muß sich dabei im Einklang mit allen anderen Verfassungsnormen halten; insbesondere ist er an den verfassungsrechtlichen Grundsatz der Verhältnismäßigkeit und den Gleichheitssatz des Art. 3 I GG gebunden. Das Wohl der Allgemeinheit ist nicht nur Grund, sondern auch Grenze für die dem Eigentum aufzuerlegenden Belastungen. Einschränkungen der Eigentümerbefugnisse dürfen nicht weitergehen, als der Schutzzweck reicht, dem die Regelung dient. Der Kernbereich der Eigentumsgarantie darf dabei nicht ausgehöhlt werden. Zu diesem gehört sowohl die Privatnützigkeit, also die Zuordnung des Eigentumsobjekts zu einem Rechtsträger, dem es als Grundlage privater Initiative von Nutzen sein soll, als auch die grundsätzliche Verfügungsbefugnis über den Eigentumsgegenstand (vgl. BVerfGE 70, 19] [200]; BVerfGE 79, 174 [198]; BVerfGE 87, 114 [138 f.]; BVerfGE 91, 294 [308]). Der Regelungsbefugnis des Gesetzgebers sind unterschiedliche Schranken gezogen. Soweit das Eigentum die persönliche Freiheit des einzelnen im vermögensrechtlichen Bereich sichert, genießt es einen besonders ausgeprägten Schutz (vgl. BVerfGE 42, 263 [294]; BVerfGE 50, 290 [340]; BVerfGE 70, 191 [201]; BVerfGE 95, 64 [84]). Demgegenüber ist die Gestaltungsfreiheit des Gesetzgebers um so gröBer, je stärker der soziale Bezug des Eigentumsobjekts ist; hierfür sind dessen Eigenart und Funktion von entscheidender Bedeutung (vgl. BVerfGE 53, 257 [292]). Begrenzungen der Eigentümerbefugnisse sind in diesem Rahmen als Ausfluß der Sozialgebundenheit des Eigentums (Art. 14 II GG) grundsätzlich entschädigungslos hinzunehmen."171

Beide Leitprinzipen, das der Privatnützigkeit (Art. 14 Abs. 1 Satz 1 GG) und das der Sozialpflichtigkeit (Art. 14 Abs. 2 GG), besitzen denselben Rang. Bei der Ausgestaltung und Begrenzung des Eigentums ist deshalb sowohl der freiheitskonstituierenden Bedeutung als auch der gesellschaftsgestaltenden Wirkung des Eigentums gleichermaBen Rechnung zu tragen. In ihrer „dialektischen“ Verbindung bilden sie ein eigentumsspezifisches Ausgleichsgebot. Das Grundgesetz - so wie es vom Bundesverfassungsgericht interpretiert wird - hat sich demnach beim Eigentum für eine Rechtseinrichtung entschieden, die stets und umfassend dem Gemeinwohl verpflichtet ist. ${ }^{172}$ Es unterscheidet sich von daher grundlegend von den übrigen im Grundgesetz anerkannten Freiheitsrechten.

Entscheidender Maßstab für die verfassungsrechtliche Beurteilung eigentumsausgestaltender und -begrenzender Regelungen bildet die soziale Funktion des Eigentumsobjekts, d. h. die Frage, in welchem Umfang Nichteigentümer auf die Nutzung des Eigentumsobjekts angewiesen sind oder die Nutzung des Eigentums nachteilige Auswirkungen auf andere hat. Anschaulich werden diese Grundsätze in einer Entscheidung des Bundesverfassungsgerichts über die Einschränkung des Kündigungsrechts eines Vermieters beschrieben. Nach $\S 573$ BGB ( $§ 564 b$ a. F.) muß der Vermieter ein

\footnotetext{
${ }^{170}$ Näher dazu Bumke 1998, S. 102 ff.

${ }^{171}$ BVerfGE 100, 226, 240 f. - Denkmalschutz.

${ }^{172}$ Anderer Ansicht Leisner 1972; Leisner 1996, S. 21, 41 ff.; Hösch 2000, S. 199 ff. m. w. N.
} 
berechtigtes Interesse an der Kündigung haben. Zur verfassungsrechtlichen Rechtfertigung dieser Pflicht führte das Gericht aus:

„Die Einschränkung des freien Kündigungsrechts des Vermieters von Wohnraum durch das Erfordernis des berechtigten Interesses stellt eine zulässige Beschränkung der aus dem Eigentum fließenden freien Verfügungsbefugnis des Eigentümers dar. Die Sozialbindung des Eigentums von Wohnraum beruht darauf, daß dieser nicht unbeschränkt zur Verfügung steht und als Lebensmittelpunkt des Mieters anzusehen ist. Große Teile der Bevölkerung sind nach wie vor nicht in der Lage, aus eigener Kraft Wohnraum für sich zu schaffen, und deshalb auf Mietwohnungen unausweichlich angewiesen [...]. Im Hinblick auf die regelmäßig nicht unbeträchtlichen Kosten und Unzuträglichkeiten in persönlicher, familiärer, wirtschaftlicher und sozialer Hinsicht, die ein Wohnungswechsel für den Mieter in der Regel mit sich bringt [...], erscheint eine Beschränkung des Kündigungsrechts auf Fälle, in denen der Vermieter ein berechtigtes Interesse an der Beendigung des Mietverhältnisses hat, gerechtfertigt. [...] Der Ausschluß einer willkürlich, ohne beachtliche Gründe veranlaßten Kündigung kann schon deshalb verfassungsrechtlich nicht beanstandet werden, weil einer derartige Ausübung von Eigentümerbefugnissen im Hinblick auf die soziale Bedeutung der Wohnung für die hierauf angewiesenen Menschen keinen verfassungsrechtlichen Schutz genießt. [...] Den schutzwürdigen Belangen des Eigentümers wird dadurch Rechnung getragen, daß ihm bei Eigenbedarf die Beendigung des Mietverhältnisses ermöglicht wird." ${ }^{\text {"173 }}$

Beim Lesen dieser Ausführungen gewinnt man den Eindruck, die Gemeinwohlbindung folge dem Gesichtspunkt der Sachgesetzlichkeit. Die Sozialbindung reicht genau so weit wie die tatsächlichen Gegebenheiten es verlangen. Doch beschleichen einen schnell Zweifel, ob den Eigentumsobjekten tatsächlich soziale Funktionen in dem Sinne innewohnen, daß man sie bloß empirisch zu ermitteln braucht. Handelt es sich bei der sozialen Funktion aber um eine gesellschaftliche Zuschreibung, so steht man wieder am Anfang: Man muß sich fragen, von wem auf welche Weise und mit welcher Verbindlichkeit wem gegenüber die Maßstäbe der Privatnützigkeit und Sozialpflichtigkeit entfaltet werden und so das Gemeinwohl definiert wird. Dies führt weiter zur allgemeineren Frage nach dem Prozeß der Konstitutionalisierung und damit auch über das hier verfolgte Thema hinaus. ${ }^{174}$

\section{Sozialbindung des Eigentums}

„Eigentum verpflichtet. Sein Gebrauch soll zugleich dem Wohle der Allgemeinheit dienen." So lautet Art. 14 Abs. 2 GG. Es handelt sich dabei - ohne daß es dazu einer Hochstilisierung bedürfte ${ }^{175}$ - um eine Grundpflicht, jedenfalls wenn man diesen Begriff etwa mit Otto Luchterhandt wie folgt umschreibt: „Unter dem Grundgesetz sind

${ }^{173}$ BVerfGE 68, 361, 370 f. - Eigenbedarf.

${ }_{174}$ Näher dazu Schuppert/Bumke 2000.

${ }^{175}$ So aber Stern 1994, S. 1044. Der von Stern gegen die Klassifizierung erhobene Einwand mangelnder Bestimmtheit trifft - je nachdem wie hoch man die Anforderungen daran stellt - auch andere Grundpflichten wie etwa die Friedens- und Nichtstörungspflicht. Entscheidender ist indes, daß bei einem Gegenstand wie dem Eigentum die Unbestimmtheit unvermeidbar ist, weil das Eigentum ohne rechtliche Ausgestaltung nicht greifbar wird. 
Grundpflichten $[\ldots]$ solche $[\ldots]$, die $[\ldots]$ herausragende Bedeutung für das Gemeinwesen besitzen und die insbesondere aufgrund ihrer Höchstpersönlichkeit, Unentgeltlichkeit, Schwere, Dauer und der Wahrscheinlichkeit ihrer Aktualisierung Freiheit und Eigentum des einzelnen regelmäßig in hohem Grade belasten. ${ }^{6176}$ Doch welchen normativen Inhalt hat diese Grundpflicht? Die Antwort darauf ist umstritten und dieser Streit erfaßt auch die Bedeutung des Art. 14 Abs. 2 GG als gewährleistungsspezifische Vorgabe für den ausgestaltenden oder beschränkenden Gesetzgeber. ${ }^{177}$

Um nicht in ein zu großes Durcheinander zu geraten, sollte man folgende Diskussionen abschichten: Es stellt sich zum einen die Frage, wer Adressat der Grundpflicht ist, wozu diese verpflichtet und wem gegenüber sie besteht (a). Zum anderen ist man uneins über die weiteren Funktionen des Art. 14 Abs. 2 GG. Dabei geht es um die Frage, ob diese Bestimmung nur dem Gesetzgeber oder auch den Gerichten, ja vielleicht sogar der Verwaltung die Befugnis verleiht, einem Eigentümer Pflichten (Gebote oder Verbote) aufzuerlegen (b)? Als drittes und letztes wird in diesem Zusammenhang über das Verhältnis der Handlungsfreiheit des Eigentümers den ihm durch die Rechtsordnung auferlegten Pflichten nachgedacht (c).

a) Als Adressaten von Grundpflichten kommen nur die Bürger in Betracht; hier also die Eigentümer. Etwas schwieriger wird es bei der Suche der Berechtigten. Das durch die Grundpflichten geschaffene Verfassungsrechtsverhältnis besteht - so wie bei den Grundrechten auch - grundsätzlich nur zwischen Staat und Bürger. ${ }^{178}$ Dementsprechend kommt auch bei Grundpflichten wie etwa dem Gesetzesgehorsam, der Wehrpflicht (Art. 12a Abs. 1 GG) und den sog. Hand- und Spanndiensten (Art. 12 Abs. 2 GG), von vornherein kein Zweifel an der ausschließlichen Berechtigung des Staates auf. Doch so wie es unmittelbar den Bürger bindende Grundrechte gibt (z. B. Art. 9 Abs. 3 GG), ${ }^{179}$ könnte es auch unmittelbar berechtigende Grundpflichten geben. Ob dies bei der Sozialbindungsklausel der Fall ist, hängt vom Inhalt der Pflicht ab. Dient diese auch unmittelbar den Interessen anderer Bürger und bedarf sie keiner vorherigen gesetzgeberischen Konkretisierung, ${ }^{180}$ so ist kein Grund erkennbar, warum die Bürger nicht auch Berechtigte sein sollten. Nach der exemplarischen Auffassung von Otto Kimminich ist der Eigentümer ,positiv verpflichtet, den Gebrauch seines Eigentums so einzurichten, daß das Wohl der Allgemeinheit dadurch

\footnotetext{
${ }^{176}$ Luchterhandt 1988, S. 587.

${ }^{177}$ Siehe dazu mit unterschiedlichen Schwerpunkten Hofmann 1992, Rn. 18, 42 f.; Schmidt 1999, S. 240 ff.; Hösch 2000, S. 180 ff. Ausführlich zu den entscheidenden Punkten Wendt 1985, S. $294 \mathrm{ff}$.

${ }^{178}$ So auch, aber ohne sich mit der Möglichkeit einer Berechtigung des Bürgers auseinanderzusetzen, Schmidt 1999, S. 83.

${ }^{179}$ Als weiteres Grundrecht kommt noch Art. 1 Abs. 1 GG in Betracht (so die h. M. siehe Stern 1988, S. 29 f. m. w. N.). Luchterhandt 1988, S. 447 ff. gelangt nur deshalb zu der Annahme einer Grundpflicht, die sich aus Art. 1 Abs. 1 GG ergibt, weil er den Grundrechtscharakter dieser Bestimmung verneint; näher zur Diskussion um den Grundrechtscharakter des Art. 1 Abs. 1 GG siehe Enders 1997, Teil 1.

${ }^{180}$ An diesem Erfordernis scheitert die Deutung des Art. 14 Abs. 3 GG als eine private, unmittelbar berechtigende Grundpflicht. Denn der sog. Junktimklausel in Art. 14 Abs. 3 Satz 2 GG kann nur in Form einer gesetzlichen Regelung entsprochen werden.
} 
gefördert wird“. ${ }^{181}$ Als Berechtigter käme danach nur der Staat in Betracht. Doch wird diese allgemeine Pflicht vielfach im Sinne der Polizeipflicht des Eigentümers ${ }^{182}$ spezifiziert. Aufgrund dieser Pflicht hat jeder Eigentümer zu verhindern, daß von seinem Eigentum konkrete Gefahren für andere Menschen oder Sachen ausgehen. In dieser Ausformung gehört die Sozialpflicht zu den Kernbestandteilen der Grundpflicht, andere nicht zu schädigen. ${ }^{183}$ Doch selbst für die so spezifizierte Eigentumspflicht ergeben sich Schwierigkeiten bei der Durchsetzung: Kommt nämlich der Eigentümer seiner Polizeipflicht nicht freiwillig nach, so reicht die Grundpflicht nicht aus, um das gewünschte staatliche Einschreiten zu legitimieren, da bei der zwangsweisen Durchsetzung der Polizeipflicht stets Positionen beeinträchtigt werden, die grundrechtlich geschützt sind. ${ }^{184}$ Wendet man sich nunmehr dem konkreten Inhalt der Sozialpflicht zu, so werden beträchtliche Unsicherheiten erkennbar. ${ }^{185}$ Seinen tieferen Grund findet dies in der Eigenart des Eigentums: Wenn Eigentum nicht ohne rechtliche Ausgestaltung denkbar ist, dann lassen sich auch die Pflichten eines Eigentümers nur stets in Bezug auf eine bestimmte Eigentumsrechtsordnung bestimmen. So wenig wie es natürliche Eigentumsrechte geben kann, so unmöglich ist auch die Existenz natürlicher Eigentümerpflichten. Gemeinwohlbindung und Eigentümerpflichten bestehen nur nach Maßgabe der einfachen Rechtsordnung. Selbst die relativ scharfen Umrisse, die man von der Polizeipflicht zeichnen könnte, beruhen eben doch auf der tradierten einfachrechtlichen Ausformung. Als verfassungsunmittelbare Rechtspflicht mit einem konkretisierbaren Inhalt kommt demnach allenfalls das Teilstück der Polizeipflicht in Betracht, bei dem keine ernstzunehmenden Zweifel am Verpflichtungsinhalt bestünden. Das - in Anbetracht der vorhandenen staatlichen Eingriffsbefugnisse nur auf der theoretischen Ebene existierende - Problem der Rechtsdurchsetzung bliebe freilich auch in diesem Fall bestehen.

b) Art. 14 Abs. 1 Satz 2 GG weist dem Gesetzgeber die Rechtsmacht zu, die Eigentumsordnung auszugestalten und bestehende Eigentumsrechte zu beschränken. Art. 14 Abs. 2 GG bildet zusammen mit dem sich aus Art. 14 Abs. 1 Satz 1 GG ergebenen Gebot der Privatnützigkeit für beide Formen staatlicher Grundrechtsberührung den verfassungsrechtlichen Maßstab. Für die Annahme, Art. 14 Abs. 2 GG beinhalte zudem noch

${ }^{181}$ Kimminich 1992, Rn. 153 (ihm folgend etwa Wieland 1996, Rn. 82). Nur scheinbar weicht die Position von Pestalozza 1982, S. 2169 f. von dieser Konzeption ab (a. A. Schmidt 1999, S. 241). Da die Pflichten, die Pestalozza für den Eigentümer herleitet, nicht zu unmittelbaren Beschränkungen der Befugnisse des Eigentümers führen, sondern nach seiner Auffassung der vorherigen gesetzlichen Regelung bedürfen, sind die Unterschiede gegenüber der Position von Kimminich letztlich gering.

${ }^{182}$ So etwa Wieland 1996, Rn. 83; Kimminich 1992, Rn. 158.

${ }^{183}$ Sie erfreut sich bei denen, die die Figur der Grundpflicht nicht generell ablesen, allgemeiner Anerkennung, Stern 1994, S. 1028 f.

${ }^{184}$ Dies dürfte ein wichtiger Grund sein, warum auch die, die in Art. 14 Abs. 2 GG eine Grundpflicht sehen, von einer "lex imperfecta“ sprechen (so Bryde 2000, Rn. 69; Hofmann 1992, Rn. 42 mit Anm. 125).

${ }^{185}$ Sie werden auch von Wendt 1985, S. 303 ff. vermerkt und als ein Einwand gegen die Einordnung des Art. 14 Abs. 2 GG als Grundpflicht erhoben; ebenso Stern 1994, S. 1044. 
eine Eingriffsermächtigung, ${ }^{186}$ ist im bundesverfassungsgerichtlichen Eigentumsverständnis weder ein sinnvoller Platz noch ein rechtliches Bedürfnis erkennbar. Wie auch sonst darf die Verwaltung auch hier nur aufgrund einer gesetzlichen Ermächtigung Eigentumsrechte verkürzen. Aufgrund der durch den in Art. 14 Abs. 1 Satz 2 GG aufgestellten Grundrechtsvorbehalt erfolgten Rechtsmachtzuweisung gilt das Erfordernis einer gesetzlichen Grundlage auch im Bereich der Grundrechtsausgestaltung. Fraglich und dementsprechend auch in der Literatur umstritten ist allein, ob und in welchem Umfang Gerichte befugt sind, die Eigentumsordnung auszugestalten und gegebenenfalls bestehende Eigentumsrechte zu beschränken. Sofern nicht bloß die Sorge vor sozialpolitisch agierenden Richtern die Ablehnung einer derartigen Richtermacht motiviert, kann als Grund dafür auf den Vorbehalt des Gesetzes und die grundgesetzlichen Vorbehalte verwiesen werden. ${ }^{187}$ Übersehen wird dabei, daß sich beide Figuren traditionell auf das Verhältnis von Gesetzgebung und Verwaltung beziehen. ${ }^{188}$ Die bloße Erstrekkung des Gesetzesvorbehalts auf die Gerichte wird weder deren Stellung in der grundgesetzlichen Funktionsordnung gerecht noch läßt sie sich mit der Rechtsprechungspraxis des Bundesverfassungsgerichts vereinbaren. Nach dieser Praxis sind Gerichte auch ohne gesetzliche Ermächtigungsgrundlage dazu befugt, in grundrechtlich geschützte Freiheiten einzugreifen. Dies gilt nicht nur soweit das Verbot der Rechtsschutzverweigerung den Gerichten gebietet, jeden Rechtsstreit zwischen Privaten zu entscheiden, ${ }^{189}$ sondern auch in anderen Bereichen. Beispielsweise hat das Gericht die Möglichkeit eines richterrechtlichen Sozietätsverbots anerkannt. ${ }^{190}$ Letztlich bleibt jedoch die Reichweite der gerichtlichen Befugnisse höchst diffus: Ein Grund dafür ergibt sich aus dem Umstand, daß das Bundesverfassungsgericht die Frage der gerichtlichen Ausgestaltungs- und Begrenzungsbefugnisse nicht als Kompetenzproblem behandelt, sondern darin ein Methodenproblem sieht, in dessen Mittelpunkt das Kriterium der Rechtslücke steht. ${ }^{191}$ Hinzu kommt, daß die Grenzen des Gesetzesvorbehalts diffus sind, weil die Rechtsanalogie als ein legitimes Mittel der Rechtsanwendung anerkannt wird, ihre Anwendung aber gerade das Fehlen einer ausdrücklichen gesetzlichen Ermächtigungsgrundlage voraussetzt. Erkennt man trotz dieser Unsicherheiten eine beschränkte Ausgestaltungs- und Begrenzungsbefugnis der Gerichte an, die sie auch in

\footnotetext{
${ }^{186}$ So Kimminich 1992, Rn. 159, 165.

${ }^{187}$ In diesem Sinne Wieland 1996, Rn. 44 und allgemein für die Grundrechte Hillgruber 1996, S. 123; dagegen Battis 1999, S. 679 ff. Das daneben angeführte Erfordernis gesetzlicher Ausgestaltung beruht auf einem Zirkelschluß: Aus dem Erfordernis rechtlicher Ausgestaltung kann nämlich nicht geschlossen werden, daß dies nur durch den Gesetzgeber geschehen kann. Vielmehr handelt es sich um eine kompetenzrechtliche Frage (dazu sogleich oben im Text).

${ }^{188}$ Sehr anschaulich geht dies aus den Ausführungen von Thoma 1932, S. 221, 233 ff. hervor, wo zwar Verwaltung und Rechtsprechung nebeneinander abgehandelt werden, ihr Verhältnis zur Gesetzgebung aber völlig unterschiedlich ausgestaltet wird.

${ }^{189}$ Für diesen Bereich ausdrücklich anerkannt in BVerfGE 84, 212, $226 \mathrm{f}$. - Aussperrung. Durch diese Entscheidung werden die Einschränkungen, die man aus BVerfGE 57, 220, 246 - Bethel herauslesen kann (näher dazu Wank 1988, S. 332 f.), implizit aufgegeben.

${ }^{190}$ Siehe z. B. BVerfGE 98, 49, 59 - Sozietätsverbot.

${ }^{191}$ Siehe BVerfGE 34, 269, 286 - Soraya; 65, 182, 191 f.; 82, 6, 12.
} 
der Rechtspraxis wahrnehmen, ${ }^{192}$ so hängt auch diese Entscheidung nicht von Art. 14 Abs. 2 GG ab. Vielmehr besteht dessen Bedeutung darin, verbindlicher Maßstab für die Konkretisierung der einfachen Eigentumsordnung durch die Gerichte zu sein. ${ }^{193}$

c) In der Gemeinwohlbindung des Eigentümers nach Art. 14 Abs. 2 GG wird schließlich eine Gefahr für die Entscheidungs- und Handlungsfreiheit des Eigentümers gesehen. So wendet Rudolf Wendt gegen die These der unmittelbaren Begründung konkreter Eigentumsbeschränkungen durch Art. 14 Abs. 2 GG ein, daß dies mit der grundrechtlichen Freiheitsvorstellung unvereinbar sei. Sei der Gebrauch des Eigentums stets am Gemeinwohl auszurichten, so degeneriere das Freiheitsrecht zu einer treuhänderischen Verwaltungsbefugnis. ${ }^{194}$ Und Ulrich Hösch sekundiert ihm mit der Behauptung, daß das eigentumsspezifische Ausgleichsgebot dazu führe, daß Eigentumsrechte ihrem Inhalt nach beliebig würden. ${ }^{195}$ Beide sprechen sich deshalb für einen Vorrang der Eigentümerfreiheit gegenüber der Gemeinwohlbindung aus. ${ }^{196}$

Hinter dieser Position steht zum einen die Sorge um eine wirkungsmächtige Bindung des Gesetzgebers, wenn er Eigentumsrechte ausgestaltet. Indes ist der Gesetzgeber nicht nur dazu verpflichtet, eine funktionsfähige Eigentumsordnung bereitzustellen, sondern er ist bei der konkreten Gestaltung der Eigentumsrechte an das eigentumsspezifische Ausgleichsgebot gebunden. Die Ausformung eines Eigentumsrechts als „reine(s) Pflichtenstatut" wäre damit nicht vereinbar und verfassungswidrig. Man braucht sich deshalb nicht vor einem „Leerlaufen“ (Richard Thoma) zu sorgen.

Zum anderen zielt die - vor allem auch mit dem Namen Walter Leisner verbunde$n e^{197}$ - Position auf eine Stärkung der Eigentümerstellung. Sofern man zugesteht, daß der Staat Bereiche wie das Wohnraummietrecht auch eigentümerfreundlicher gestalten könnte, ohne daran durch die Eigentumsgarantie gehindert zu sein, so handelt es sich dabei eher um eine gesellschaftspolitische als um eine verfassungsrechtliche Position. Ist man wie Ulrich Hösch der Meinung, das geltende Wohnraummietrecht führe zu einem für den Eigentümer unzumutbaren Pflichtenstatus, ${ }^{198}$ läßt sich dem immerhin entgegenhalten, daß dieses Wohnraummietrecht offenbar einer ökonomisch attraktiven Eigentumsnutzung nicht entgegensteht. Denn warum würde sonst weiterhin in großem Umfang neuer Mietwohnraum geschaffen? Dann aber fällt es schwer zu begründen, warum es an der verfassungsrechtlich gebotenen Privatnützigkeit fehlen sollte.

Um eine verfassungsrechtliche Frage aber geht es, wenn man sich für den Vorrang der Freiheit des Eigentümers einsetzt. Verstanden als Asymmetrie zwischen Freiheit und Pflicht ist dagegen nichts einzuwenden. In der bürgerlichen Verkehrsgesellschaft

\footnotetext{
${ }^{192}$ Siehe dazu Luchterhandt 1988, S. 550 ff.

${ }^{193}$ Hofmann 1992, Rn. 43 spricht in diesem Zusammenhang anschaulich von „Grundpflichten als Interpretamente der Rechtsanwendung". Selbst Wendt 1985, S. 305 Anm. 77 erkennt die Wirkung des Art. 14 Abs. 2 GG als „Auslegungsrichtlinie“ an.

${ }^{194} \mathrm{Vgl}$. Wendt 1985, S. 300.

${ }^{195}$ Vgl. Hösch 2000, S. 200.

${ }^{196}$ Siehe Hösch 2000, S. 201; Wendt 1985, S. 300 f. Auf dieser Vorrangidee fußt auch das von Wendt entwickelte Verständnis von Art. 14 Abs. 1 Satz 2 GG. Dazu näher Bumke 1998, S. 190 f.

${ }^{197}$ Siehe dazu die in Anm. 172 genannten Arbeiten.

${ }^{198} \mathrm{Vgl}$. Hösch 2000, S. 190 ff.
} 
beruht die Güterverteilung überwiegend auf den Verfügungs- und Nutzungsentscheidungen der Eigentümer. Der soziale Wohlfahrtsstaat mag diese Entscheidungen beschränken und sektoral ausschließen, doch bleibt er im Grundgefüge eine marktwirtschaftliche Ordnung. Soll der Vorrang der Freiheit aber mehr besagen, ist folgendes zu bedenken: Gerade weil es keine natürlichen Eigentumsrechte gibt und weil mit der jeweiligen Eigentumsausgestaltung Rechtsmacht zugewiesen wird und wichtige Spielregeln für das gesellschaftliche Miteinander festgelegt werden, ist es angemessener, von einem gleichberechtigten Nebeneinander von Privatnützigkeit und Sozialpflichtigkeit auszugehen. Als Ausgangspunkt demgegenüber ein Prinzip anzuerkennen, demzufolge dem Eigentümer möglichst weitgehende Ausschließungs- und Nutzungsbefugnisse eingeräumt werden sollten, wird nicht der besonderen Struktur des Eigentums gerecht.

\section{Ausblick}

Mit dem Ende des Sozialismus in Osteuropa ist die Eigentumsidee der bürgerlichen Verkehrsgesellschaft als einziges Ordnungsmodell für die Verteilung der Güter einer Gesellschaft übrig geblieben. Auf die europäische Variante, die anders als die amerikanische Alternative nicht allein von der Selbstherrlichkeit des Eigentümers und dessen Leistungen denkt, sondern Eigentümerbelieben und Gemeinwohlbindung als gleichursprünglich begreift, griffen die osteuropäischen Staaten zurück. Die europäische Variante verfügt über eine doppelte Legitimationsgrundlage - bestehend aus dem Ideal, seine eigenen Vorstellungen vom guten Leben verwirklichen zu können, und dem Ideal einer gerechten Gesellschaft. Sie war deshalb besonders gut als Leitbild im Transformationsprozeß geeignet. Bot sie doch als Bild der künftigen, guten Ordnung' eine Gesellschaft an, die sich zwar den Gesetzen der Marktwirtschaft und damit dem Egoismus und der Willkür des Einzelnen unterwarf, in der aber zugleich das Wohl der Allgemeinheit, und das hieß in erster Linie die Interessen der Nichteigentümer, berücksichtigt wurde.

Mit dem Scheitern des Sozialismus wandelte sich auch der Diskurs um das Eigentum und seine gemeinwohlverträgliche Ausformung fundamental: Mit einem Mal fehlte es an einem Gegenentwurf, so daß ernstzunehmende, d. h. einer Auseinandersetzung bedürftige und würdige Kritik nur noch immanent ansetzen konnte. Gestritten wird nicht mehr über die Legitimität des Eigentums, sondern nur noch über das Verhältnis der beiden Leitvorstellungen - Privatnützigkeit und Sozialpflichtigkeit - zueinander und den Weg, auf dem sie zu verwirklichen sind. Auf diese Weise gewann das Eigentumsideal der bürgerlichen Verkehrsgesellschaft den Status einer wahren, für jede industrialisierte Gesellschaft richtigen Ordnungsvorstellung. Wie erstaunlich dieser Vorgang ist, wird deutlich, wenn man bedenkt, daß auf der Basis dieser Eigentumsvorstellung die Schere zwischen Arm und Reich immer weiter wächst.

Versteht man unter einer Institution „relativ auf Dauer gestellte, durch Internalisierung verfestigte $[\ldots]$ Sinngebilde mit regulierender und orientierender Funktion" ${ }^{199}$ so

${ }^{199}$ Göhler 1994, S. 19, 22. 
handelt es sich bei der Eigentumsvorstellung der bürgerlichen Verkehrsgesellschaft um eine solche. Dagegen entzieht sich die konkrete Eigentumsordnung in ihrer Vielgestaltigkeit und Disparität der Vorstellung von Einheit und Stabilität. Dies ist freilich nicht weiter hinderlich, weil die Eigentumsordnung als Teil der Rechtsordnung Befolgung für jede ihrer Regelungen verlangt und Einrichtungen bereitstehen, um den Geltungsanspruch des Rechts aufrechtzuerhalten. Man sollte deshalb zwischen dem allgemeinen Diskurs über die Eigentumsidee und dem speziell auf die Ausgestaltung der konkreten Eigentumsrechtsordnung bezogenen Diskurs unterscheiden. Aufgaben und Befugnisse (= Kompetenzen) der Akteure bei der Ausgestaltung der Eigentumsordnung und damit bei der Definition konkreter Gemeinwohlbelange sind durch die Rechtsordnung selbst festgelegt. Diese Festlegungen sind - rechtlich betrachtet - abschließend. Eigentum existiert nur nach Maßgabe der Rechtsordnung und kann deshalb nur nach deren Regeln verändert werden. Von daher gesehen, läßt sich auch die Definitionsmacht präzise bestimmen: Sie obliegt in erster Linie dem Gesetzgeber und wird abschließend von den Gerichten konkretisiert. Gebunden sind beide an die Eigentumsgarantie des Art. 14 GG, dessen rechtlicher Gehalt vom Bundesverfassungsgericht verbindlich festgelegt wird, welches über die Vereinbarkeit der Eigentumsrechtsordnung mit dem Grundgesetz wacht. Soweit ist die Situation klar und einfach. Doch verschwimmt sie, sobald man die Unsicherheiten einbezieht, die mit der Auslegung und Anwendung der Verfassung verbunden sind und die es in aller Regel unmöglich machen, zu entscheiden, ob das Bundesverfassungsgericht die richtigen gewährleistungsspezifischen Vorgaben entwickelt und zutreffend angewandt hat. Der so eröffnete diskursive Raum läßt sich nur unzureichend disziplinieren. Die zu seiner genaueren Vermessung entwickelten Regeln und Handlungsmaximen führen zu keinen Maßstäben, mit denen sich die Unsicherheiten beseitigen ließen. Sie dienen der Praxis vielmehr dazu, mögliche Formen des juristischen Diskurses festzulegen. Unter diesen Umständen kann deshalb auch der „Krach“ von Akteuren, die sich nicht an die juristischen Diskursformen halten, erheblichen Einfluß auf die Bestimmung des Gemeinwohls bei der Ausgestaltung der Eigentumsordnung gewinnen.

\section{Literatur:}

Alexy, R. (1985), Theorie der Grundrechte, Baden-Baden.

Anschütz, G. (1897), Der Ersatzanspruch aus Vermögensbeschädigungen durch rechtmäßige Handhabung der Staatsgewalt, in: Verwaltungsarchiv 5, 1-147.

Anschütz, G. $\left(1933^{14}\right)$, Die Verfassung des Deutschen Reiches vom 11. August 1919, Kommentar, Berlin.

Apelt, W. (1946), Geschichte der Weimarer Republik, München.

Barnett, R. E. (1998), The Structure of Liberty. Justice and the Rule of Law, Oxford.

Battis, U. (1999), Zur Bestimmung von Inhalt und Schranken des Eigentums durch Gesetzgeber und Gerichte, in: Freiheit und Eigentum. Festschrift für W. Leisner zum 70. Geburtstag, hg. v. J. Isensee und H. Lecheler, Berlin, S. 679-687.

Becker, L. C. (1977), Property Rights, London. 
Behrens, P. (1986), Die ökonomischen Grundlagen des Rechts. Politische Ökonomie als rationale Jurisprudenz, Tübingen.

Berkemann, J. (1986), Geschichte, Strategie und Intensität richterlicher Gesetzeskontrolle im Aufwertungsurteil des Reichsgerichts vom 4. November 1925 (RGZ 111, 320), in: Europäische Grundrechtszeitschrift, S. 80-94.

Böhm, F. (1933), Wettbewerb und Monopolkampf. Eine Untersuchung zur Frage des wirtschaftlichen Kampfrechts und zur Frage der rechtlichen Struktur der geltenden Wirtschaftsverfassung, Berlin.

Brennan, G./Buchanan, J. M. (1992), Die Begründung von Regeln. Konstitutionelle Politische Ökonomie, Tübingen.

Breuer, R. (1976), Die Bodennutzung im Konflikt zwischen Städtebau und Eigentumsgarantie, München.

Brocker, M. (1992), Arbeit und Eigentum. Der Paradigmenwechsel in der neuzeitlichen Eigentumstheorie, Darmstadt.

Brünneck, A. v. (1984), Die Eigentumsgarantie des Grundgesetzes, Baden-Baden.

Brüggemeier, F.-J. (1996), Das unendliche Meer der Lüfte. Luftverschmutzung, Industrialisierung und Risikodebatten im 19. Jahrhundert, Essen.

Bryde, B.-O. $\left(2000^{5}\right)$, Kommentierung Art. 14 GG, in: Grundgesetzkommentar, Bd. 1, hg. v. I. v. Münch und P. Kunig, München.

Bullinger, M. (1968), Öffentliches Recht und Privatrecht, Stuttgart u. a.

Bumke, C. (1998), Der Grundrechtsvorbehalt, Baden-Baden.

Depenheuer, O. (1999), Kommentierung Art. 14 GG, in: Das Bonner Grundgesetz, Kommentar, Bd. 1, hg. v. C. Stark, München.

Die Deutsche Nationalversammlung im Jahre 1919 in ihrer Arbeit für den Aufbau des neuen deutschen Volksstaates (1919), hg. v. E. Heilfron, Berlin.

Die Verwaltung (2001), Regulierte Selbstregulierung als Steuerungskonzept des Gewährleistungsstaates. Beiheft 4, Berlin.

Enders, C. (1997), Die Menschenwürde in der Verfassungsordnung. Zur Dogmatik des Art. 1 GG, Tübingen.

Eschenbach, J. (1996), Der verfassungsrechtliche Schutz des Eigentums, Berlin.

Fleiner, F. (1908), Einzelrecht und öffentliches Interesse, in: Festgabe für Paul Laband zum fünfzigsten Jahrestag der Doktor-Promotion, dargeb. v. W. v. Calker u. a., Bd. 2, Tübingen, S. 1-27.

Floßmann, U. (1976), Eigentumsbegriff und Bodenordnung im historischen Wandel. Ein Beitrag zum Rechtsverständnis der konstitutionellen Eigentumsgewährleistung des 19. Jahrhunderts, Wien.

Friedrich, M. (1997), Geschichte der deutschen Staatsrechtswissenschaft, Berlin.

Gierke, O. (1905), Deutsches Privatrecht. Bd. 2: Sachenrecht, Leipzig.

Glos, G. (1998), Der Schutz obligatorischer Rechte durch die Eigentumsgarantie. Ein Beitrag zur Geschichte und dogmatischen Struktur des Eigentumsgrundrechts, Berlin.

Göhler, G. (1994), Politische Institutionen und ihr Kontext, in: Die Eigenart der Institutionen. Zum Profil politischer Institutionentheorie, hg. v. G. Göhler, Baden-Baden, S. 19-46.

Goldschmidt, H. (1920), Eigentum und Eigentumsteilrechte in ihrem Verhältnis zur Sozialisierung, Marburg.

Grimm, D. (1979), Die Entwicklung des Enteignungsrechts unter dem Einfluß der Industrialisierung, in: Wissenschaft und Kodifikation des Privatrechts im 19. Jahrhundert, hg. v. H. Coing und W. Wilhelm, Bd. 4, Frankfurt/M., S. 121-141. 
Günter, J. (1998), Berufsfreiheit und Eigentum in der Europäischen Union. Eine rechtsvergleichende Studie, Heidelberg.

Gusy, C. (1993), Die Grundrechte in der Weimarer Republik, in: Zeitschrift für Neuere Rechtsgeschichte 15, S. 163-183.

Gusy, C. (1997), Die Weimarer Reichsverfassung, Tübingen.

Häberle, P. (1970), Das öffentliche Interesse als juristisches Problem, Eine Analyse von Gesetzgebung und Rechtsprechung, Bad Homburg.

Handwörterbuch zur Deutschen Rechtsgeschichte (1984), hg. v. A. Erler u. a. Berlin.

Hayek, F. A. (1945), The Use of Knowledge in Society, in: American Economic Review 35, S. 519 530.

Hecker, D. (1990), Eigentum als Sachherrschaft. Zur Genese und Kritik eines besonderen Herrschaftsanspruchs, Paderborn u. a.

Hedemann, J. W. (1930), Die Fortschritte des Zivilrechts im 19. Jahrhundert, 2. Teil, 1. Halbbd.: Das materielle Bodenrecht, Berlin.

Hensel, A. (1929), Grundrechte und Rechtsprechung, in: Die Reichsgerichtspraxis im deutschen Rechtsleben. Festgabe der juristischen Fakultäten zum 50jährigen Bestehen des Reichsgerichts, hg. v. O. Schreiber, Berlin/Leipzig.

Hillgruber, C. (1996), Richterliche Rechtsfortbildung als Verfassungsproblem, in: Juristenzeitung, S. 118-125.

Hippel, E. v. (1932), Das richterliche Prüfungsrecht, in: Handbuch des Deutschen Staatesrechts, hg. v. G. Anschütz und R. Thoma, Bd. 2, Tübingen, S. 546-563.

Hofmann, H. (1992), Grundpflichten und Grundrechte, in: Handbuch des Staatsrechts, hg. v. J. Isensee und P. Kirchhof, Bd. V, Heidelberg, § 114.

Honore, T. (1961), Ownership, in: Oxford Esssays in Jurisprudence, ed. by A. G. Guest, Oxford, S. $107-138$.

Hösch, U. (2000), Eigentum und Freiheit. Ein Beitrag zur inhaltlichen Bestimmung der Gewährleistung des Eigentums durch Art. 14 Abs. 1 Satz 1 GG, Tübingen.

Huber, E. R. $\left(1988^{3}\right)$, Deutsche Verfassungsgeschichte seit 1789, Bd. 3, Stuttgart u. a.

Huber, E. R. (1992), Deutsche Verfassungsgeschichte seit 1789, Bd. 5., Stuttgart u. a.

Ihering, R. $\left(1874^{3}\right)$, Geist des römischen Rechts auf den verschiedenen Stufen seiner Entwicklung, Leipzig.

Ihering, R. $\left(1884^{2}\right)$, Der Zweck im Recht, Bd. 1, Leipzig.

Isensee, J. (1996), Vorwort, in: W. Leisner, Eigentum, Schriften zu Eigentumsgrundrecht und Wirtschaftsverfassung 1970-1996, Berlin, S. III-XII.

Jellinek, G. (1919), Gesetz und Verordnung, Tübingen.

Jellinek, W. (1930), Eigentumsbegrenzung und Enteignung, in: Verhandlungen des 36. Deutschen Juristentages, Bd. 1, Berlin/Leipzig, S. 295-332.

Jellinek, W. $\left(1931^{3}\right)$, Verwaltungsrecht, Berlin u. a.

Kaufmann, F.-X. (1997), Normative Konflikte in Deutschland. Basiskonsens, Wertewandel und soziale Bewegungen, in: Grenzen der Gesellschaft, hg. v. P. L. Berger, Gütersloh, S. 155-171.

Kimminich, O. (1992), Kommentierung Art. 14 GG, in: Bonner Kommentar zum Grundgesetz, hg. v. R. Dolzer, Heidelberg. 
Kirchheimer, O. (1972), Die Grenzen der Enteignung. Ein Beitrag zur Entwicklungsgeschichte des Enteignungsinstituts und zur Auslegung des Art. 153 der Weimarer Verfassung (1930), in: ders., Funktionen des Staats und Verfassung, Frankfurt/M., S. 223-294.

Kirchhof, P. (1981), Besteuerung und Eigentum, in: Veröffentlichungen der Vereinigung der Deutschen Staatsrechtslehrer 39, S. 213-285.

Klemmer, M. (1996), Gesetzesbindung und Richterfreiheit. Die Entscheidungen des Reichsgerichts in Zivilsachen während der Weimarer Republik und im späten Kaiserreich, Baden-Baden.

Krölls, A. (1994), Grundgesetz und kapitalistische Marktwirtschaft. Die Wirtschaftsverfassung der Bundesrepublik, Frankfurt/M.

Krückmann, P. (1925), Enteignung und Einziehung nach alter und neuer Reichsverfassung, Leipzig.

Krückmann, P. (1930), Enteignung, Einziehung, Kontrahierungszwang. Änderung der Rechtseinrichtung, Rückwirkung und die Rechtsprechung des Reichsgerichts, Berlin.

Kühne, J.-D. (1998²), Die Reichsverfassung der Paulskirche. Vorbild und Verwirklichung im späteren deutschen Rechtsleben, Neuwied.

Kutscher, H. (1937), Die Enteignung. Ein Beitrag zur Lehre von der Enteignung und vom Eigentum, Stuttgart.

Laband, P. $\left(1911^{5}\right)$, Das Staatsrecht des Deutschen Reiches, Bd. 2, Tübingen.

Ladeur, K.-H. (2000), Negative Freiheitsrechte und gesellschaftliche Selbstorganisation. Die Erzeugung von Sozialkapital durch Institutionen, Tübingen.

Layer, M. (1902), Principien des Enteigungsrechts, Leipzig.

Leibholz, G. $\left(1959^{2}\right)$, Die Gleichheit vor dem Gesetz, Eine Studie auf rechtsvergleichender und rechtsphilosophischer Grundlage, München/Berlin.

Leisner, W. (1972), Sozialbindung des Eigentums, Berlin

Leisner, W. (1989), Eigentum, in: Handbuch des Staatsrechts, hg. v. P. Kirchhof und J. Isensee, Bd. 6, Heidelberg, § 149.

Leisner, W. (1996), Eigentum - Grundlage der Freiheit, in: ders., Eigentum, Schriften zu Eigentumsgrundrecht und Wirtschaftsverfassung 1970-1996, hg. v. J. Isensee, Berlin, S. 21-51.

Lepsius, O. (2002), Besitz. Sachherrschaft im Öffentlichen Recht, Tübingen.

Locke, J. (1977), Zwei Abhandlungen über die Regierung, Frankfurt/M.

Lübbe-Wolff, G. (1986), Das wohlerwobene Recht als Grenze der Gesetzgebung im neuzehnten Jahrhundert, in: Zeitschrift der Savigny-Stiftung, Germanistische Abteilung 103, S. 104-139.

Luchterhandt, O. (1988), Grundpflichten als Verfassungsproblem in Deutschland, Geschichtliche Entwicklung und Grundpflichten unter dem Grundgesetz, Berlin.

Luhmann, N. (1993), Das Recht der Gesellschaft, Frankfurt/M.

Mainzer, O. (1929), Gleichheit vor dem Gesetz, Gerechtigkeit und Recht, Entwickelt an der Rechtsfrage: Welche Gewalten bindet der Gleichheitssatz in Art. 109 I RV?, Berlin.

Malmedier, B. (1999), Vom wohlerworbenen Recht zur verrechtlichten Freiheit, Diss. Berlin.

Mayer, O. $\left(1924^{3}\right)$, Deutsches Verwaltungsrecht, Bd. 2, Berlin.

Mende, H. (1926), Die Aufhebung des Gothaischen „Konfiskationsgesetzes“ durch das Reichsgericht auf Grund des Art. 13 Abs. 2 der Reichsverfassung, in: Archiv des Öffentlichen Rechts (n. F.) 10, S. $247-256$.

Merrill, T. W. (1998), Property and the right to exclude, in: Nebraska Law Review, S. 730-765. 
Mohnhaupt, H. (1995), Privilegien und „gemeines Wohl“ im ALR sowie deren Behandlung durch Theorie und Praxis im 19. Jahrhundert, in: 200 Jahre Allgemeines Landrecht für die preußischen Staaten, hg. v. H. Mohnhaupt und B. Dölemeyer, Frankfurt/M., S. 105-144.

Mugdan, B. (1899), Die gesammten Materialien zum Bürgerlichen Gesetzbuch für das Deutsche Reich, Bd. 3, Berlin.

Munzer, S. R. (1990), A Theory of Property, Cambrigde u. a.

Naschold, F. /Bogumil, J. (1998), Modernisierung des Staates. New public management und Verwaltungsreform, Opladen.

Nipperdey, T. $\left(1991^{2}\right)$, Deutsche Geschichte 1866-1918, Bd. 1, München.

Nörr, K. W. (1996a), Die Leiden des Privatrechts, Tübingen.

Nörr, K. W. (1996b), Der Richter zwischen Gesetz und Wirklichkeit, Die Reaktion des Reichsgerichts auf die Krisen von Weltkrieg und Inflation, und die Entfaltung eines neuen richterlichen Selbstverständnisses, Heidelberg.

Nussbaum, A. (1922), Das neue deutsche Wirtschaftsrecht, Eine systematische Übersicht über die Entwicklung des Privatrechts und der benachbarten Rechtgebiete seit Ausbruch des Weltkrieges, Berlin.

Ogorek, R. (1986), Richterkönig oder Subsumtionsautomat. Zur Justiztheorie im 19. Jahrhundert, Frankfurt/M.

Ogorek, R. (1988), Individueller Rechtsschutz gegenüber der Staatsgewalt. Zur Entwicklung der Verwaltungsgerichtsbarkeit im 19. Jahrhundert, in: Bürgertum im 19. Jahrhundert. Deutschland im europäischen Vergleich, hg. v. J. Kocka, Bd. 1, München, S. 372-405.

Penner, J. E. (1997), The Idea of Property in Law, Oxford.

Pestalozza, C. (1982), Eigentum verpflichtet, in: Neue Juristische Wochenschrift, S. 2169-2170.

Podlech, A. (1976), Eigentum. Entscheidungsstruktur einer Gesellschaft, in: Der Staat 15, S. 31-52.

Poscher, R. (2001), Grundrechte als Abwehrrechte, Habilitationsschrift.

Puchta, G. F. $\left(1881^{\circ}\right)$, Cursus der Institutionen, Bd. 2: System und Geschichte des römischen Privatrechts, Leipzig.

Radbruch, G. (1930), Art. 157 Abs. 1, in: Die Grundrechte und Grundpflichten der Reichsverfassung, Kommentar zum zweiten Teil der Reichsverfassung, hg. v. H. C. Nipperdey, Bd. 3, Berlin, S. 349358.

Reichold, H. (1995), Betriebsverfassungsrecht als Sozialprivatrecht, Historisch-dogmatische Grundlagen von 1848 bis zur Gegenwart, München.

Richter, K. (1931), Der verfassungsmäßige Schutz des Privatvermögens, in: Leipziger Zeitschrift für Deutsches Recht 25, Sp. 649-757.

Rittstieg, H. (1975), Eigentum als Verfassungsproblem, Darmstadt.

Rönne, L. v. $\left(1882^{4}\right)$, Das Staatsrecht der Preußischen Monarchie, Bd. 2, Leipzig.

Rüthers, B $\left(1988^{3}\right)$, Die unbegrenzte Auslegung. Zum Wandel der Privatrechtsordnung im Nationalsozialismus, Heidelberg.

Sass, W. (1992), Art. 14 GG und das Entschädigungserfordernis, Heidelberg.

Schelcher, W. (1930), Art. 153, in: Die Grundrechte und Grundpflichten der Reichsverfassung, Kommentar zum zweiten Teil der Reichsverfassung, hg. v. H. C. Nipperdey, Bd. 3, Berlin, S.196-249.

Schmidt, T. I. (1999), Grundpflichten, Baden-Baden.

Schmitt, C. (1926), Unabhängigkeit der Richter. Gleichheit vor dem Gesetz und Gewährleistung des Privateigentums nach der Weimarer Verfassung, Ein Rechtsgutachten zu den Gesetzesentwürfen 
über die Vermögensauseinandersetzungen mit den früher regierenden Fürstenhäusern, Berlin/Leipzig.

Schmitt, C. (1928), Verfassungslehre, München/Leipzig.

Schmitt, C. (1958), Bemerkung zu „Die Auflösung des Enteignungsbegriffs“ (1929), in: ders., Verfassungsrechtliche Aufsätze aus den Jahren 1924-1954: Materialien zu einer Verfassungslehre, Berlin, S. 118-123.

Schönberger, C. (1997), Das Parlament im Anstaltsstaat. Zur Theorie parlamentarischer Repräsentation in der Staatsrechtslehre des Kaiserreichs (1871-1919), Frankfurt/M.

Schuppert, G. F. (1995), Rigidität und Flexibilität von Verfassungsrecht - Überlegungen zur Steuerungsfunktion von Verfassungsrecht in normalen wie in "schwierigen Zeiten“, in: Archiv des Öffentlichen Rechts 120, S. 32-99.

Schuppert, G. F. (2000), Verwaltungswissenschaft. Verwaltung, Verwaltungsrecht, Verwaltungslehre, Baden-Baden.

Schuppert, G. F./Bumke, C. (2000), Die Konstitutionalisierung der Rechtsordnung, Baden-Baden.

Schwab, D. (1975), Eigentum, in: Geschichtliche Grundbegriffe, hg. v. O. Brunner, W. Conze und R. Koselleck, Bd. 2, S. 65-115.

Sieckmann, J.-R. (1998), Modelle des Eigentumsschutzes. Eine Untersuchung zur Eigentumsgarantie des Art. 14 GG, Baden-Baden.

Siemann, W. (1995), Vom Staatenbund zum Nationalstaat. Deutschland 1806-1871, München.

Stein, E. (1967), Wirtschaftsaufsicht, Tübingen.

Stein, L. v. (1962), Die Verwaltungslehre, Bd. 7, Die Entwährung. Grundentlastung, Ablösung, Gemeinheitstheilung, Enteignung und Staatsnotrecht in England, Frankreich und Deutschland (1868), Nachdruck Aalen.

Stern, K. (1988), Das Staatsrecht der Bundesrepublik Deutschland, Bd. 3, 1. Halbd., München.

Stern, K. (1994), Das Staatsrecht der Bundesrepublik Deutschland, Bd. 3, 2. Halbd., München.

Stier-Somlo, F. (1911), Rechtsstaat, Verwaltung und Eigentum, Eine kritische Auseinandersetzung und eine neue Lehre, Berlin.

Stödter, R. (1933), Öffentlich-rechtliche Entschädigung, Hamburg.

Stolleis, M. (1989), Die Entstehung des Interventionsstaates und das öffentliche Recht, in: Zeitschrift furr Neuere Rechtsgeschichte 11, S. 129-147

Stolleis, M. (1999), Geschichte des öffentlichen Rechts in Deutschland, Bd. 3, München.

Thier, A. (2000), Zwischen actio negatoria und Aufopferungsanspruch: Nachbarschaftliche Nutzungskonflikte in der Rechtsprechung des 19. und 20. Jahrhunderts, in: Das Bürgerliche Gesetzbuch und seine Richter. Zur Reaktion der Rechtsprechung auf die Kodifikation des deutschen Privatrechts (1896-1914), hg. v. U. Falk und H. Mohnhaupt, Frankfurt/M., S. 407-449.

Thoma, R. (1930), Die juristische Bedeutung der grundrechtlichen Sätze der Deutschen Reichsverfassung im Allgemeinen, in: Die Grundrechte und Grundpflichten der Reichsverfassung. Kommentar zum zweiten Teil der Reichsverfassung, hg. v. H. C. Nipperdey, Bd. I, Berlin, S. 1-53.

Thoma, R. (1932), Der Vorbehalt der Legislative und das Prinzip der Gesetzmäßigkeit von Verwaltung und Rechtsprechung, in: Handbuch des Deutschen Staatsrechts, hg. v. G. Anschütz und R. Thoma, Bd. 2, Tübingen, S. 221-236.

Triepel, H. (1924), Goldbilanzverordnung und Vorzugsaktien, Zur Frage der Rechtsgültigkeit der über sogenannte schuldverschreibungsähnliche Aktien in den Durchführungsbestimmungen zur Goldbilanz-Verordnung enthaltenen Vorschriften, Berlin/Leipzig. 
Trute, H.-H. (1999), Verantwortungsteilung als Schlüsselbegriff eines sich verändernden Verhältnisses von öffentlichem und privatem Sektor, in: Jenseits von Privatisierung und „schlankem“ Staat. Verantwortungsteilung als Schlüsselbegriff eines sich verändernden Verhältnisses von öffentlichem und privatem Sektor, hg. v. G. F. Schuppert, Baden-Baden, S. 13-45.

Uerpmann, R. (1999), Das öffentliche Interesse. Seine Bedeutung als Tatbestandsmerkmal und als dogmatischer Begriff, Tübingen.

Voßkuhle, A. (1999), Gesetzgeberische Regelungsstrategien der Verantwortungsteilung zwischen öffentlichem und privatem Sektor, in: Jenseits von Privatisierung und „schlankem“ Staat. Verantwortungsteilung als Schlüsselbegriff eines sich verändernden Verhältnisses von öffentlichem und privatem Sektor, hg. v. G. F. Schuppert, Baden-Baden, S. 47-90.

Wahl, R. (1981), Der Vorrang der Verfassung, in: Der Staat 20, S. 485-516.

Waldron, J. (1988), The Right of Private Property, Oxford.

Wank, R. (1988), Richterliche Rechtsfortbildung und Verfassungsrecht, in: Zeitschrift für Unternehmens- und Gesellschaftsrecht, S. 314-380.

Wendenburg, H. (1984), Die Debatte um die Verfassungsgerichtsbarkeit und der Methodenstreit der Staatsrechtslehre in der Weimarer Republik, Göttingen.

Wendt, R. (1985), Eigentum und Gesetzgebung, Hamburg.

Werthmann, S. (1995), Vom Ende der Patrimonialgerichtsbarkeit, Ein Beitrag zur Justizgeschichte des 19. Jahrhunderts, Frankfurt/M.

Wieacker, F./Weber W. (1935), Eigentum und Enteignung, Hamburg.

Wiegand, W. (1976), Zur theoretischen Begründung der Bodenmobilisierung in der Rechtswissenschaft: der abstrakte Eigentumsbegriff, in: Wissenschaft und Kodifikation des Privatrechts im 19. Jahrhundert, Bd. 3: Die rechtliche und wirtschaftliche Entwicklung des Grundeigentums und Grundkredits, hg. v. H. Coing und W. Wilhelm, Frankfurt/M., S. 118-158.

Wieland, J. (1996), Art. 14 GG, in: Grundgesetz Kommentar, hg. v. H. Dreier, Bd. 1, Tübingen.

Wilhelm, J. (1993), Sachenrecht, Berlin/New York.

Windscheid, B. $\left(1891^{7}\right)$, Lehrbuch des Pandektenrecht, Bd. 1., Frankfurt/M.

Winkler, H. A. (1993), Weimar 1918-1933. Die Geschichte der ersten Demokratie, München.

Wittmayer, L. $\left(1926^{4}\right)$, Artikel: Enteignung, in: Handwörterbuch der Staatswissenschaften, hg, v. L. Elster u. a., Bd. 3, Jena, S. 740-763.

Wolff, M. (1923), Reichsverfassung und Eigentum. Festgabe der Berliner juristischen Fakultät für Wilhelm Kahl zum Doktorjubiläum am 19. April 1923, Tübingen.

Wolff, M. $\left(1929^{8}\right)$, Sachenrecht, Marburg. 